UNIVERSIDADE DE SÃO PAULO

FACULDADE DE MEDICINA DE RIBEIRÃO PRETO DEPARTAMENTO DE CLÍNICA MÉDICA

PRISCILLA VARGAS WALSH GONÇALVES DOS SANTOS

RELAÇÃO IMUNOGENÉTICA DOS PÊNFIGOS COM A LEISHMANIOSE TEGUMENTAR

Ribeirão Preto 
PRISCILLA VARGAS WALSH GONÇALVES DOS SANTOS

\title{
RELAÇÃO IMUNOGENÉTICA DOS PÊNFIGOS COM A LEISHMANIOSE TEGUMENTAR
}

\author{
Tese apresentada à Faculdade de Medicina de Ribeirão \\ Preto da Universidade de São Paulo para obtenção do \\ Título de Doutor em Ciências Médicas do Programa de \\ Clínica Médica.
}

Orientadora: Profa. Dra. Ana Maria Ferreira Roselino

Ribeirão Preto 
AUTORIZO A REPRODUÇÃO E DIVULGAÇÃO TOTAL OU PARCIAL DESTE TRABALHO, POR

QUALQUER MEIO CONVENCIONAL OU ELETRÔNICO, PARA FINS DE ESTUDO E PESQUISA, DESDE QUE CITADA A FONTE.

FICHA CATALOGRÁFICA

Santos, Priscilla Vargas Walsh Gonçalves dos

Relação imunogenética dos pênfigos com a leishmaniose tegumentar / Priscilla Vargas Walsh Gonçalves dos Santos; orientadora Ana Maria Ferreira Roselino. Ribeirão Preto, 2015.

101 f.: il. $30 \mathrm{~cm}$.

Tese (Doutorado) - Faculdade de Medicina de Ribeirão Preto da Universidade de São Paulo. Programa de Pós-Graduação em Clínica Médica. Área de concentração: Clínica Médica

1. ELISA, 2. HLA, 3. Imunogenética, 4. Leishmaniose, 5. Pênfigo. 
Nome: SANTOS, Priscilla Vargas Walsh Gonçalves

Título: Relação imunogenética dos pênfigos com a leishmaniose tegumentar

Tese apresentada à Faculdade de Medicina de Ribeirão Preto da Universidade de São Paulo para obtenção do título de Doutor em Ciências Médicas do Programa de Clínica Médica. Essa Tese compõe o projeto Temático FAPESP de número: 2010/51729-2.

Data da Defesa:

\section{Banca Examinadora}

Prof. Dr.

Instituição: Assinatura:

Prof. Dr.

Instituição: Assinatura:

Prof. Dr.

Instituição: Assinatura:

Prof. Dr.

Instituição: Assinatura:

Prof. Dr.

Instituição: Assinatura: 


\section{DEDICATÓRIA}

Ao meu marido, Raphael, com muito amor e gratidão, por estar sempre ao meu lado, por incentivar meu crescimento, por vibrar com as minhas conquistas. Obrigada, meu amor, por sua compreensão, carinho e apoio tão fundamentais na realização deste trabalho.

À minha mãe, Mirtha, por seu exemplo de determinação e sucesso, e pela admiração e cumplicidade com que sempre me apoiou em todas as etapas da minha vida.

Ao meu filho, Pedro, que, mesmo ainda tão pequeno, já é o meu maior incentivo para seguir meus objetivos e tentar ser melhor a cada dia. 


\section{AGRADECIMENTOS}

A Deus, por me presentear todos os dias com tantas graças, e, em especial, pela conclusão deste doutorado.

Aos meus familiares e amigos pela compreensão e apoio. Minhas conquistas fazem mais sentido compartilhadas com vocês.

À Prof. Dra. Ana Maria Roselino, pelo exemplo que tem sido para mim. Excelente médica e professora, excerce o papel de orientadora brilhantemente, nos guiando no aprendizado e crescimento científico. Mais do que ensinamentos de um doutorado, a senhora me deu ensinamentos de uma vida! Obrigada!

À biomédica Aline Lobo, bolsista TT3 da FAPESP, Laboratório do Setor de Dermatologia, HCFMRP-USP, pelo auxílio na coleta das amostras.

À biomédica Aline Rafaela da Silva Rodrigues Machado, aluna de Doutorado, bolsista CAPES, Laboratório do Setor de Dermatologia, HC-FMRP-USP, amiga querida que o doutorado me presenteou, pela ajuda na coleta de dados e experimentos laboratoriais, mas, principalmente, pela disponibilidade, parceria e sorriso sempre alegre.

À biomédica Margarida Passeri do Nascimento, Laboratório de Sorologia, HC-FMRP-USP, pelo jeito doce e carinhoso com que sempre me ajudou e ensinou a realizar os ensaios ELISA.

À biomédica Maria José Franco Brochado, PhD, pós-doutoranda, bolsista FAPESP, Laboratório do Setor de Dermatologia, HC-FMRP-USP, pela enorme ajuda com a organização das amostras para os testes $H L A$ e pela estatística do estudo.

À biomédica Natalia de Paula, pelo auxílio em organizar o Laboratório do Setor de Dermatologia do HC-FMRP-USP. 
À biomédica Neifi Deghaide, do Laboratório de Imunogenética do Hemocentro de Ribeirão Preto, pela tipagem $H L A$.

À médica veterinária Olivia Kim, PhD, Laboratório do Setor de Dermatologia, HC-FMRP-USP, pela ajuda com a extração das proteínas e com o immunoblotting.

Ao Dr. Sebastián Vernal Carránza, aluno de Mestrado, bolsista CAPES, Laboratório do Setor de Dermatologia, HC-FMRP-USP, pelos ensaios de blotting.

À biomédica Aline Turatti, PhD, Laboratório do Setor de Dermatologia, HC-FMRP-USP, pela realização da imunofluorescência indireta.

Ao biomédico David Falango, Laboratório de Sorologia, HC-FMRP-USP, pela sorologia para Chagas.

Aos pacientes e voluntários desse estudo pela colaboração e pela confiança depositada.

Aos médicos assistentes e residentes do Ambulatório de Dermatologia do HC-FMRP, que me acolheram todo esse tempo.

À FAPESP, pelo apoio financeiro imprescindível a esse projeto de pesquisa. Essa tese constitui o subprojeto VII do Projeto Temático FAPESP "Relação dos Fatores Imunogenéticos e Ambientais na Etiopatogênese dos Pênfigos em Amostragem Brasileira" (Processo de número 2010/51729-2).

A todos que contribuíram, direta ou indiretamente, para a realização deste trabalho, o meu eterno e sincero agradecimento. 


\section{RESUMO}

Santos, P. V. W. G. Relação imunogenética dos pênfigos com a leishmaniose tegumentar. 2015. 101f. Tese (Doutorado) - Faculdade de Medicina de Ribeirão Preto, Universidade de São Paulo, Ribeirão Preto, São Paulo, 2015.

Pênfigo é uma dermatose bolhosa autoimune, endêmica em algumas áreas, como no nordeste do estado de São Paulo, Brasil, caracterizada pela produção de autoanticorpos contra desmogleínas (Dsg) - proteínas de adesão dos queratinócitos. O pênfigo vulgar (PV) acomete mucosas e pele, pela produção de anti-Dsg 3 e 1, respectivamente. O pênfigo foliáceo (PF) apresenta lesões exclusivamente na pele, pela produção de anti-Dgs1. Esta região também é endêmica para a Leishmaniose Tegumentar Americana (LTA), cujo principal fator etiológico é Leishmania (Viannia) braziliensis. Objetivos: Relacionar fatores imunogenéticos dos pênfigos com aqueles da LTA, investigando, em pacientes com pênfigos, LTA e em controles: a resposta humoral às Dsg 1 e 3 e contra Chagas; a resposta humoral e celular aos antígenos de leishmania; e a associação dos alelos $H L A$ de classe II $-D R$ e $-D Q$ no grupo LTA com aqueles de suscetibilidade e de resistência descritos nos pênfigos. Métodos: A resposta humoral foi investigada por: (i) ELISA para determinação dos anticorpos anti-Dsg 1 e 3 , anti- $L$. $V$. braziliensis e contra T. cruzi; (ii) imunoblotting (IB) com extrato proteico de epiderme e com extrato proteico de $L$. $(V$.) braziliensis; (iii) imunofluorescência indireta (IFI) com substrato de pele humana e soro de pacientes com LTA. A resposta celular foi realizada por teste intradérmico de Montenegro (TIM). A tipificação dos alelos $H L A-D R$ e $-D Q$ foi realizada por PCR-SSOP. Resultados: A resposta humoral às Dsg confirmou o esperado - anti-Dsg1: 84,6\% no grupo PF e 54,8\% no grupo PV; e antiDsg3: 83,9\% no PV; não havendo diferença significativa entre os grupos LTA e controles - anti-Dsg1: $16 \%$ nos familiares de PF (FPF); $5,2 \%$ no grupo LTA; 4,2\% no grupo FPV; e $2,7 \%$ nos controles vizinhos; e anti-Dsg3: $12 \%$ no grupo FPF; $6,4 \%$ no grupo PF e 5,2\% no grupo LTA. Houve reconhecimento dos peptídeos de $130 \mathrm{kDa}$ (corresponde ao PM da Dsg3), 145kDa, 150kDa (Dsg2), $160 \mathrm{kDa}$ (Dsg1), 230kDa (BP230), 250kDa, 290kDa, 350kDa, 410kDa, 425kDa e $460 \mathrm{kDa}$ da epiderme humana por soro de pacientes com LTA. A IFI resultou positiva para anti-IgG em $2 / 6$ pacientes com LTA. Em um deles, houve reconhecimento de peptídeos intercelulares da epiderme, guardando semelhança aos pênfigos; e, no outro, de antígenos da zona da membrana basal, guardando semelhança ao penfigoide bolhoso. A resposta humoral a $L$. $(V$.) braziliensis resultou mais elevada no grupo LTA ( $73 \%$ para LTAc e $62 \%$ para LTAm) em relação aos demais grupos, sem diferença significativa entre os grupos pênfigos (1,3\% no grupo PF e $1,6 \%$ no PV) e os controles $(10,8 \%$ nos controles vizinhos e 4\% no grupo FPF, FPV e controles Banco de Sangue). Pacientes com pênfigos apresentaram títulos sorológicos para $T$. cruzi semelhantes aos controles. Houve reconhecimento de peptídeos de $L$. $(V$.) braziliensis pelo soro dos pacientes com pênfigo $(45 \mathrm{kDa}, 95 \mathrm{kDa}, 100 \mathrm{kDa}$, $120 \mathrm{kDa}, 125 \mathrm{kDa}, 145 \mathrm{kDa}, 150 \mathrm{kDa}, 305 \mathrm{kDa}, 330 \mathrm{kDa}, 410 \mathrm{kDa}$ e $>500 \mathrm{kDa})$. O TIM foi negativo nos 6 pacientes com PF ou PV avaliados. Os alelos DRB1*01:02 e DQA1*01 mostraram associação de resistência para LTA e suscetibilidade para PF; o alelo $D R B 1^{*} 04: 02$ de resistência para LTA e suscetibilidade para PV; os alelos $D R B 1 * 07: 01$ e *11:01 de suscetibilidade para LTA e resistência para PF; e o $D Q A 1^{*}$ 01:02 mostrou associação de suscetibilidade a ambos LTA e PF. Conclusões: os pacientes com LTA têm resposta humoral às Dsg 1 e 3, e os pacientes com pênfigo, aos antígenos de $L$. $(V$.) braziliensis e de $T$. cruzi semelhante aos controles. Os soros de pacientes com pênfigos reconhecem peptídeos da epiderme e da zona da membrana basal por IB e IFI. Os demais peptídeos reconhecidos pelos pacientes com LTA ao extrato epidérmico, assim como dos pacientes com pênfigos ao extrato de $L$. $(V$.) braziliensis necessitam sequenciamento. As associações de suscetibilidade ou resistência dos alelos $H L A$ de classe II $-D R$ e $-D Q$ são opostas para LTA e pênfigo. Os resultados confirmam a não participação do parasito $L$. $(V$.) braziliensis na patogênese dos pênfigos, assim como corroboram a observação clínica da ausência da associação de ambas as doenças na região do estudo.

Palavras chaves: Chagas; Desmogleína; HLA; Leishmania Viannia braziliensis; Leishmaniose; Pênfigo. 


\begin{abstract}
Santos, P. V. W. G. Imunogenetic relationship between pemphigus and cutaneous leishmaniasis. 2015. 101p. Tese (Doutorado) - Faculdade de Medicina de Ribeirão Preto, Universidade de São Paulo, Ribeirão Preto, 2015.

Pemphigus is an autoimmune bullous dermatosis, endemic in some areas, such as in the northeastern of São Paulo state, characterized by the production of autoantibodies against desmoglein (Dsg) keratinocytes adhesion proteins. Pemphigus vulgaris (PV) affects mucous membranes and skin, by the production of anti-Dsg 3 and 1, respectively. Pemphigus foliaceus (PF) affects only the skin, by the production of anti-Dsg 1. This region is also endemic for American Cutaneous Leishmaniasis (ACL), whose main etiological factor is Leishmania (V.) braziliensis. Objectives: To relate immunogenetic factors of pemphigus with those of ACL, investigating, in patients with pemphigus, ACL and controls: the humoral response to Dsg 1 and 3; the humoral and cellular responses to Leishmania antigens; and the association of class II -DR and -DQ HLA alleles in ACL group with those of susceptibility and resistance described in pemphigus. Methods: The humoral response was investigated by (i) ELISA for determination of anti-Dsg1 and anti-Dsg3 antibodies and anti-antibodies from $T$. cruzi and $L$. braziliensis; (ii) immunoblotting (IB) with protein extract of the epidermis and protein extract of $L$. braziliensis; (iii) indirect immunofluorescence (IIF) with human skin substrate and serum of ACL patients. The cellular response was carried out by intradermal test Montenegro (ITM). The typing of HLA-DQ and -DR alleles was performed by PCR-SSOP. Results: The humoral response to Dsg confirmed expected in groups of PV and PF (anti-Dsg1: 84.6\% in the PF group and 54.8\% in the PV group, and anti-Dsg3: $83.9 \%$ in PV), with no significant difference between the ACL and control groups [anti-Dsg1: $16 \%$ in relatives of PF (RPF), 5.2\% in the ACL, $4.2 \%$ in relatives of PV (RPV) and $2.7 \%$ of controls neighbors; anti-Dsg $3: 12 \%$ in RPF, $6.4 \%$ in the PF group and 5.2\% in ACL)]. There has been recognition of peptides $130 \mathrm{kDa}, 145 \mathrm{kDa}, 150 \mathrm{kDa}, 160 \mathrm{kDa}, 230 \mathrm{kDa}, 250 \mathrm{kDa}, 290 \mathrm{kDa}$, $350 \mathrm{kDa}, 410 \mathrm{kDa}, 425 \mathrm{kDa}$ and $460 \mathrm{kDa}$ of human epidermis by serum of ACL patients. The IFI was positive in 1/6 ACL patients evaluated. The humoral response to L. braziliensis resulted higher in ACL group ( $73 \%$ to ACLc and $62 \%$ to ACLm) compared to the other groups, with no significant difference between pemphigus groups (1.3\% in the PF group and $1.6 \%$ the group PV) and controls (10.8\% in neighboring controls and 4\% in FPF, in FPV and BS controls). Patients with pemphigus have serological titers to T. cruzi similar to controls. There was L. braziliensis recognition of peptides by the patients with pemphigus $(45 \mathrm{kDa}, 95 \mathrm{kDa}, 100 \mathrm{kDa}, 120 \mathrm{kDa}, 125 \mathrm{kDa}, 145 \mathrm{kDa}, 150 \mathrm{kDa}, 305$ $\mathrm{kDa}, 330 \mathrm{kDa}, 410 \mathrm{kDa}$ and $>500 \mathrm{kDa}$ ). The ITM was negative in 06 patients with PF or PV evaluated. The $D R B 1 * 01: 02$ and $D Q A 1 * 01$ showed resistance association for LTA and susceptibility to PF; allele $D R B 1^{*} 04: 02$ resistance to ACL and susceptibility to PV; the $D R B 1^{*} 07: 01$ and *11:01 susceptibility to ACL and resistance to PF; and $D Q A 1^{*} 01: 02$ showed susceptibility association with both ACL and PF. Conclusions: Patients with ACL have humoral response to Dsg 1 and 3, and pemphigus patients to L. braziliensis and T. cruzi antigens similar to controls. The peptides recognized by patients with pemphigus to $L$. braziliensis extract require sequencing. The susceptibility or resistance associations of class II $-D R$ and $-D Q H L A$ alleles are opposed to ACL and pemphigus. The results confirm the non-participation of the parasite $L$. (V.) braziliensis in the pathogenesis of pemphigus, as well as support the clinical observation of the absence of both diseases association.
\end{abstract}

Key-words: Chagas disease; Desmoglein; HLA; Leishmania Viannia braziliensis; Leishmaniasis; Pemphigus. 


\section{LISTA DE FIGURAS}

Figura 1. Densidade Óptica para diferentes concentrações do antígeno (extratos proteicos de $L$. (Viannia) braziliensis) frente a soros positivo com título alto $(++)$, positivo com título baixo $(+) \mathrm{e}$ negativo (-), diluídos 1:50.

Figura 2. Densidade Óptica para diferentes concentrações do antígeno (extratos proteicos de $L$. (Viannia) braziliensis) frente a soros positivo com título alto $(++)$, positivo com título baixo $(+)$ e negativo (-), diluídos 1:100.

Figura 3. Gel de acrilamida 4-15\% corado por prata com produtos proteicos de epiderme humana. Observar marcação do PM (kDa) dos peptídeos correspondentes as desmogleínas.

Figura 4. Produtos proteicos de Leishmania Viannia braziliensis obtidos por kit comercial (4 primeiras colunas) e por tratamento com Trizol (4 últimas colunas - muito claras). Concentração inicial do extrato obtido por kit comercial de $389,6 \mathrm{mg} / \mathrm{mL}$, concentração inicial estimada do extrato obtido por Trizol de $8,1 \mathrm{mg} / \mathrm{mL}$ e diluição seriada de 1:10 a 1:80.

Figura 5. Análise das leituras a $450 \mathrm{~nm}$ do ELISA anti-desmogleína 1 e 3 conforme os grupos avaliados, em Unidade de valor $/ \mathrm{mL}(\mathrm{U} / \mathrm{mL})$. Os boxes representam valores entre $25 \%$ e $75 \%$. As barras representam valor mínimo e máximo. A linha horizontal dentro dos boxes representa a mediana dos valores. A linha tracejada: cut-off para limiar de normalidade.

Figura 6. Análise das leituras a $492 \mathrm{~nm}$ do ELISA anti - L. braziliensis conforme os grupos avaliados. Valores em D.O. (densidade óptica). Os boxes representam valores entre $25 \%$ e $75 \%$. As barras representam valor mínimo e máximo. A linha horizontal dentro dos boxes representa a mediana dos valores. A linha tracejada representa o Cut off $=0,192$.

Figura 7. Correlação dos títulos (D.O.) anti-Dsg e anti-L. braziliensis nos grupos LTA e pênfigos. a. Anti-Dsg 1 e anti-L. braziliensis no grupo LTA-c ( $\mathrm{r}=0,3834 ; \mathrm{p}=0,0192) ; \mathrm{b}$. Anti-Dsg 3 e anti-L. braziliensis no grupo LTA-c $(\mathrm{r}=0,589 ; \mathrm{p}=0,001)$; $\mathrm{c}$. Anti-Dsg 1 e anti-L. braziliensis no grupo LTA-m ( $(\mathrm{r}=0,2909 ; \mathrm{p}=0,2)$; $\mathrm{d}$. Anti-Dsg 3 e anti-L. braziliensis no grupo LTA-m $(\mathrm{r}=0,4714$; $\mathrm{p}=0,03)$.

Figura 8. Immunoblotting com extrato proteico de epiderme e soro de pacientes e controles com marcador Precision Plus Protein ${ }^{\mathrm{TM}}$ Dual Color Standards, BioRad. Os PMs dos peptídeos (kDa) estão marcados ao lado de cada fita. Marcação da banda $160 \mathrm{kDa}$ (desmogleína 1) nas amostras dos pacientes com PF; marcação da banda $130 \mathrm{kDa}$ (desmogleina 3) nas amostras dos pacientes com PV; detecção da banda $150 \mathrm{kDa}$ (desmogleina 2) nas amostras dos pacientes com pênfigos; ausência de marcação na maioria dos controles; reconhecimento de outros peptídeos da epiderme pelos soros do grupo LTA, em especial a banda de $230 \mathrm{kDa}$.

Figura 9. A. Imunofluorescência indireta (IFI) com substrato de pele de prepúcio incubada com soro 1:10 de paciente com LTA forma mucosa (amostra 318 - vide tabela 06) e anti-IgG humana com fluoresceína 1:50. Observar fluorescência granular em torno dos queratinócitos, guardando semelhança à IFI dos pênfigos. B. IFI em substrato de pele facial Salt Split incubada com soro 1:10 de paciente com LTA forma mucosa (amostra 96 - vide tabela 9). Observar: fluorescência no teto da clivagem, guardando semelhança a IFI do penfigoide bolhoso. Corte corado com Azul de Evans (em vermelho) $[400 \mathrm{x}]$ 
Figura 10. Immunoblotting com extrato proteico de $L$. (V.) braziliensis e soro de pacientes e controles, com marcador Precision Plus Protein ${ }^{\mathrm{TM}}$ Dual Color Standards, BioRad. Os PMs dos peptídeos $(\mathrm{kDa})$ estão marcados ao lado de cada fita. Observar marcação dos peptídeos de 330 $\mathrm{kDa}, 410 \mathrm{kDa}$ e de $\mathrm{PM}$ maior que $500 \mathrm{kDa}$.

Figura 11. Análise das leituras (Índice $\mathrm{S} / \mathrm{CO}$ ) do exame sorológico anti-T. cruzi (S/CO) conforme os grupos avaliados. Os boxes representam valores das medianas. As barras representam valor mínimo e máximo. A linha horizontal tracejada representa o cut off $=1$. 


\section{LISTA DE TABELAS}

Tabela 1. Dados relacionados à frequência de anticorpos contra desmogleínas (Dsg) em pacientes com pênfigos e controles de acordo com a população estudada

Tabela 2. Alelos HLA de classe II de suscetibilidade aos pênfigos em amostras brasileiras .27

Tabela 3. Alelos $H L A$ relacionados à suscetibilidade à LTA em amostras brasileiras 32

Tabela 4. Distribuição dos dados demográficos dos grupos em estudo - Leishmaniose tegumentar Americana forma cutânea localizada (LTAc), LTA forma mucosa (LTAm), pênfigo vulgar (PV), pênfigo foliáceo (PF), familiares de pênfigo vulgar (FPV), familiares de pênfigo foliáceo (FPF), Controles vizinhos dos pacientes com pênfigo, controles do banco de sangue (BS).

Tabela 5. Dados demográficos dos grupos em estudo na caracterização dos alelos $H L A$. 40

Tabela 6. Desempenho dos métodos de extração da proteína de L. (V.) braziliensis LTUP 393.

Tabela 7. Distribuição dos resultados do ensaio ELISA anti-Dsg 1 e 3 conforme os grupos avaliados...

Tabela 8. Distribuição dos resultados do ELISA anti-L. braziliensis conforme os grupos avaliados. Cut off (média + 2DP): DO 0,192

Tabela 9. Dados demográficos e laboratoriais dos pacientes e controles que realizaram Immunoblotting e IFI..

Tabela 10. Distribuição dos resultados do exame sorológico anti-T. cruzi conforme os grupos avaliados......

Tabela 11. Dados demográficos, clínicos e laboratoriais dos pacientes com Pênfigo que realizaram Teste de Montenegro

Tabela 12. Análise da frequência dos alelos $H L A-D R B 1$ entre os grupos estudados. Valores de $\mathrm{p} \leq$ 0,001 foram considerados estatisticamente significativos e destacados por cor: alelos de resistência em amarelo e de suscetibilidade em verde.

Tabela 13. Análise da frequência dos alelos $H L A-D Q A 1$ entre os grupos estudados. Valores de $\mathrm{p} \leq$ 0,001 foram considerados estatisticamente significativos e destacados por cor: alelos de resistência em amarelo e de suscetibilidade em verde.

Tabela 14. Análise da frequência dos alelos $H L A-D Q B 1$ entre os grupos estudados. Valores de $\mathrm{p} \leq$ 0,001 foram considerados estatisticamente significativos e destacados por cor: alelos de resistência em amarelo e de suscetibilidade em verde.

Tabela 15. Associação dos alelos $H L A-D R B 1$ à suscetibilidade ou resistência às doenças estudadas. 
Tabela 16. Associação dos alelos $H L A-D Q A 1$ à suscetibilidade ou resistência às doenças estudadas.

Tabela 17. Associação dos alelos $H L A-D Q B 1$ à suscetibilidade ou resistência às doenças estudadas. 


\section{LISTA DE ABREVIAÇÕES E SIGLAS}

BS

Banco de sangue

BReg

Células B Reguladoras

Dsg

Desmogleína

EDTA

Ácido etilenodiamino tetra-acético

ELISA

Enzyme-Linked Immunosorbent Assay

ESP

Estado de São Paulo

FasL

Fas Ligante

FPF

Familiares de paciente com pênfigo foliáceo

FPV

Familiares de paciente com pênfigo vulgar

$H L A$

Human Leukocyte Antigen

HSP

Heat Shock Protein

IB

Immunoblotting

Ig

Imunoglobulina

IFD

Imunofluorescência direta

IFI

Imunofluorescência indireta

IFN - $\gamma$

Interferon- $\gamma$

IL

Interleucina

IRM

Intradermorreação de Montenegro

LTA

Leishmaniose tegumentar Americana

LTA-c

Leishmaniose tegumentar Americana forma cutânea

LTA-m

Leishmaniose tegumentar Americana forma mucosa

L. (V.) braziliensis

Leishmania (Viannia) braziliensis

Lu. Longipalpis

Lutzomyia longipalpis

MAPK

Mitogen-activated protein kinase

$\mathrm{MHC}$

Major histology histocompatibility

PBS

Phosphate-buffered saline (tampão fosfato-salino) 
PF

PMSF

PV

RFLP

RLU

TGF- $\beta$

$\mathrm{Th}$

TNF

TReg
Pênfigo foliáceo

Phenylmethylsulfonyl fluoride

Pênfigo vulgar

Restriction fragment lenght polymorphism

Reactive Ligth Unity

Transforming Growth Factor - $\beta$

Células T helper

Tumor necrosis factor (Fator de necrose tumoral)

Células T Reguladoras 


\section{LISTA DE SÍMBOLOS}

$\begin{array}{ll}\mathrm{kDa} & \text { quilodaltons } \\ \mathrm{mg} & \text { miligrama } \\ \mathrm{mL} & \text { mililitro } \\ \mathrm{mM} & \text { miliMol } \\ \mathrm{rpm} & \text { rotações por minuto } \\ \mathrm{V} & \text { Volts } \\ \mu \mathrm{g} & \text { micrograma } \\ \mu \mathrm{L} & \text { microlitro } \\ \mu \mathrm{m} & \text { micrômetro } \\ \% & \text { Porcentagem } \\ { }^{\circ} \mathrm{C} & \text { grau Celsius } \\ < & \text { menor que } \\ > & \text { maior que } \\ \leq & \text { menor ou igual } \\ \geq & \text { maior ou igual } \\ & \end{array}$




\section{SUMÁRIO}

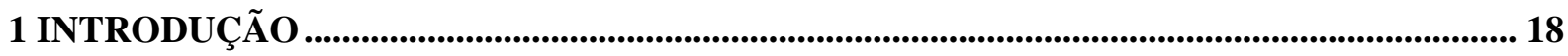

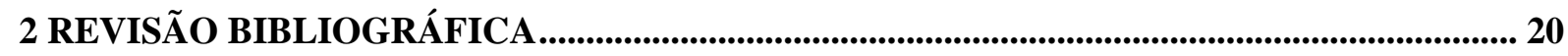

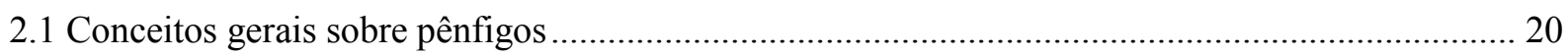

2.2 Patogênese dos pênfigos - Anticorpos dirigidos contra Dsg 1 e Dsg3 …...................................... 21

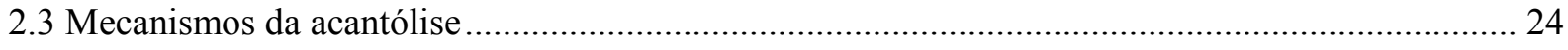

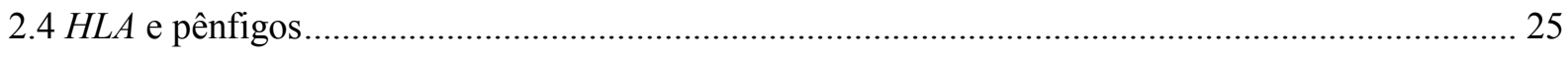

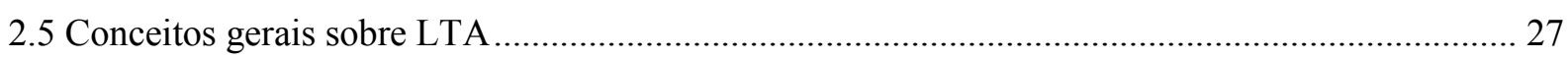

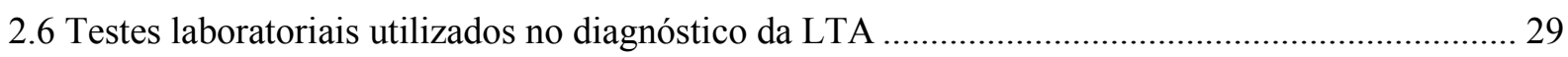

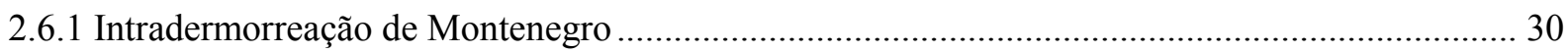

2.6.2 ELISA para detecção de anticorpos contra leishmania ............................................................... 30

2.6.3 Reação cruzada nos testes imunológicos para Leishmaniose e Doença de Chagas ..................... 31

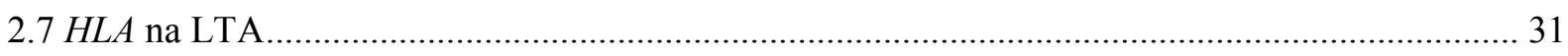

2.8 Anticorpos contra proteínas salivares de insetos hematófagos nos pênfigos e nas leishmanioses.. 33

2.9 Anticorpos contra desmogleínas em doenças transmitidas por insetos hematófagos ..................... 34

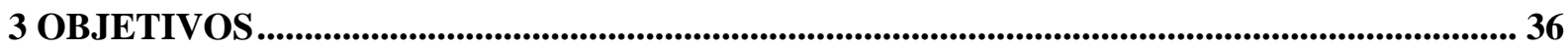

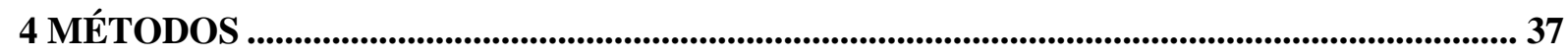

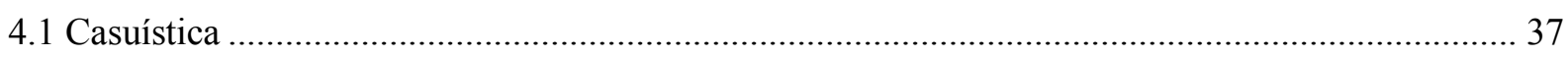

4.2 ELISA para determinação da resposta humoral às Dsg1 e 3 (objetivo i) ........................................ 40

4.3 ELISA in house para determinação da resposta humoral ao extrato proteico de L. (Viannia)

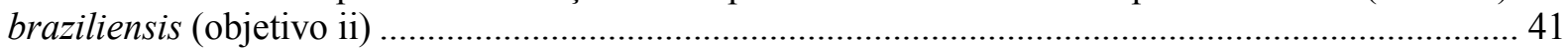

4.4 Immunoblotting para pesquisa do reconhecimento de peptídeos da epiderme humana (objetivo

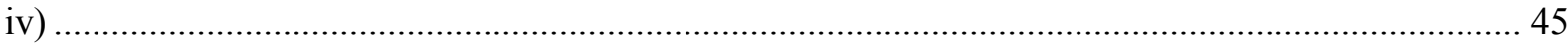

4.5 Imunofluorescência indireta para pesquisa do reconhecimento dos peptídeos da epiderme

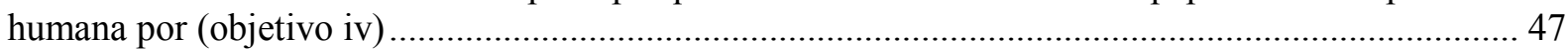

4.6 Immunoblotting para pesquisa do reconhecimento dos peptídeos de L. (V.) braziliensis

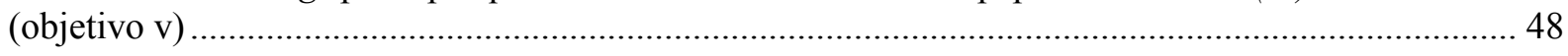

4.7 Exame sorológico para determinação de anticorpos contra Trypanosoma cruzi (objetivo vi) ........ 49

4.8 Teste de Montenegro para pesquisa de resposta celular a leishmania (objetivo vii) ........................ 50

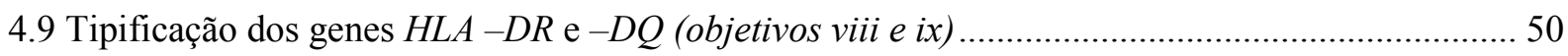

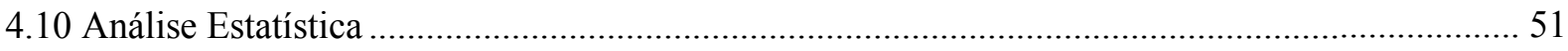

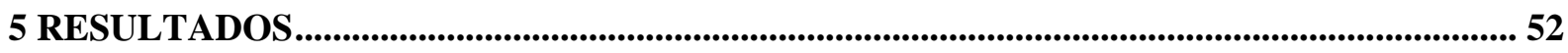

5.1 Resultado do ELISA para determinação dos anticorpos anti-Dsg1 e anti-Dsg3 (objetivo i) .......... 52 
5.2 Resultado do ensaio ELISA in house para determinação dos anticorpos contra L. braziliensis (objetivo ii).

5.3 Correlação dos títulos (D.O.) anti-Desmogleínas e anti-L. braziliensis nos grupos LTA e nos grupos pênfigos (objetivo iii)

5.4 Resultado do Immunoblotting com extrato proteico de epiderme humana e soro de pacientes e controles (objetivo iv)

5.5 Resultado da Imunofluorescência Indireta com substrato de pele de prepúcio humano e soros de pacientes com LTA (objetivo iv).

5.6 Resultado do Immunoblotting com extrato proteico de L. $(V$.) braziliensis e soro de pacientes e controles (objetivo v)

5.7 Resultado do exame sorológico para determinação dos anticorpos contra T. cruzi (objetivo vi) .......... 64

5.8 Resultado da Reação Intradérmica de Montenegro (objetivo vii)..................................................... 65

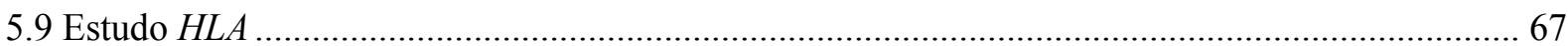

5.9.1 Frequência dos alelos $H L A-D R$ e $-D Q$ nos grupos estudados (objetivo viii) ............................... 67

5.9.2 Associação dos alelos $H L A$ de suscetibilidade ou de resistência à LTA, PF e PV (objetivo ix).. 72

6 DISCUSSÃO

7 CONCLUSÕES

7.1 Conclusão Final.

8 REFERÊNCIAS.

9 ANEXOS 


\section{INTRODUÇÃO}

Pênfigos são doenças bolhosas autoimunes, caracterizados pela produção de autoanticorpos da classe IgG contra desmogleínas (Dsg) - proteínas da família das caderinas, responsáveis pela adesão entre os queratinócitos. Enquanto o pênfigo vulgar (PV) afeta a pele e mucosas pela produção de autoanticorpos contra Dsg1 e Dsg3, respectivamente, o pênfigo foliáceo (PF) acomete exclusivamente a pele, e apresenta somente anticorpos anti-Dsg1.

Relatos recentes confirmam modificações clínico-epidemiológicas relacionadas ao PV, com acometimento de indivíduos mais jovens e aumento da incidência em área endêmica para o PF (cuja forma endêmica é também conhecida como fogo selvagem), configurando o PV endêmico.

Sendo a região nordeste do estado de São Paulo endêmica para ambos PF e PV, assim como para a Leishmaniose Tegumentar Americana (LTA), nosso grupo de pesquisa vem estudando aspectos epidemiológicos e clínico-laboratoriais, genéticos e fisiopatogênicos dos pênfigos, aliados à epidemiologia molecular da LTA.

Nosso grupo foi pioneiro ao relatar a presença de anticorpos contra maxadilan, proteína salivar do inseto hematófago Lutzomyia longipalpis, transmissor da leishmaniose visceral, em amostras de soro de pacientes com PF e com LTA. Ainda, relatamos a presença de anticorpos anti-Dsg1 e antiDsg3 em amostras de soro de pacientes com LTA, assim como anticorpos contra extratos proteicos dos insetos hematófagos Aedes aegypti, Lu. longipalpis e Simulium nigrimanum em amostras de soro de pacientes com PF.

Um grupo de pesquisadores da Tunísia vem relacionando a exposição a proteínas de Phlebotomus papatasi e de Leishmania major como possíveis agentes etiológicos para os pênfigos, quando pacientes com hidatidose e leishmaniose apresentaram anticorpos contra Dsg1. Em 2004, Diaz e col. relataram alta prevalência de anticorpos contra Dsg1 em amostras de soro de pacientes com LTA, e, mais recentemente, o mesmo grupo demonstrou que antígenos salivares de Lu. longipalpis, especificamente a proteína salivar LJM11, são reconhecidos por anticorpos de pacientes com fogo selvagem. 
Assim, o presente estudo teve por objetivo relacionar aspectos imunogenéticos dos pênfigos com a LTA, com a finalidade de configurar a exposição aos antígenos da leishmania como possível fator ambiental influenciador no desencadeamento dos pênfigos na área de estudo. Para esse propósito, investigou-se nos grupos pênfigos, LTA e controles: (i) a resposta humoral às Dsg 1 e 3 e aos antígenos de $L .(V$.$) braziliensis por ensaio ELISA; (ii) a correlação dos títulos de anticorpos contra$ Dsg 1 e 3 com os anticorpos contra L. (V.) braziliensis; (iii) o reconhecimento dos peptídeos da epiderme humana e dos peptídeos de L. (V.) braziliensis por immunoblotting e por imunofluorescência indireta; (iv) a resposta humoral aos antígenos de Trypanosoma cruzi por exame sorológico para Chagas, por haver reação sorológica cruzada entre LTA e Chagas; (v) a resposta celular pela intradermorreação de Montenegro; (vi) a frequência dos alelos $H L A$ de classe II $-D R$ e $-D Q$ no grupo LTA quando comparado ao grupo controle, assim como a associação no grupo LTA com aqueles de suscetibilidade e de resistência descritos nos pênfigos.

Espera-se que os resultados desse projeto possam contribuir para a relação da leishmaniose tegumentar com a patogênese dos pênfigos na região nordeste do estado de São Paulo. 


\section{REVISÃO BIBLIOGRÁFICA}

\subsection{Conceitos gerais sobre pênfigos}

Conceitualmente, os pênfigos, dermatoses bolhosas autoimunes, caracterizam-se pela presença de autoanticorpos circulantes da classe Imunoglobulina G (IgG) contra glicoproteínas da família das caderinas, uma das famílias responsáveis pela adesão dos queratinócitos (MORITA et al., 2011; SIMPSON et al., 2011). Enquanto o PV afeta a pele e mucosas pela produção de autoanticorpos contra Dsg 1 e Dsg3, respectivamente, o PF acomete exclusivamente a pele, e apresenta somente anticorpos anti-Dsg1 (AOKI et al., 2011; JAMES et al., 2011; JOLY, SIN, 2011; KOULU et al., 1984; STANLEY et al., 1984; STANLEY et al., 1986; VENUGOPAL, MURRELL, 2011).

A deposição dos autoanticorpos na epiderme, visualizados na imunofluorescência direta (IFD) ou na imunofluorescência indireta (IFI), mais precisamente no envoltório dos queratinócitos, embora não distinga os dois tipos de pênfigos, origina acantólise suprabasal no PV, e acantólise subcórnea no PF (BEUTNER et al., 1968; POHLA-GUBO, HINTNER, 2011).

A clínica dessas doenças, de certa forma, reflete essas informações acima. O PF caracteriza-se por apresentar bolhas superficiais na pele, sem afetar as mucosas, que se rompem facilmente, deixando áreas erosadas, às vezes confluentes. As lesões iniciais acometem geralmente a face, pescoço e tronco superior - áreas seborreicas - configurando a forma localizada ou frustra (Pênfigo seborreico ou frustro). As lesões podem permanecer de forma localizada, ou se estender de forma crânio-caudal (forma generalizada). O PV, por outro lado, caracteriza-se por lesões mucosas (de ocorrência em 90\% dos casos, com lesão da mucosa oral como manifestação inicial da doença em 50-70\%) e por apresentar bolhas flácidas, sobre base normal ou eritematosa que, ao se romperem, deixam áreas erodidas, úmidas, sangrentas e dolorosas. As lesões podem ser localizadas ou generalizadas (SAMPAIO, 2007).

Hoje, com a utilização de técnicas de imunoprecipitação e blotting, e protein array, tem-se o conhecimento de que mais de 50 antígenos são reconhecidos pelos autoanticorpos $\operatorname{IgG}$ circulantes dos pacientes com pênfigo. A teoria monopatogênica cai por terra, e o mecanismo de acantólise com 
formação de bolha passa a ser associado à citotoxicidade mediada por células, enzimas proteolíticas e citocinas pró-inflamatórias e pró-apoptóticas, e aos autoanticorpos dirigidos contra numerosos alvos da epiderme e de órgãos internos, mecanismo proposto como apoptólise. Assim, a constelação de autoanticorpos simultaneamente atinge várias proteínas dos queratinócitos, com ativação de sinalizadores citoplasmáticos e nucleares, culminando com o rompimento do envoltório dos queratinócitos da epiderme e apoptose (GRANDO, 2012; HISAMATSU et al., 2003).

Por serem ambos os pênfigos endêmicos na região nordeste do ESP, nosso grupo tem se dedicado ao seu estudo há alguns anos, com relatos epidemiológicos que confirmam a endemicidade do PF na região de Ribeirão Preto, ESP (ROSELINO, ALMEIDA, 1995; CHIOSSI, ROSELINO, 2001), e com a recente publicação que confirma modificações clínico-epidemiológicas relacionadas ao aumento da incidência do PV em área endêmica para o PF, que passa a afetar também indivíduos mais jovens, configurando o PV endêmico (GONÇALVES et al., 2011).

Em relação à fisiopatologia do $\mathrm{PF}$, temos demonstrado a sua associação com sintomas da síndrome metabólica (AMBIEL, ROSELINO, 2010); o aumento do número das células dendríticas no infiltrado dérmico em biópsias cutâneas e sua relação com a titulação de autoanticorpos séricos (CHIOSSI et al., 2004); padrão de citocinas T helper (Th)1/Th2 (ZEOTI et al., 2000) e a associação com cininas (ROSATELLI et al., 2005) no sangue periférico; e apoptose de queratinócitos em biópsias de lesão e de região perilesional do PF (ZUCCOLOTTO et al., 2003).

\subsection{Patogênese dos pênfigos - Anticorpos dirigidos contra Dsg 1 e Dsg3}

Os pênfigos são caracterizados principalmente pela produção de IgG contra desmogleínas, presentes na epiderme. Quando em atividade, a IFD confirma depósito de anti-IgG humana na superfície dos queratinócitos da pele lesada e perilesional, correspondendo ao reconhecimento de depósitos de autoanticorpos IgG contra Dsg. E, dependendo do substrato, $80 \%$ dos pacientes com pênfigos apresentam IFI positiva para IgG anti-Dsg (STANLEY, 2003).

Nos pênfigos, como em outras doenças autoimunes, a produção desses autoanticorpos se dá pelas células B, em decorrência da perda da própria (self) tolerância. Tal perda pode ocorrer 
centralmente, por falha na seleção negativa das células autorreativas no timo, ou perifericamente, por falha na inativação dessas células autorreativas que escaparam à deleção no timo e atingiram o sangue periférico. Envolvidas nesse processo imune, células T Reguladoras (TReg) foram descritas pela primeira vez em 1995, por Sakaguchi et al. (1995), como células T derivadas do timo capazes de regular a resposta imune a antígenos próprios e não próprios. Investigando sua participação na patogênese dos pênfigos, Sugiyama et al. (2007) evidenciaram redução de cerca de dez vezes do número de células Treg em relação ao total de células CD4+ em pacientes com PV - mas não nos pacientes com PF, bem como da expressão de Foxp3, quando comparados aos controles (SUGIYAMA et al., 2007). Mais recentemente, foram descritas as células B reguladoras (BReg), capazes de fazer inibição da função das células T através da produção de Interleucina (IL) - 10 e Transforming Growth Factor - $\beta$ (TGF- $\beta$ ) (MIZOGUCHI, 2006). Foi demonstrado que pacientes com pênfigo têm aumento das BReg, mas com secreção deficiente de IL-10 (Zhu, 2015). Como consequência, as células apresentadoras de antígenos se ligam às células $\mathrm{T}$ capazes de reconhecer os autoantígenos, levando, em última análise, à produção de autoanticorpos contra Dsg 1 e Dsg3.

No PV, os autoanticorpos são direcionados contra Dsg3, de 130 kDa, enquanto no PF, o alvo é a Dsg1, de 160 kDa. Pacientes com PV, que apresentam lesões mucosas e cutâneas, possuem anticorpos anti-Dsg3 e anti-Dsg1, enquanto aqueles que possuem somente IgG anti-Dsg3 apresentam afecção apenas da mucosa. Isto ocorre devido à maior concentração de Dsg1 em relação à Dsg3 no estrato epidérmico da pele, e o contrário ocorre na camada espinhosa das membranas mucosas. Os autoanticorpos circulantes podem ser quantificados por ensaio ELISA, e a atividade da doença pode estar relacionada ou não com o título dos autoanticorpos séricos (AMAGAI, 2010; STANLEY, 2003; TRON et al., 2005; WASCHKE, 2008; YE QIAN et al., 2009).

Têm sido demonstradas mudanças nos padrões epidemiológicos e clínicos, tanto do PV quanto do PF, com descrição do encontro de anticorpos anti-Dsg em indivíduos saudáveis com familiar acometido por pênfigo ou em moradores de áreas endêmicas para PF. Há casos de transição de fenótipos de PV para PF e vice-versa, com expressão de anticorpos anti-Dsg1 no PV e anti-Dsg3 no PF; fenótipo de PV em área endêmica para PF, além do acometimento de jovens e membros familiares 
por PV (GONÇALVES et al., 2011; KALLEL SELLAMI et al., 2004; ROCHA-ALVAREZ et al., 2007; SAMI et al., 2001).

Diversos outros estudos de pênfigos em diferentes populações vêm mostrando esta intrigante mudança no perfil clínico e imunológico da doença, alguns deles descritos brevemente na Tabela 1.

Tabela 1. Dados relacionados à frequência de anticorpos contra desmogleínas (Dsg) em pacientes com pênfigos e controles, de acordo com a população estudada, em literatura consultada

Forma clínica do pênfigo (Origem) / Tamanho amostral

Anti--Dsg 1 Anti--Dsg 3 Referência

\begin{tabular}{|c|c|c|c|}
\hline PF (EUA e Japão) / 35 & NA & $28 \%$ & \multirow{5}{*}{ Artega et al., 2002} \\
\hline PF (Brasil) / 241 & NA & $7,50 \%$ & \\
\hline PV (Brasil, EUA, Japão, Espanha) / 83 & NA & $98,70 \%$ & \\
\hline Outras doenças bolhosas (EUA) / 62 & NA & $0 \%$ & \\
\hline Controles saudáveis (EUA) / 50 & NA & $0 \%$ & \\
\hline PF (Reserva Limão Verde Brasil) / 21 & $95 \%$ & $43 \%$ & \multirow{4}{*}{$\begin{array}{l}\text { Vargas et al., } \\
\quad 2006\end{array}$} \\
\hline $\begin{array}{l}\text { Controles moradores de área endêmica } \\
\text { (Reserva Limão Verde Brasil) / } 146\end{array}$ & $30 \%$ & $36 \%$ & \\
\hline $\begin{array}{l}\text { Controles moradores de área próxima à } \\
\text { endêmica (Brasil) / } 120\end{array}$ & $10 \%$ & $6,7 \%$ & \\
\hline $\begin{array}{l}\text { Controles distantes da área endêmica } \\
\text { (SP - Brasil e Universidade da Carolina } \\
\text { do Norte - EUA) / } 38\end{array}$ & $0 \%$ & $0 \%$ & \\
\hline PF (Reserva Limão Verde Brasil) /31 & $61 \%$ & NA & \multirow{4}{*}{ Diaz et al., 2008} \\
\hline $\begin{array}{l}\text { PF (Hospitais de Campo Grande, Goiás, } \\
\text { São Paulo - BR) / } 155\end{array}$ & $85 \%$ & NA & \\
\hline PF (EUA) / 20 & $70 \%$ & NA & \\
\hline PF (Japão) / 20 & $100 \%$ & NA & \\
\hline
\end{tabular}

PF: pênfigo foliáceo; PV: pênfigo vulgar; Anti--Dsg1: anticorpo contra a desmogleina 1; Anti--Dsg3: anticorpo contra a desmogleina 3; NA: Não Avaliado. 


\subsection{Mecanismos da acantólise}

O mecanismo fisiopatológico da acantólise ainda não está completamente esclarecido. A observação de que autoanticorpos IgG nos pênfigos eram dirigidos às desmogleínas 1 e 3 levou à hipótese de que a ligação dos anticorpos a porções específicas da desmogleína comprometeria as interações do tipo trans entre os desmossomos intercelulares, e o processo de acantólise seria decorrente da alteração espacial estérica (steric hindrance). Outras hipóteses, no entanto, vêm sendo levantadas, como a indução de vias de sinalização mediadas pelos anticorpos, que levaria à perda da adesão celular e à apoptose (STANLEY, AMAGAI, 2006).

Seishima et al. (1995) foram os primeiros a descrever a ativação de vias de sinalização em células expostas aos autoanticorpos anti-desmogleínas, quando observaram o aumento nos níveis intracelulares de cálcio no interior dos queratinócitos expostos ao soro de pacientes com PV. Em estudos subsequentes, demonstrou-se a ativação de outras moléculas de sinalização, incluindo proteína quinase C e fosfolipase C (OSADA et al., 1997; SEISHIMA et al., 1999). Novas vias de sinalização vêm sendo descritas, que podem contribuir para a perda da adesão entre os queratinócitos, ou serem induzidas pela perda da adesão mediada por anticorpos (AOYAMA et al, 1999; CALDELARI, 2001; CHERNYAVSKY, 2007; DELVA 2008; WASCHKE, 2006).

Um terceiro mecanismo sugerido para a indução da acantólise é a via da apoptose. Há relatos de apoptose em queratinócitos expostos ao soro de pacientes com pênfigo ou à IgG anti-desmogleína purificada, observada em culturas de tecido in vitro, em modelos de pênfigo em camundongos, ou ainda em biópsias de pele humana (WANG et al., 2004; WOLF et al., 2005). No entanto, embora haja evidências da apoptose nos pênfigos, permanece o questionamento de que ela seja uma causa, resultado ou ainda um subproduto da acantólise. Dados atuais sugerem que a apoptose não é necessária para a formação de bolhas nos pênfigos, porém, a ativação de proteínas proapoptóticas, incluindo as caspases, pode sensibilizar os queratinócitos à acantólise mediada pelos anticorpos IgG antidesmogleína (GRANDO, 2012).

Observou-se aumento do Fas Ligante (FasL) no soro e em biópsias de pele de pacientes com PV, sugerindo que a apoptose seria desencadeada pela via Fas/FasL (PACHECO et al., 2009; 
PUVIANI et al., 2003; SAYAMA et al., 1994; WANG et al., 2004; WOLF et al., 2005). Zuccolotto et al., 2003, demonstraram a expressão da apoptose em amostras perilesionais de pacientes com PF. Relata-se ainda a presença de apoptose em biópsias de pele de FS, associada ao aumento de citocinas proinflamatórias como Tumor Necrose Factor- $\alpha$ (TNF- $\alpha$ ), Interferon- $\gamma$ (IFN- $\gamma$ ) e IL-1, sugerindo que mediadores inflamatórios podem contribuir para a indução da apoptose no FS (RODRIGUES et al., 2009)

Li et al. (2009) analisaram a habilidade dos inibidores das caspases em bloquear a acantólise in vivo usando modelos de PF em camundongos. Observaram que o pré-tratamento com inibidores de caspases Ac-DEVD-mck ou Boc-D-fmk em camundongos neonatos preveniu a formação de bolhas nesses animais.

A ativação da quinase p38 mitogen-activated protein kinase (MAPK) tem sido estudada como parte do mecanismo precoce pelo qual os anticorpos antidesmogleínas induzem a perda da adesão celular em PV e PF. Observou-se fosforilação da Heat Shock Protein (HSP) 27 e da p38MAPK em biópsias de pele de modelos de PV e PF em camundongos, e a formação de bolhas foi inibida quando tratados com inibidores da p38MPAK (BERKOWITZ et al., 2006; BERKOWITZ et al., 2008; KAWASAKI et al., 2006). Estudos posteriores mostraram que autoanticorpos IgG anti-Dsg 3 de pacientes com PV induziram a internalização celular da Dsg3 em endossomos. Essa internalização e subsequente degradação da Dsg3 foram bloqueadas quando utilizados inibidores da p38MAPK, destacando sua importância na regulação da patogenicidade dos autoanticorpos anti-Dsg no PV (JOLLY et al., 2010).

\subsection{HLA e pênfigos}

O complexo principal de histocompatibilidade (CPH ou MHC - Major histology histocompatibility) representa o conjunto de genes responsáveis por codificar as moléculas de histocompatibilidade em uma determinada espécie, sendo chamado no ser humano de sistema HLA. Codificam glicoproteínas de superfície celular, que atuam no reconhecimento e apresentação de antígenos. Em humanos, esses genes estão localizados no braço curto do cromossomo 6 e reunidos em 
3 grupos, denominados genes de classe I, classe II e classe III. Os genes de classe I codificam as moléculas clássicas de histocompatibilidade $H L A-A,-B$ e $-C$. Os genes de classe II codificam as moléculas clássicas de histocompatibilidade $H L A-D R,-D Q$ e $-D P$ e as moléculas não clássicas $H L A$ $D M$ e $D O$. Os genes de classe III, embora estejam incluídos dentro do $\mathrm{CPH}$ ou $\mathrm{MHC}$, não codificam moléculas de histocompatibilidade, e sim, outras moléculas, algumas delas fazendo parte do sistema imune. As moléculas de classe I estão presentes na maioria das células somáticas, e as de classe II ocorrem predominantemente em linfócitos $\mathrm{B}$, macrófagos, células apresentadoras de antígeno e linfócitos T ativados (KLEIN, 2000).

Sabe-se que os lócus MHC, particularmente alelos $H L A$ de classe II (HLA II), estão associados ao PV e PF (CERNA et al., 1993; MIYAGAWA et al., 1997; MORAES et al., 1997; PETZL-ERLER, SANTAMARÍA, 1989; SINHA, 2011). A expressão dos alelos HLA DRB1*0404, *1402 ou *1406 está significantemente relacionada ao PF. Esses alelos dividem um epítopo comum, que é representado por uma sequência de aminoácidos (LLEQRRAA) presente na região hipervariável do gene $D R B 1$ nas posições 67-74, e conferem susceptibilidade ao PF endêmico (CULTON et al., 2008).

Numa revisão, alelos $H L A D R B 1^{*} 0402$ e $D Q B 1^{*} 0503$ estão associados a ambos os tipos de pênfigos (TRON et al., 2006).

Em estudo do nosso grupo, verificou-se aumento significante na frequência do $H L A-A * 69$ e $H L A-D R B 1^{*} 01$ nos pacientes com PF. Naquela data, relatou-se que pacientes com PV, provenientes de Batatais (cidade próxima a Ribeirão Preto, pertencente à região nordeste do ESP, endêmica para PF), expressavam HLA de classe II de susceptibilidade semelhante aos pacientes com PF (Roselino et al.; 1998).

A Tabela 2 resume os estudos realizados com amostras brasileiras. 
Tabela 2. Alelos $H L A$ de classe II de suscetibilidade aos pênfigos em amostras brasileiras

\begin{tabular}{|c|c|c|c|}
\hline & $-D R B 1$ & $-D Q B 1$ & Referência \\
\hline \multicolumn{4}{|c|}{ Suscetibilidade } \\
\hline \multirow[t]{3}{*}{ PV } & $* 04: 02 * 08: 04 * 14$ & & Weber et al., 2011 \\
\hline & $\begin{array}{l}* 01: 01 / 02 / 03 * 04: 04 / 06 / 10 \\
* 14: 06 * 16: 01\end{array}$ & & Pavoni et al., 2003 \\
\hline & $* 04: 04 * 14: 02 / 06$ & $* 03: 02$ & Moraes et al., 1997 \\
\hline \multirow[t]{3}{*}{$\mathrm{PF}$} & $* 04: 04 / 07 * 08: 02 * 14: 02 * 16: 02$ & & Cerna et al., 1993 \\
\hline & *01:02 & & Moraes et al., 1991 \\
\hline & $* 01 * 04 * 16$ & & $\begin{array}{c}\text { Petzl-Erler; Santamaria, } \\
1989\end{array}$ \\
\hline \multicolumn{4}{|c|}{ Resistência } \\
\hline \multirow{3}{*}{ PF } & $\begin{array}{l}* 03: 01 * 07: 01 * 08: 01 * 11: 01 / 04 \\
* 14: 02\end{array}$ & & Pavoni et al., 2003 \\
\hline & & *06:02 & Moraes et al., 1991 \\
\hline & $* 07$ & & $\begin{array}{c}\text { Petzl-Erler; Santamaria, } \\
1989\end{array}$ \\
\hline
\end{tabular}

PV: pênfigo vulgar; PF: pênfigo foliáceo

\subsection{Conceitos gerais sobre LTA}

A leishmaniose tegumentar Americana (LTA) tem apresentado aumento acentuado na sua incidência, principalmente nas últimas décadas, e há cerca de 1,5 milhões de novos casos de leishmaniose cutânea por ano (DESJEUX, 2004). A LTA ocorre nas Américas desde o sul dos Estados Unidos até o norte da Argentina, sendo o foco mais importante o sul-americano. Nos últimos anos, o Ministério da Saúde registrou média anual de 35 mil novos casos de LTA no Brasil.

É uma doença infecciosa que envolve pele, mucosa e cartilagens, causada por espécies de protozoários do gênero Leishmania, transmitidos por insetos vetores. Os insetos vetores são dípteros pequenos (2-3mm) pertencentes à família Psychodidae, e a diversos-gêneros, Phlebotomus no Velho Mundo (Europa, Ásia e África), e Lutzomyia e, mais raramente, Psychodopygus no Novo Mundo 
(Américas), possuindo ampla distribuição nas regiões tropicais e subtropicais. Só a fêmea é antropofilica e hematófaga (MEDEIROS; ROSELINO, 1999).

A leishmania é injetada no hospedeiro vertebrado na forma de promastigotas, que são fagocitadas pelos macrófagos e, dentro dessas células do sistema fagocítico mononuclear, são diferenciadas em amastigotas e então proliferam, estabelecendo a infecção (GOTO; LINDOSO, 2010).

Nas Américas, a LTA é causada pelos complexos Leishmania braziliensis e Leishmania mexicana. No Brasil, são descritos Leishmania (Leishmania) amazonensis, Leishmania (Viannia) braziliensis e Leishmania (Viannia) guyanensis. Através de sequenciamento de DNA, nosso grupo confirmou o envolvimento de L. amazonensis nos casos de LTA do estado de São Paulo (MEDEIROS et al., 2008)

A leishmaniose depende de fatores de virulência do próprio parasito (espécie leishmania infectante) e da resposta imune estabelecida pelo hospedeiro (homem). Portanto, dependendo da espécie infectante e da resposta imunecelular do indivíduo infectado, podem ser observadas desde a infecção subclínica, lesões localizadas, lesões generalizadas, lesões mucosas, até a forma anérgica. Nosso grupo demonstrou acúmulo de células Treg em lesões infectadas por Leishmania e sua possível contribuição para o controle local da função das células T efetoras (CAMPANELLI et al., 2006).

As formas clínicas são: Leishmaniose cutânea localizada, Leishmaniose cutânea difusa, Leishmaniose mucocutânea e Leishmaniose recidivante. Em relação a esta última, Gomes et al. (2015) demonstraram que o tratamento padrão do Ministério da Saúde, com antimoniato de Nmetilglucamina, é efetivo em preveni-la.

Ainda em relação às formas clínicas, nosso grupo relatou, em 2007, uma série de casos de leishmaniose oral, apresentação mucocutânea pouco usual (MOTTA et al., 2007).

Esse amplo espectro de apresentação clínica pode, às vezes, dificultar e retardar o diagnóstico. Aspectos epidemiológicos, clínicos e laboratoriais devem ser levados em conta para o diagnóstico de LTA. 


\subsection{Testes laboratoriais utilizados no diagnóstico da LTA}

O diagnóstico da LTA é feito com base nos dados clínicos e epidemiológicos e é confirmado por meio de diferentes métodos laboratoriais. Estes podem, algumas vezes, ser difíceis, visto que a detecção do parasito na lesão se torna mais remota conforme a doença se torna crônica (MEDEIROS; ROSELINO, 1999).

Vários métodos imunológicos vêm sendo desenvolvidos e adaptados para demonstrar a resposta imune tanto celular quanto humoral. A sensibilidade e a especificidade desses métodos dependem, dentre outras variáveis, da técnica, da amostra e da pureza do antígeno empregado. Em geral, os testes imunológicos têm boa sensibilidade, mas especificidade baixa, e os parasitológicos têm boa especificidade, no entanto, baixa sensibilidade (GOMES et al., 2014a).

Dentre os testes laboratoriais utilizados, estão, com desempenhos variáveis, a reação intradérmica de Montenegro (IRM), testes sorológicos tais como a reação de imunofluorescência indireta (RIFI), o teste imunoenzimático (Enzyme-Linked Immunosorbent Assay - ELISA) e o imunnoblotting (Western Blot), a pesquisa de leishmania em material de biópsia de pele ou mucosa, e a reação em cadeia da polimerase (Polymerase Chain Reaction - PCR) (GOMES et al., 2014b). A RIFI é o teste mais utilizado. É uma técnica sensível, porém com possibilidade de reações cruzadas especialmente com a doença de Chagas e calazar (KAR, 1995).

No intuito de avaliar esses métodos diagnósticos, nosso grupo vem desempenhando diversos estudos. Medeiros et al. (2002), demostraram a utilidade da PCR como método diagnóstico para LTA, relatando sensibilidade de $81 \%$. Garcia et al. (2005), objetivando comparar técnicas para diagnóstico e, mais especificamente, o sequenciamento de DNA e a PCR-RFLP (Restriction fragmente lenght polymorphism) na determinação da espécie de leishmania, avaliaram diversos testes num grupo de pacientes com LTA, obtendo resultados estatisticamente equivalentes para diagnóstico com a IRM e a PCR, e também equivalentes para identificação da espécie da leishmania no sequenciamento de DNA e na PCR-RFLP, sendo essa última de menor custo e menor tempo de execução.

Mais recentemente, Ferreira et al. (2006), também avaliaram diversos métodos comparativamente, obtendo sensibilidade para o ELISA de $85 \%$, para a PCR de $81 \%$, para a IRM de 
$64.4 \%$, para a RIFI de $58,1 \%$ e presença de parasitos na biópsia em $34 \%$ da amostra avaliada. E Gomes et al. (2014-a) relataram a efetividade da PCR com primers para amplificação de fragmento de kDNA a partir de amostras de swab nasal, saliva e oral filter paper imprints (OFPI) para diagnóstico de LTA mucosa, com melhor desempenho no swab nasal, com acurácia de 86\%.

\subsubsection{Intradermorreação de Montenegro}

Amplamente empregada e bastante útil, a intradermorreação com antígeno preparado de cultura de Leishmania spp foi realizada pela primeira vez por Montenegro, em 1926. O teste consiste numa injeção intradérmica de promastigotas mortas, cujo resultado positivo é interpretado como sinal da efetividade da resposta imune celular do indivíduo ao parasito. É uma reação imune do tipo IV e mimetiza a resposta inflamatória granulomatosa que ocorre nas lesões de leishmaniose. Torna-se positivo em torno de quatro meses após o início da lesão cutânea, mas não diferencia doença atual e pregressa (na maioria das vezes permanece positivo mesmo após o tratamento), nem distingue doença de infecção, e é habitualmente negativo nas formas cutâneas difusas e nos pacientes imunodeprimidos. (MONTENEGRO, 1926)

Essa reação de hipersensibilidade tardia possui sensibilidade variando entre 86 e 100\%, e especificidade de aproximadamente 100\% (FURTADO, 1980; GUEDES et al., 1990), o que a consagrou como uma das provas mais usadas na confirmação da doença ativa, no diagnóstico retrospectivo e em inquéritos epidemiológicos de LTA (DINIZ et al., 2011). O resultado positivo em pacientes de área endêmica, sem história ou sinais sugestivos de doença, é considerado como infecção subclínica (NOGUEIRA et al., 2008).

\subsubsection{ELISA para deteç̧ão de anticorpos contra leishmania}

O ensaio ELISA tem sido demonstrado como de grande valor para o diagnóstico complementar da LTA em diversos estudos. Nosso grupo demonstrou, em pacientes com LTA, os seguintes resultados de sensibilidade: ELISA $=85 \% ;$ PCR $=81 \% ;$ IRM $=64.4 \% ;$ IFI $=58,1 \%$; presença de parasitos na biópsia $=34 \%$, além de positividade do ensaio ELISA em parcela expressiva 
dos pacientes que apresentavam outros testes diagnósticos negativos (foi positivo em $100 \%$ dos pacientes com PCR negativa; em 84,8\% dos casos com biópsias mostrando ausência de parasitos e em $75 \%$ dos não reativos à IRM), mostrando a utilidade do ELISA como método diagnóstico da LTA (FERREIRA et al., 2006).

Barroso-Freitas, em 2009, reafirmou a indicação do ensaio ELISA para o diagnóstico da LTA, mostrando boa acurácia e boa reprodutibilidade, e sugeriu a associação da RIFI com o ensaio ELISA no intuito de aumentar a sensibilidade diagnóstica laboratorial.

Gil et al. (2011), além de confirmarem boa sensibilidade do teste com 3 espécies diferentes de leishmania (L. braziliensis, L. amazonensis, L. guyanensis), mostraram que não houve diferença na sensibilidade do teste independente da espécie utilizada como antígeno. E Soares et al., em 2015, corroboraram com esse dado, demostrando boa acurácia do ensaio ELISA com exoantígenos de Leishmania (Leishmania) mexicana para diagnóstico da LTA numa região de maior predomínio de Leishmania (Viannia) braziliensis.

\subsubsection{Reação cruzada nos testes imunológicos para Leishmaniose e Doença de Chagas}

A ocorrência de reação cruzada é fator limitador da especificidade dos testes imunológicos para Leishmaniose e Doença de Chagas e deve ser sempre lembrada quando se está pesquisando uma dessas enfermidades. Decorre da estreita relação filogenética entre Trypanosoma cruzi e Leishmania spp (EL-SAYED et al., 2005), dificultando a diferenciação entre tais doenças. Essa questão se torna um entrave diagnóstico especialmente nas áreas de sobreposição de endemicidade para ambas as doenças, fato citado com frequência na literatura (CABALLERO et al., 2007; VEGA BENEDETTI. et a, 2013; CERVANTES-LANDÍN. et al, 2014).

\subsection{HLA na LTA}

Estudo avaliando em 43 pacientes LTA e 111 controles do estado do Paraná, região sul do Brasil, a associação do $H L A$ com LTA mucosa, caracterizou os alelos $H L A-A,-B,-C,-D R$ e- $D Q$, e 
demonstrou maior frequência do $H L A-D Q \mathrm{w} 3$ (nomenclatura desmembrada e modificada em 1987, e, depois em 1989, para $-D Q B 1 * 03: 01, * 03: 02$ e *03:03) e descreveu associação negativa, ou seja, menor frequência do $H L A-D R 2$ (nomenclatura desmembrada e modificada em 1987, e, depois em 1989, para $-D R B 1 * 15: 01, D R B 1 * 15: 02, D R B 1 * 16: 01$ e $D R B 1 * 16: 02)$ entre os pacientes com LTA (PETZL-ERLER et al., 1993). Estudo mais recente, em população do sudeste do Brasil, com 169 pacientes LTA e 270 controels saudáveis, investigando $H L A-A$, HLA-B e HLA-DRB1, mostrou maior frequência do $H L A-D R B 1 * 13$ e $H L A-B^{*} 35$ e *44 na LTA cutânea, e menor frequência do $H L A-B^{*} 45$ na LTA cutânea, do $-B^{*} 27$ na LTA mucosa, do $-B^{*} 49$ na recorrente e $-B^{*} 52$ na reinfecção (RIBASSILVA et al., 2013).

A Tabela 3 resume os estudos realizados com amostras brasileiras.

Tabela 3. Alelos $H L A$ relacionados à suscetibilidade à LTA em amostras brasileiras

\begin{tabular}{|c|c|c|c|c|}
\hline & $-B$ & $-D R B 1$ & $-D Q$ & Referência \\
\hline \multicolumn{5}{|l|}{ Suscetibilidade } \\
\hline LTA mucosa & & & w $3^{1}$ & Petzl-Erler et al., 1991 \\
\hline LTA cutânea & $* 35 * 44$ & $* 13$ & & Ribas-Silva et al., 2013 \\
\hline \multicolumn{5}{|l|}{ Resistência } \\
\hline LTA mucosa & & $D R 2^{2}$ & & Petzl-Erler et al., 1991 \\
\hline LTA cutânea & $* 45$ & & & Ribas-Silva et al., 2013 \\
\hline LTA mucosa & $* 27$ & & & \\
\hline LTA recorrente & $* 49$ & & & \\
\hline Reinfecção & $* 52$ & & & \\
\hline
\end{tabular}

Percebe-se que o alelo $-D Q B 1^{*} 03$, descrito como de suscetibilidade para LTA mucosa, é também citado no pênfigo, com caracterização em alta definição, posicionando o *03:01 como de resistência para PF e o *3:02 como de suscetibilidade para PF, e o alelo $-D R B 1 * 16$, descrito como de 
resistência para LTA mucosa, é também descrito como de suscetibilidade para PF, conforme apontado nas Tabelas 2 e 4. Os demais alelos identificados não coincidem nem com os de susceptibilidade nem com os de resistência descritos para os pênfigos.

\subsection{Anticorpos contra proteínas salivares de insetos hematófagos nos pênfigos e nas leishmanioses}

Os pênfigos têm sido extensivamente estudados ao nível molecular, em especial suas características imunológicas e genéticas, porém, a etiopatogênese ainda se encontra incompreendida. Fatores genéticos relacionados às moléculas $H L A$ de classe II $-D R$ e $-D Q$, aliados a fatores ambientais, como vírus, metais pesados, pesticidas e proteínas salivares de insetos hematófagos são implicados na susceptibilidade à doença (ABRÉU-VÉLEZ et al., 2010). O PF vem sendo relacionado à picada de insetos hematófagos, em especial Simulium nigrimanum, desde a década de 40 (VIEIRA, 1942).

Sendo a região nordeste do estado de São Paulo endêmica para ambos, PF e PV (GONÇALVES et al., 2011), assim como para a leishmaniose tegumentar Americana (LTA) (MEDEIROS, ROSELINO, 1999), nosso grupo vem estudando aspectos clínico-laboratoriais (FREITAS et al., 2007; MOREIRA et al., 2004; ROSALBA, ROSELINO, 2007); genéticos (GATTI et al., 2008); e também aspectos relacionados à epidemiologia molecular da LTA (ALBERTO et al., 1993; GARCIA et al., 2005; MEDEIROS et al., 2002; MEDEIROS et al., 2008).

Dessa forma, com a hipótese de que proteínas salivares de insetos hematófagos pudessem ter semelhança antigênica com as desmogleínas, fomos pioneiros ao relacionar ambas as doenças ao estudar a presença de anticorpos contra proteína salivar do inseto hematófago Lutzomyia longipalpis, transmissor da leishmaniose visceral, denominada maxadilan, em amostras de soro de pacientes com PF (FLORES et al., 2009; ROSELINO et al., 2001; ROSELINO et al., 2006).

A seguir, também de forma inédita, constatamos que amostras de soro de pacientes com LTA também reagiam contra a proteína Maxadilan, e que o vetor Lutzomyia neivai, transmissor da LTA na região nordeste do estado de São Paulo, também expressava a proteína maxadilan, inicialmente descrita somente em Lu. longipalpis (AIRES et al., 2005). 
Nos últimos anos, temos estudado a relação da etiopatogênese do PF com as proteínas salivares dos insetos hematófagos Aedes aegypti, Lu. longipalpis e Simulium nigrimanum (KIM et al., 2008; KIM et al., 2010; KIM, 2012).

Recentemente, Zaraa et al., 2012, na Tunísia, em estudo caso-controle, demonstraram, por ELISA e confirmação por blotting, que 26\% (8/31) dos pacientes com PF reagiram contra proteína salivar do vetor Phlebotomus papatasi, comparados a 6,4\% (2/31) dos controles. Em relação ao grupo com leishmaniose cutânea causada por L. major e controles, $53 \%(32 / 60)$ dos pacientes e $62 \%(37 / 60)$ dos controles apresentaram positividade dos testes (ZARAA et al., 2012).

E ainda, o grupo do Diaz demonstrou que antígenos salivares de Lu. longipalpis, especificamente a proteína salivar LJM11, são reconhecidos por anticorpos de pacientes com fogo selvagem (QIAN et al., 2012).

Transcriptomas de proteínas salivares de insetos hematófagos, como Simulium nigrimanum e Triatoma matogrossensis, têm sido descritos no intuito de se poder testar os soros de pacientes com pênfigo contra proteínas salivares, configurando a exposição a picadas desses insetos como possível fator ambiental. (ASSUMPÇÃO et al., 2012; RIBEIRO et al., 2010)

\subsection{Anticorpos contra desmogleínas em doenças transmitidas por insetos hematófagos}

Diaz et al. (2004), considerando que antígenos provenientes dos insetos hematófagos pudessem desencadear a formação de anticorpos contra desmogleína por reação cruzada, identificaram, por ensaio ELISA, anticorpos anti-Dsg 1 em 83\% (34/41) dos pacientes com Oncocercose, 43\% (38/88) na leishmaniose tegumentar e 58\% (18/31) na doença de Chagas. Utilizaram como controles soros de pacientes com doenças não relacionadas à transmissão por insetos, obtendo positividade em $25 \%(7 / 28)$ na paracoccidiodomicose e $17 \%(14 / 83)$ na hanseníase. As porcentagens de positividade, quando comparadas àquela do grupo de indivíduos saudáveis descrita na literatura, no qual 20\% apresentaram positividade ao teste contra Dsg1 (WARREN et al., 2000), foram significantes para as doenças transmitidas por artrópodos. 
A seguir, na Tunísia, demonstrou-se que $40 \%$ (14/35) dos pacientes com hidatidose e $21,7 \%$ (5/23) daqueles com leishmaniose visceral também apresentaram anticorpos contra Dsg1, comparados a 6,57\% (10/152) dos controles (KALLEL SELLAMI et al., 2007). Também na Tunísia, a pesquisa de anticorpos anti-Dsg1 por ELISA em 60 pacientes com leishmaniose cutânea causada por L. major, comparados aos controles, mostrou que $13,3 \%$ dos pacientes e $1,6 \%$ dos controles apresentaram o teste positivo (ZARAA et al., 2012).

Nosso grupo mostrou a prevalência de anticorpos séricos contra Dsg1 em 90\% (38/42) dos pacientes com PF, e em 23,8\% (5/21) dos pacientes com LTA, comparados a $0 \%(0 / 7)$ dos controles. Em relação à Dsg3, 7,1\% (3/42) dos pacientes com PF apresentaram positividade, em relação a 4,76\% (1/21) dos pacientes com LTA, e 0\% (0/7) dos controles (KIM, 2012). 


\section{OBJETIVOS}

Objetivo Geral:

Teve-se por objetivo geral relacionar fatores imunogenéticos dos pênfigos com aqueles da LTA, com a finalidade de configurar a exposição aos antígenos da leishmania como possível fator ambiental influenciador no desencadeamento dos pênfigos na área de estudo.

Objetivos específicos:

Investigou-se, em amostras de soros de pacientes com pênfigos, LTA e controles,

i. a resposta humoral às desmogleínas 1 e 3 por ensaio ELISA;

ii. a resposta humoral aos antígenos de $L .(V$.) braziliensis por ensaio ELISA;

iii. a correlação dos títulos de anticorpos contra desmogleínas 1 e 3 com os anticorpos contra $L$. (V.) braziliensis;

iv. o reconhecimento dos peptídeos da epiderme humana por immunoblotting e por imunofluorescência indireta;

v. o reconhecimento dos peptídeos de $L$. (V.) braziliensis por immunoblotting;

vi. a resposta humoral aos antígenos de Trypanosoma cruzi por exame sorológico para Chagas;

vii. a resposta celular pela intradermorreação de Montenegro;

viii. a frequência dos alelos $H L A$ de classe II $-D R$ e $-D Q$ no grupo LTA quando comparado ao grupo controle;

ix. a associação dos alelos $H L A$ de classe II $-D R$ e $-D Q$ no grupo LTA com aqueles de suscetibilidade e de resistência descritos nos pênfigos. 


\section{MÉTODOS}

Trata-se de estudo transversal analítico.

Este projeto foi aprovado pelo CEP local, processo HCRP no.8716/2013 (Anexo 4). O Banco de amostras biológicas do Laboratório Multiusuário de Biologia Molecular, Departamento de Clínica Médica, situado no Anexo B da FMRP-USP, tem a aprovação do CEP, Processo HCRP- no. 3605/2006 (Anexo 5). E o projeto temático "Relação dos fatores imunogenéticos e ambientais na etiopatogênese dos pênfigos em amostragem brasileira", no qual este projeto está inserido, tem a aprovação no CEP local, Processo HCRP 10/51729-2 (Anexo 6).

\subsection{Casuística}

\section{Ensaios ELISA}

Para os ensaios ELISA foram utilizadas amostras de soro - de pacientes com pênfigo, LTA e controles - do banco biológico do Laboratório Multiusuário de Biologia Molecular, coletadas no período de 1997 a 2012. A escolha das amostras se baseou no critério da procedência da região NE do ESP.

Os pacientes tiveram seus prontuários revistos para a confirmação dos dados demográficos, como gênero e idade, para a identificação das formas clínicas do pênfigo e da LTA, e do local de procedência.

Um grupo controle foi constituído por familiares ou vizinhos dos pacientes com pênfigo procedentes da área de estudo. E para o ELISA com antígenos de L. (V.) braziliensis, um segundo grupo controle foi constituído por amostras de soro de doadores do banco de sangue (BS) do Hemocentro de Ribeirão Preto, HC-FMRP-USP. Salienta-se a importância de se constituir grupo controle de amostras do BS por serem consideradas isentas de doenças infectocontagiosas.

A casuística foi composta por: 140 pacientes com pênfigo (78 com PF, 62 com PV), 58 pacientes com LTA [37 com a forma cutânea (LTAc), 21 com a forma mucosa (LTAm)], 86 
indivíduos controles (25 familiares de pacientes com PF (FPF), 24 FPV, 37 vizinhos de pacientes com PF ou PV) e 51 do grupo Controle BS. As características demográficas estão mostradas na Tabela 4.

Houve prevalência do gênero feminino nos grupos PV (72,6\%), FPF (72\%) e FPV (70,8\%), enquanto nos grupos LTAc e controles BS, houve prevalência do gênero masculino, de 70,3\% e $76,5 \%$, respectivamente $(\mathrm{p}<0,05)$.

Em relação à idade, a faixa etária foi mais alta no grupo LTAm (mediana de 59 anos) em relação aos grupos PF (34 anos) ( $p<0,001)$, FPV (36,5 anos) e controles vizinhos $(46,5$ anos $)(p<0,01)$; e mais alta no grupo PV (45 anos) em relação ao grupo $\mathrm{PF}(\mathrm{p}<0,05)$.

\section{Immunoblotting e Imunofluorescência Indireta}

Para os ensaios de IB com L. (V.) braziliensis e IB com extrato de epiderme, foram selecionadas 18 amostras de soro a partir dos resultados dos ensaios ELISA e, dentre estas, para a IFI, as 6 amostras de pacientes com LTA.

\section{Teste de Montenegro}

O teste de Montenegro foi realizado em 6 pacientes com pênfigo (2 com PF e 4 com PV). Foram incluídos aleatoriamente, conforme demanda natural do ambulatório, aqueles pacientes com o diagnóstico clínico de pênfigo em atividade, confirmado por histopatológico e IFD, e que estivessem sem uso de corticoide ou qualquer outra droga imunossupressora por no mínimo 60 dias. Desses 6 pacientes, 4 estavam em remissão, sem imunossupressor há pelo menos 16 meses; 1 era caso novo, com 6 meses de doença, sem nunca ter usado imunossupressor; e 1 estava sem tratamento sistêmico há 2 anos e 5 meses, usando corticoide tópico esporadicamente. Como a lesão era pequena e o uso esporádico, foi considerado que esse tópico não seria capaz de interferir na resposta ao montenegro e a paciente foi considerada sem uso de imunossupressor. Assim, todos os indivíduos avaliados estavam sem corticoides ou imunossupressores por no mínimo 16 meses. 
Tabela 4. Distribuição dos dados demográficos dos grupos em estudo - Leishmaniose tegumentar Americana forma cutânea localizada (LTAc) e mucosa (LTAm), pênfigo vulgar (PV), pênfigo foliáceo (PF), familiares de pênfigo vulgar (FPV), familiares de pênfigo foliáceo (FPF), Controles vizinhos dos pacientes com pênfigo, controles do banco de sangue (BS).

\begin{tabular}{|c|c|c|c|c|c|c|c|c|c|c|}
\hline & & LTAc & LTAm & PV & $\mathrm{PF}$ & FPF & FPV & Controles vizinhos & Controles BS & Valor de P \\
\hline \multirow{3}{*}{ Gênero } & & $\mathrm{N}=37$ & $\mathrm{~N}=21$ & $\mathrm{~N}=62$ & $\mathrm{~N}=78$ & $\mathrm{~N}=25$ & $\mathrm{~N}=24$ & $\mathrm{~N}=37$ & $\mathrm{~N}=51$ & \\
\hline & Masculino & $26(70,3 \%)$ & $12(57,1 \%)$ & $17(27,4 \%)$ & $37(47,4 \%)$ & $7(28 \%)$ & $7(29,2 \%)$ & $16(43,2 \%)$ & $39(76,5 \%)$ & \multirow{2}{*}{$\mathrm{P}<0,05$} \\
\hline & Feminino & $11(29,7 \%)$ & $9(42,9 \%)$ & $45(72,6 \%)$ & $41(52,6 \%)$ & $18(72 \%)$ & $17(70,8 \%)$ & $21(56,8 \%)$ & $12(23,5 \%)$ & \\
\hline \multirow{5}{*}{$\begin{array}{l}\text { Idade } \\
\text { (anos) }\end{array}$} & \multirow{5}{*}{ Mediana } & \multirow{5}{*}{41} & \multirow{5}{*}{$59^{* \& \#}$} & \multirow{5}{*}{$45^{\epsilon}$} & \multirow{5}{*}{$34^{*} €$} & $(\mathrm{~N}=23)$ & $(\mathrm{N}=20)$ & $(\mathrm{N}=32)$ & \multirow{5}{*}{41} & \\
\hline & & & & & & \multirow{4}{*}{42} & \multirow{4}{*}{$36,5^{\&}$} & \multirow{4}{*}{$46,5^{¥}$} & & $* \mathrm{p}<0.001$ \\
\hline & & & & & & & & & & $\& \mathrm{p}<0.01$ \\
\hline & & & & & & & & & & $¥ \mathrm{p}<0.01$ \\
\hline & & & & & & & & & & $€<0.05$ \\
\hline
\end{tabular}

M: masculino; F: feminino; N: tamanho amostral 


\section{Caracterização dos alelos $H L A$}

Para a análise dos alelos $H L A-D R$ e $-D Q$ foram utilizadas amostras de DNA de 35 pacientes com LTAc e 21 com LTAm; 86 pacientes com PF, e 82 com PV. O grupo controle foi constituído por 1592 indivíduos sadios, doadores de medula óssea do BS do Hemocentro.

O grupo controle, constituído por familiares, não foi utilizado devido ao compartilhamento de alelos $H L A$ com os pacientes de pênfigo.

Os dados demográficos dos pacientes e controles podem ser vistos na tabela 5.

Tabela 5. Distribuição dos dados demográficos dos grupos em estudo na caracterização dos alelos HLA

\begin{tabular}{|c|c|c|c|c|c|c|c|}
\hline & & $\begin{array}{r}\text { LTAc } \\
\mathrm{N}=35\end{array}$ & $\begin{array}{c}\text { LTAm } \\
\mathrm{N}=21\end{array}$ & $\begin{array}{c}\mathrm{PV} \\
\mathrm{N}=82\end{array}$ & $\begin{array}{c}\mathrm{PF} \\
\mathrm{N}=86\end{array}$ & $\begin{array}{c}\text { Controles } \\
\text { BS N }=1592\end{array}$ & Valor de $\mathrm{P}$ \\
\hline \multirow{2}{*}{ Gênero } & M & 25 & 12 & 25 & 36 & 949 & \multirow{2}{*}{$<0,05$} \\
\hline & & 10 & 9 & 57 & 50 & 643 & \\
\hline \multirow{3}{*}{$\begin{array}{l}\text { Idade } \\
\text { (anos) }\end{array}$} & Média & 40,74 & 56,52 & 49,48 & 39,06 & 35,74 & \multirow{3}{*}{$<0,05$} \\
\hline & SD & 16,63 & 14,92 & 17,05 & 16,22 & 9,04 & \\
\hline & Mediana & 41 & 59 & 49 & 37 & 34 & \\
\hline
\end{tabular}

\subsection{ELISA para determinação da resposta humoral às Dsg1 e 3 (objetivo i)}

O ensaio ELISA foi realizado a partir de kits comerciais (Dsg1 \& Dsg3 Elisa Test System, RG-7593-D, MBL, Nagoya, Japan), segundo as instruções do fabricante.

O cálculo dos resultados foi realizado conforme as orientações do fabricante do kit, de acordo com a fórmula a seguir, onde $\mathrm{A}_{450}$ é o valor da leitura da densidade óptica da amostra em espectrofotômetro, sob absorbância de 450nm, após realização do teste: 
Unidade de Valor $(\mathrm{U} / \mathrm{mL})$

$(\mathrm{U} / \mathrm{mL})=$ $\underline{\mathrm{A}}_{450} \leq \underline{\mathrm{Amostra}}>-\mathrm{A}_{450} \leq$ Calibrador Negativo $>$ X 100

$\left(\mathrm{A}_{450}<\right.$ Calibrador da Desmogleína $>-\mathrm{A}_{450}<$ Calibrador Negativo $\left.>\right)$

$\mathrm{A}_{450 \text { : }}$ abreviação para valor de absorbância a 450nm

Os resultados obtidos em $\mathrm{U} / \mathrm{mL}$ pela fórmula acima comparados com o ponto de corte sugerido pelo fabricante, e interpretados da seguinte forma:

$\begin{array}{lrr} & \text { Dsg1 } & \text { Dsg3 } \\ \text { Negativo } & <14 & <9 \\ \text { Indeterminado } & 14-20 & 9-20 \\ \text { Positivo } & >20 & >20\end{array}$

\subsection{ELISA in house para determinação da resposta humoral ao extrato proteico de L. (Viannia) braziliensis (objetivo ii)}

\section{Extração de proteínas da cultura de L. (Viannia) braziliensis}

Tanto para o ELISA in house quanto para o IB, foram utilizados extratos proteicos de leishmania obtidos a partir da cepa LTUP 393 de L. (Viannia) braziliensis (obtida de úlcera cutânea de um paciente da área endêmica de Corte de Pedra, BA, Brasil), cedida pelo Prof. Dr. João Santana da Silva. A cultura foi mantida no Departamento de Bioquímica e Imunologia da Faculdade de Medicina de Ribeirão Preto -USP, em meio Schneider (Sigma, Saint Louis, USA) suplementado com $20 \%$ de soro fetal bovino (Cultilab, Campinas, SP, Brasil), $4 \mathrm{mM} \mathrm{NaHCO}$, $100 \mathrm{U} / \mathrm{mL}$ penicilina, $100 \mu \mathrm{g} / \mathrm{mL}$ estreptomicina (todos da Gibco, Grand Island, NY, USA), e $2 \%$ de urina humana masculina a $25{ }^{\circ} \mathrm{C}$, e utilizada para extração no $5^{\circ}$. dia de cultivo.

A cultura foi centrifugada a $4{ }^{\circ} \mathrm{C}$ por 15 minutos, a $3000 \mathrm{rpm}$, e o sobrenadante desprezado. $\mathrm{O}$ "pellet" obtido foi utilizado para preparação do antígeno conforme técnicas descritas a seguir: 


\section{- Por Trizol}

Resumidamente, nesse método, a partir da homogeneização das culturas das leishmanias com o reagente Trizol (solução monofásica de fenol e isotiocianato de guanidina), mantém-se a preservação do RNA enquanto ocorre ruptura das células e dissolução dos componentes celulares. A adição de clorofórmio seguida por centrifugação separa a solução em uma fase aquosa, na qual o RNA encontrase dissolvido, e em uma fase orgânica contendo DNA e proteínas. Com a transferência dessa fase aquosa para um novo tubo, o RNA dissolvido é recuperado por precipitação com o uso de isopropanol.

Da mesma forma, DNA e proteínas presentes na fase orgânica também podem ser recuperados por precipitações sequenciais, primeiramente com o uso de etanol para precipitação do DNA, seguido pela precipitação de proteínas da fase orgânica com isopropanol.

\section{- Por kit comercial Total Protein Extraction da Millipore}

Extração realizada segundo as especificações do fabricante:

Realizada diluição de uma alíquota da solução 50xPI no TM buffer, e adição à amostra na proporção de 2,5 $\mathrm{mL}$ para cada grama de tecido, seguida de resfriamento em gelo por 5 minutos. Homogenização das células por 20 segundos e colocação no gelo seco por 15 segundos. Nova homogenização das células por 20 segundos, seguida de agitação das células a $4^{\circ} \mathrm{C}$ por 20 minutos. Centrifugação a $11.000 \mathrm{rpm}$ a $4^{\circ} \mathrm{C}$ por 20 minutos e coleta do sobrenadante.

\section{- Comparação entre os métodos}

Para a decisão de qual o melhor método a ser usado na extração, foi realizada comparação entre a extração pelo Trizol e a extração pelo kit comercial citado acima, pelo método de quantificação de Bradford, com a colaboração da Profa. Karla Arruda.

Nesse método de quantificação, as amostras foram diluídas no Reagente de Bradford e foi usada uma amostra de concentração conhecida para a construção da curva padrão. Preparou-se inicialmente uma solução de BSA (Bovine Serum Albumine) a $1 \mathrm{mg} / \mathrm{mL}$ e, a partir dessa solução, procedeu-se as diluições seriadas em $\mathrm{H}_{2} \mathrm{O}$ (Milli-Q) para a obtenção das demais concentrações $(0,5$ $\mathrm{mg} / \mathrm{mL} ; 0,25 \mathrm{mg} / \mathrm{mL}$ e $0,125 \mathrm{mg} / \mathrm{mL}$ ). Foram separados $10 \mu 1$ de cada diluição e adicionados $790 \mu 1 \mathrm{de}$ 
$\mathrm{H}_{2} \mathrm{O}$ (Milli-Q) acrescidos de $200 \mu 1$ do reagente de Bradford, e um branco com $800 \mu$ de água Milli-Q e $200 \mu 1$ do reagente de Bradford, para a confecção da curva padrão. Posteriormente, preparou-se um outro tudo contendo $10 \mu \mathrm{l}$ da amostra diluída (1:10) com $790 \mu$ água Milli-Q e $200 \mu l$ do reagente de Bradford. Incubou-se estas diluições por 5 minutos à temperatura ambiente e mediu-se a absorbância com filtro 595nm. Posicionou-se as cubetas da curva padrão no espectrofotômetro em ordem crescente de concentração e procedeu-se a leitura. Após determinar a curva padrão, procedeu-se a leitura da amostra. A partir da absorbância, calculou-se a concentração estimada de proteína, multiplicando-se pelo fator de diluição da amostra.

Todas as leituras relativas à proteína obtida pelo Trizol deram concentrações menores que $0,08125 \mathrm{mg} / \mathrm{mL}$, de modo que o aparelho é incapaz de lê-las. Assumindo que a concentração da amostra com maior diluição $(1: 10)$ seja o menor valor detectável, o resultado obtido foi de uma concentração média de $8,1 \mathrm{mg} / \mathrm{mL}$ para a proteína extraída pelo Trizol e de $389,6 \mathrm{mg} / \mathrm{mL}$ para a proteína extraída pelo kit comercial, e o rendimento estimado calculado foi de $0,94 \%$ para a extração pelo Trizol e de $92,35 \%$ para a extração pelo kit, demonstrando claramente a superioridade do kit para tal fim (Tabela 6).

Tabela 6. Desempenho dos métodos de extração de proteína de Leishmania Viannia braziliensis LTUP 393

\begin{tabular}{ccc}
\hline Método & Concentração & Rendimento estimado \\
\hline $\begin{array}{c}\text { Kit Total Protein } \\
\text { Extraction Millipore }\end{array}$ & $389,6 \mathrm{mg} / \mathrm{mL}$ & $92,35 \%$ \\
\hline $\begin{array}{c}\text { Método de extração pelo } \\
\text { Trizol }\end{array}$ & $8,1 \mathrm{mg} / \mathrm{mL}$ & $0,94 \%$ \\
\hline
\end{tabular}

\section{ELISA in house}

As variáveis da reação como concentração do antígeno e do soro foram, então, padronizadas a partir de diluições seriadas e combinadas, tendo por finalidade a determinação das concentrações ótimas para a realização do ensaio ELISA. 


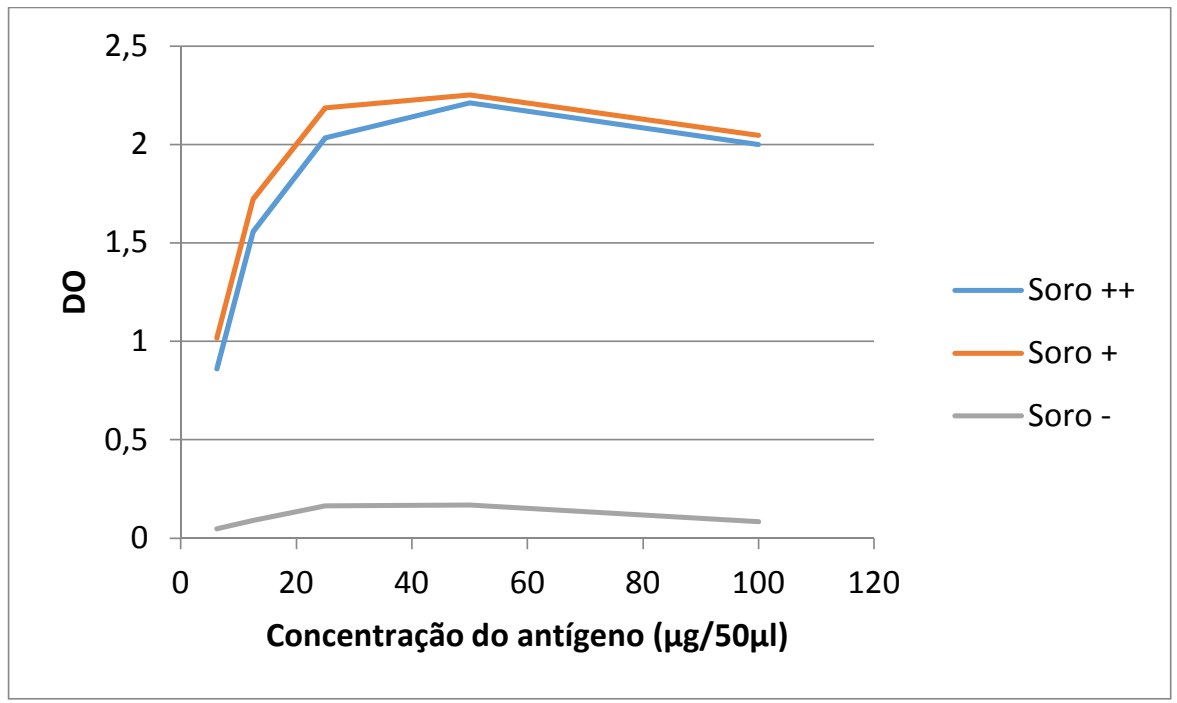

Figura 1. Densidade Óptica para diferentes concentrações do antígeno (extratos proteicos de $L$. (Viannia) braziliensis) frente a soros positivo com título alto $(++)$, positivo com título baixo $(+)$ e negativo (-), diluídos 1:50

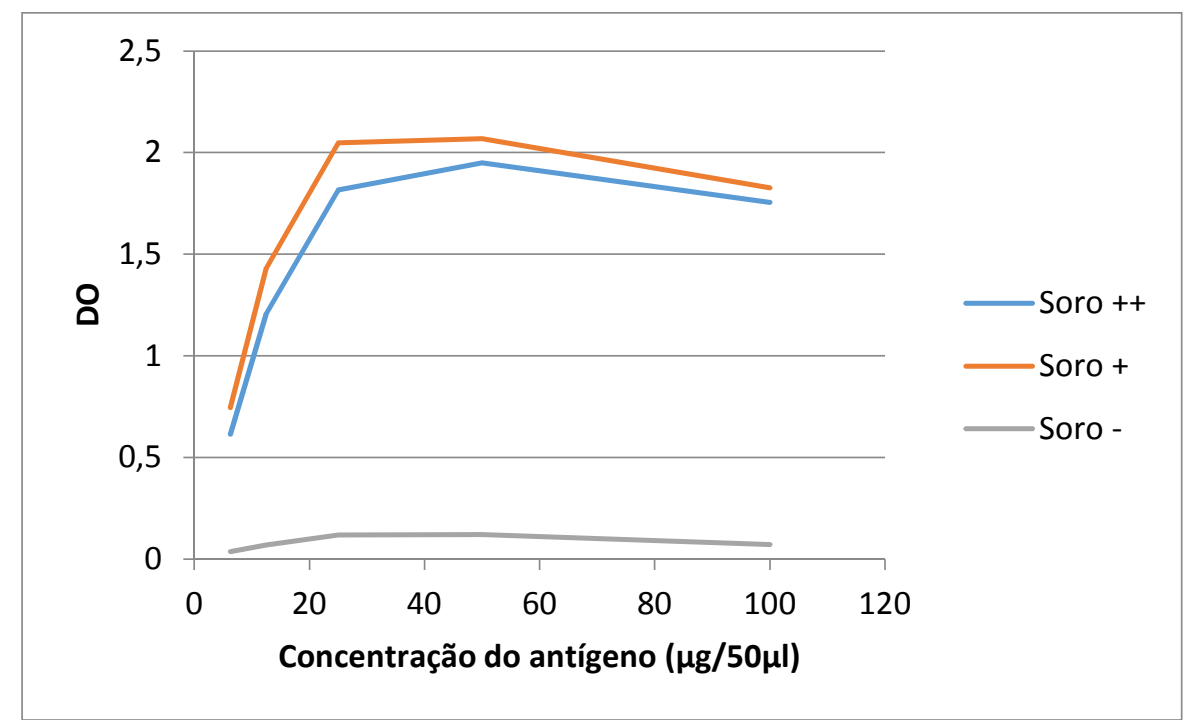

Figura 2. Densidade Óptica para diferentes concentrações do antígeno (extratos proteicos de $L$. (Viannia) braziliensis) frente a soros positivo com título alto $(++)$, positivo com título baixo $(+)$ e negativo (-), diluídos 1:100

Diante desses resultados, os parâmetros considerados ótimos foram:

- Concentração do antígeno: $25 \mu \mathrm{g} / 50 \mu 1$

- Diluição do soro: 1:100 
O ensaio ELISA in house foi, então, realizado com extratos proteicos de L. (Viannia) braziliensis, segundo metodologia descrita a seguir:

Para a sensibilização das placas de 96 poços, utilizou-se o extrato proteico de L. braziliensis extraído de cultura pelo kit comercial Total Protein Extraction Kit da Millipore. Foi utilizado 50 $\mu 1$ de solução antígeno + tampão Carbonato/Bicarbonato ph 9,8 por poço, na concentração de $25 \mu \mathrm{g} / 50 \mu 1$. Deixado overnight para sensibilizar. Após lavagem da placa com PBS Tween 4 vezes em lavadora automática, foram adicionados nos diferentes poços $50 \mu 1$ do controle positivo, do controle negativo e das amostras de soro, previamente diluídos 1:100 em tampão Tween Molico 5\%, e levada a placa à incubação por 2 horas a $37^{\circ} \mathrm{C}$ em banho maria. Foi feita nova lavagem com PBR Tween 4 vezes e adicionados, por poço, 50 $\mu 1$ de conjugado anti-IgG (Anti-Human IgG da Sigma Immuno Chemicals) diluído em Soro Fetal Bovino, na concentração de 1/500. A placa foi novamente incubada por 1 hora a $37^{\circ} \mathrm{C}$ em banho maria e submetida a nova lavagem com PBR Tween 4 vezes. Adicionados, então, $100 \mu 1$ de substrato em cada poço, inclusive no blank e feita nova incubação da placa por 10 minutos em temperatura ambiente, no escuro. Por fim, foram adicionados $100 \mu 1$ de ácido sulfúrico em cada poço para estabilizar a reação e feita leitura na absorbância 492nm.

O ponto de corte foi estabelecido através do cálculo: média de DO do grupo controle $+2 \mathrm{X}$ desvio padrão do grupo controle. DOs acima desse valor foram consideradas positivas e abaixo, negativas.

\subsection{Immunoblotting para pesquisa do reconhecimento de peptídeos da epiderme humana} (objetivo iv)

Retalho de pele normal de prepúcio (sobra de pele de postectomia, cedida pelo Prof. Dr. Carlos Molina do Departamento de Urologia), mantido a $4{ }^{\circ} \mathrm{C}$, em fragmentos de $3 \times 3 \mathrm{~cm}$, foi lavado com PBS gelado, adicionado a $500 \mathrm{~mL}$ de PBS com $2 \mathrm{mM}$ EDTA e $1 \mathrm{mM}$ PMSF e mantido a $4^{\circ} \mathrm{C}$ por 24 horas, com troca da solução após esse período e mantido a $4^{\circ} \mathrm{C}$ por mais 24 horas. Posteriormente, a derme foi separada da epiderme e cada fração foi colocada em um tubo ependorf para extração de proteína. 
Cada fragmento de epiderme foi adicionado à solução de extração - cocktail de inibidores de proteinase (Sigma-Aldrich, Cat\#P8340) - 100uL, homogeneizado por $30 \mathrm{~min}$, fervido por $5 \mathrm{~min}$, centrifugado a $14.000 \mathrm{rpm}$ por $30 \mathrm{~min}$ e, então, aliquotado (50uL) e conservado a $-80^{\circ} \mathrm{C}$.

\section{$\underline{\text { Eletroforese em gel de poliacrilanida }}$}

A partir da extração proteica, realizou-se diluição $1: 1$ contendo $50 \%$ de extrato proteico epidérmico e 50\% de tampão de redução da amostra (Tris HCl 0,125mM - pH 6.8; SDS 3.125\%, Glicerol 12,5\%, 0,00125\% de Azul de Bromofenol e 5\% $\beta$-Mercaptoetanol). A amostra foi reduzida a $99^{\circ} \mathrm{C}$ por 3 minutos (Thermomixer comfort ${ }^{\circledR}$, Eppendorf, Cat $\# 5355900-012$ ) e foram aplicados $15 \mu 1$ por poço no gel de poliacrilamida (Mini Protean TGX gels 4-15\%, 12-wells, cat \#456-1085). Paralelamente foram aplicados $6 \mu \mathrm{L}$ de Peso Molecular (Precision Plus Protein, Dual-Color ${ }^{\circledR}$, BioRad, Cat\#1610374) no poço subsequente da amostra. As amostras foram submetidas à eletroforese vertical (Mini Protean ${ }^{\circledR}$ II, Electrophoresis Cell, Bio-Rad Cat\#165-8000) em tampão de corrida SDSPAGE, por 90 minutos e amperagem contínua de $0.2 \mathrm{~mA}$, com posterior coloração do gel pelo método de prata (Figura 3).

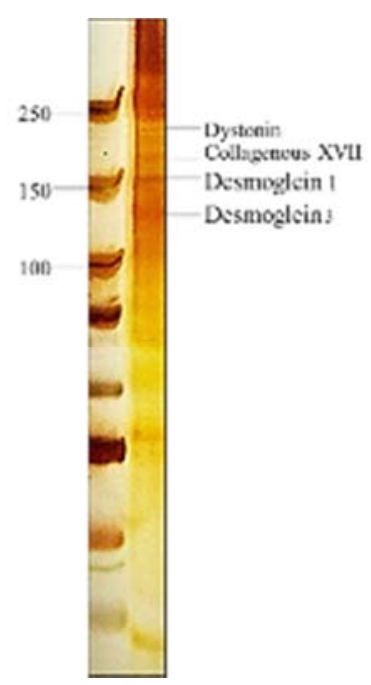

Figura 3. Gel de acrilamida $4-15 \%$ corado por prata com produtos proteicos da epiderme humana. Observar marcação do $\mathrm{PM}(\mathrm{kDa})$ dos peptídeos correspondentes às desmogleínas. 


\section{Immunoblotting}

Marcador de peso molecular (Dual-Color BioRad®, cat\#161-0374) e amostras de proteínas de epiderme foram previamente diluídos no tampão da amostra (Tris Tricina, 2- $\beta$-Mercaptoetanol e água destilada) e levados ao Thermomixer comfort ${ }^{\circledR}$, Eppendorf, Cat $\# 5355900-012$, a $99^{\circ} \mathrm{C}$ por 3 min. As amostras preparadas foram então submetidas à eletroforese (Mini-Protean II cell, Bio-Rad ${ }^{\circledR}$ cat\#1658000), com buffer Tris-Glicine/SDS, em gel de poliacrilamida (Gel 4 - 15\% BioRad® Cat\#456-1085) a $0,2 \mathrm{~mA}$, por 90 minutos. Nesse intervalo, o buffer de transferência (Tris-Glicine e metanol, pH 8) e a membrana de nitrocelulose (Bio-Rad®), Trans-blot tranfer medium \#1620114 - 15x9,32cm) foram preparados de acordo com as instruções do fabricante.

Terminada a corrida eletroforética, o gel de poliacrilamida foi montado em "sandwich" com a membrana de nitrocelulose para a transferência da proteína no sistema de transferência (Mini Trans Blot ${ }^{\circledR}$, Electrophoretic Transfer Cell, Bio-Rad, Cat\#170-3930.), a 0,2 mA, “overnight”. Após a transferência eletroforética, a membrana foi mantida na solução de bloqueio ( $3 \%$ leite desnatado em TBS), em temperatura ambiente, sob agitação, por 1 hora e em seguida, lavada. As amostras diluídas do anticorpo primário (200ul) (soros testes) foram adicionadas sobre as tiras correspondentes e incubadas "overnight" a $4^{\circ} \mathrm{C}$. Após o período de incubação, a membrana foi lavada e adicionou-se o conjugado proteína G-HRP $\left(\right.$ Bio-Rad ${ }^{\circledR}$ Immun-Blot Assay kit - protein G horseadish peroxidase cat\#170-6467), diluído em 3\% leite desnatado em TBS, e incubou-se por 2h, sob agitação. Seguiu-se à última lavagem da membrana com TTBS e, por fim, adicionou-se o reagente de cor (kit Bio Rad Buffer do Conjugado HRP + Reagente A + Reagente B), sob agitação, por 15 minutos, para revelação colorimétrica.

\subsection{Imunofluorescência indireta para pesquisa do reconhecimento dos peptídeos da epiderme humana por (objetivo iv)}

Resumidamente, a IFI foi realizada utilizando substrato de pele de prepúcio humano em criocortes de $5 \mu \mathrm{m}$, estocada a $-80^{\circ} \mathrm{C}$, segundo o protocolo a seguir: o substrato estocado foi estabilizado em temperatura ambiente por 30 minutos, fixado com acetona gelada por 10 minutos e, 
em seguida, lavado com PBS por 5 minutos, 3vezes, e novamente fixado com acetona gelada por 10 minutos. Procedeu-se à incubação com a amostra de soro teste diluída 1:10 em PBS por 30 minutos, seguida de lavagem com PBS por 5 minutos, 3 vezes. Foi feita nova incubação com anti-IgG humana (Sigma \#F4512) ligado à fluoresceína diluído 1:500 em PBS, por 30 minutos em câmara úmida e sala escura, seguida de lavagem com PBS por 5 minutos, 3 vezes. Finalizando, a montagem da lâmina foi realizada em meio glicerinado tamponado + DAPI (VectaShield $\left.{ }^{\circledR}\right)$, e a leitura feita em microscópio de fluorescência (ZEISS Imager A1).

Para a IFI Salt Split, fragmentos de pele normal foram incubados em $\mathrm{NaCl} 1 \mathrm{M}$ por 48-72 horas para clivagem da pele ao nível da lâmina lúcida da camada basal. Após a incubação, a pele foi lavada em $\mathrm{NaCl}$ 0,9\%, seca em papel filtro e congelada em tissue teck a $-80^{\circ} \mathrm{C}$, seguindo-se, então, a mesma técnica de IFI descrita acima.

\subsection{Immunoblotting para pesquisa do reconhecimento dos peptídeos de $L$. (V.) braziliensis (objetivo v)}

\section{Eletroforese em gel de poliacrilamida}

A partir do extrato proteico extraído, realizou-se diferentes diluições seriadas de 1:10 até 1:80 no tampão de redução da amostra ( $5 \mathrm{ml}$ de Tris $\mathrm{HCl}, 1,25 \mathrm{~g}$ de SDS, $5 \mathrm{ml}$ de glicerol e $0,005 \mathrm{~g}$ de Azul de Bromofenol, com 5\% $\beta$-Mercaptoetanol). A amostra foi reduzida a $100^{\circ} \mathrm{C}$ por 3 minutos e $15 \mu 1$ das diluições foram aplicadas no gel 4-15\% de poliacrilamida (Mini Protean TGX gels 4-15\% caixa com 10 unidades, cat \#456-1085). As amostras foram submetidas à eletroforese em gel de poliacrilamida (método SDS-PAGE), por 30 minutos a 200v, com posterior coloração do gel pelo método de prata.

A seguir, na Figura 4, podem-se observar os produtos proteicos de leishmanias obtidos por kit comercial e por Trizol, em 4 diluições seriadas (1:10, 1:20, 1:40, 1:80) cada. 


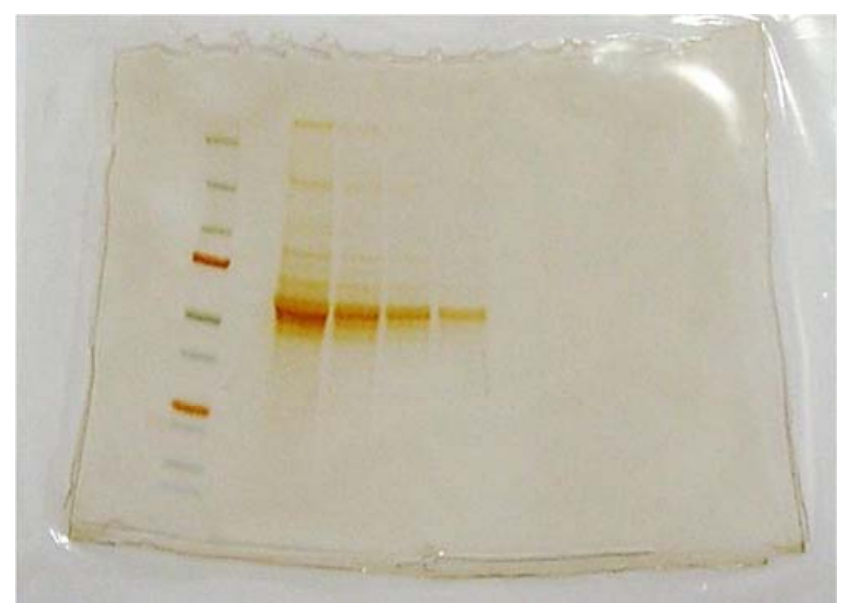

Figura 4. Produtos proteicos de L. (Viannia) braziliensis obtidos por kit comercial (4 primeiras colunas) e por tratamento com Trizol (4 últimas colunas - muito claras). Concentração inicial do extrato obtido por kit comercial de $389,6 \mathrm{mg} / \mathrm{mL}$, concentração inicial estimada do extrato obtido por Trizol de $8,1 \mathrm{mg} / \mathrm{mL}$ e diluição seriada de 1:10 a 1:80.

\section{Immunoblotting}

Foi realizado seguindo a mesma metodologia descrita para o Immunobllotting com proteínas da epiderme (vide página 52), sendo utilizado, na eletroforese, amostras de extrato proteico de $L .(V$.) braziliensis, também diluídas 1:1 no tampão da amostra.

\subsection{Exame sorológico para determinação de anticorpos contra Trypanosoma cruzi (objetivo vi)}

Foi utilizado kit comercial ARCHITECT Chagas ${ }^{\circledR}$ 2P25 (Abbott GmbH \& Co. KG, Germany), conforme instruções do fabricante. Consiste em imunoensaio de micropartículas por quimioluminescência para detecção de anticorpos IgG contra Trypanosoma cruzi em amostras humanas de soro e plasma.

Os resultados foram processados conforme recomendação do fabricante, com o software Architect of System, com cálculo do sinal quimioluminescente médio do calibrador a partir de 3 réplicas. Os resultados (índice $\mathrm{S} / \mathrm{CO}$ ) são calculados a partir da divisão do valor da amostra pelo valor armazenado no calibrador, ambos em RLU (Unidades de Luz Relativas). Valores $\mathrm{S} / \mathrm{CO}<0,8$ são considerados não reativos, valores $\mathrm{S} / \mathrm{CO} \geq 1$ são considerados reativos, e valores $\geq 0,8$ e $<1$ são considerados Zona Cinza. 


\subsection{Teste de Montenegro para pesquisa de resposta celular a leishmania (objetivo vii)}

Utilizou-se o antígeno de Montenegro do CPPI - Centro de Produção e Pesquisa de Imunobiológicos, Secretaria de Estado da Saúde / Instituto de Saúde do Paraná, cedido pelo Instituto Adolfo Lutz, Ribeirão Preto, SP. Cada frasco ampola com $1 \mathrm{~mL}$ contém suspensão de Leishmania (Leishmania) amazonensis (cepa de referência OMS MHOM/BR/73/M2269), na concentração de 40 $\mu \mathrm{g} / \mathrm{mL}$ de nitrogênio proteico.

A aplicação de $0,1 \mathrm{~mL}$ do antígeno de Montenegro é realizada via intradérmica com seringa de insulina na face anterior do antebraço, 2 a $3 \mathrm{~cm}$ abaixo da dobra antecubital. A leitura é feita em $48 \mathrm{a}$ 72 horas após a inoculação, e o resultado é considerado negativo na ausência de qualquer sinal no ponto de inoculação ou de uma pápula com menos de $5 \mathrm{~mm}$ de diâmetro, e como reação positiva a presença de uma pápula ou nódulo, igual ou superior a $5 \mathrm{~mm}$, ou ulceração.

\subsection{Tipificação dos genes $H L A-D R$ e $-D Q$ (objetivos viii $e$ ix)}

- Técnica de reação em cadeia da polimerase utilizando oligonucleotídeos sequênciaespecíficas (PCR-SSOP)

Para a caracterização dos genes $H L A-D R B 1$ e $H L A-D Q A 1-D Q B 1$ em baixa e alta resolução foi empregado o método de reação em cadeia da polimerase utilizando oligonucleotídeos sequênciaespecíficas (do inglês: Polymerase Chain Reaction-Sequence Specific Oligonucleotide Probes; PCRSSOP), pela biomédica Neifi Deghaide, do Laboratório de Imunogenética do Hemocentro de Ribeirão Preto.

Para a tipificação em baixa resolução utilizou-se os kits LABType (One Lambda Inc - Los Angeles, EUA). A partir dos resultados em baixa resolução, uma nova tipificação foi empregada para adquirir os resultados em alta resolução utilizando-se o kit específico High Definition (HD) LABType (One Lambda Inc - Los Angeles, EUA). Os procedimentos para o uso do kit foram realizados de acordo com as instruções do fabricante e tecnologia Luminex. 


\subsection{Análise Estatística}

Para a análise estatística foram utilizados os softwares Graphpad Prism 6 e SAS 9.3 (SAS Institute Inc, Cary, EUA).

Os dados com distribuição normal foram submetidos aos testes paramétricos $t$ de Student ou One-way ANOVA. Para os dados que não apresentaram distribuição normal foram utilizados os testes não paramétricos Mann-Whitney ou Kruskal-Wallis, seguido da análise dos grupos 2 a 2 pelo teste de Dunn, além do teste de correlação de Spearman. Para a análise interpretativa do cruzamento entre as variáveis sobre a casuística dos pênfigos e controles, os dados foram analisados utilizando o teste de Qui-quadrado. Valores de $\mathrm{p} \leq 0,05$ foram considerados estatisticamente significativos.

As frequências alélicas dos genes de $H L A$ classe II foram estimadas por contagem direta. A comparação das frequências alélicas dentre os grupos avaliados foi realizada utilizando-se o teste exato de Fisher. Regressão logística foi realizada para se avaliar a associação de suscetibilidade e ou proteção dos alelos com a doença estudada. Valores de $\mathrm{p} \leq 0,001$ foram considerados estatisticamente significativos. 


\section{RESULTADOS}

\subsection{Resultado do ELISA para determinação dos anticorpos anti-Dsg1 e anti-Dsg3 (objetivo i)}

A prevalência de anticorpos IgG anti-Dsg1 se mostrou maior no grupo de pacientes com PF [66/78 (84,6\%)], seguida dos grupos PV [34/62 (54,8\%)], FPF [4/25 (16\%)], LTAc [2/37 (5,4\%)], LTAm [1/21 (4,8\%)], FPV [1/24 (4,2\%)], e controles vizinhos [1/37 (2,7\%)] (Tabela 7). A prevalência entre os grupos foi significativamente diferente quando comparados o grupo PF com cada um dos demais $(\mathrm{p}<0,0001)$ e o grupo PV com cada um dos demais (PV vs FPF: $\mathrm{p}<0,003$; e PV vs demais grupos: $\mathrm{p}<0,0001)$. Não houve diferença significativa entre as prevalências de anticorpos quando comparados os demais grupos entre si $(\mathrm{p}>0,05)$.

Para o ELISA anti-Dsg3, a prevalência de anticorpos ocorreu em 83,9\% (52/62) no grupo dos pacientes com PV, em 12\% (3/25) no grupo FPF, em 6,4\% (5/78) no grupo de pacientes com PF, em 5,4\% (2/37) no grupo LTAc e em 4,8\% (1/21) no grupo LTAm $(\mathrm{P}<0,05)$. Não houve resultado positivo nos grupos FPV e controles vizinhos. A prevalência entre os grupos foi significativamente diferente quando comparado o grupo PV com cada um dos demais $(\mathrm{p}<0,0001)$. Não houve diferença significativa entre as prevalências de anticorpos quando comparados os demais grupos entre si $(\mathrm{p}>0,05)$.

Para ambos ensaios, os resultados indeterminados foram assim mantidos, sendo desconsiderados na comparação da prevalência entre os grupos.

A positividade para ambos anticorpos simultaneamente ocorreu em 30 pacientes do grupo $\mathrm{PV}$, 5 pacientes do grupo PF, 1 FPF e 2 pacientes com LTA. 
Tabela 7. Distribuição dos resultados do ELISA anti-Dsg 1 e 3 conforme os grupos avaliados.

\begin{tabular}{|c|c|c|c|c|c|c|c|c|c|}
\hline & & \multicolumn{2}{|c|}{ LTA $(n=58)$} & \multirow{2}{*}{$\mathrm{PF}(\mathrm{n}=78)$} & \multirow{2}{*}{$\mathrm{PV}(\mathrm{n}=62)$} & \multirow{2}{*}{$\begin{array}{l}\text { Controles } \\
\text { vizinhos } \\
(n=37)\end{array}$} & \multirow{2}{*}{$\operatorname{FPF}(n=25)$} & \multirow{2}{*}{$\operatorname{FPV}(n=24)$} & \multirow{2}{*}{ Valor de $\mathrm{p}$} \\
\hline & & $\begin{array}{l}\text { Cutânea } \\
(\mathrm{n}=37)\end{array}$ & $\begin{array}{l}\text { Mucosa } \\
(n=21)\end{array}$ & & & & & & \\
\hline \multirow{3}{*}{ Anti-Dsg 1} & + & $2(5,4 \%)$ & $1(4,8 \%)$ & $66(84,6 \%)$ & $34(54,8 \%)$ & $1 \quad(2,7 \%)$ & $4(16 \%)$ & $1 \quad(4,2 \%)$ & \multirow{3}{*}{$\mathrm{P}<0,05$} \\
\hline & - & $35(94,6 \%)$ & $20(95,2 \%)$ & $11(14,1 \%)$ & $27(43,5 \%)$ & $36(97,3 \%)$ & $19(76 \%)$ & $23(95,8 \%)$ & \\
\hline & I & 0 & 0 & $1(1,3 \%)$ & $1(1,6 \%)$ & 0 & $2(8 \%)$ & 0 & \\
\hline \multirow{3}{*}{ Anti-Dsg 3} & + & $2(5,4 \%)$ & $1(4,8 \%)$ & $5 \quad(6.4 \%)$ & $52(83,9 \%)$ & 0 & $3(12 \%)$ & 0 & \multirow{3}{*}{$\mathrm{p}<0,05$} \\
\hline & - & $33(89,2 \%)$ & $19(90,5 \%)$ & $70(89,8 \%)$ & $8(12,9 \%)$ & $36(97,3 \%)$ & $21(84 \%)$ & $23(95,8 \%)$ & \\
\hline & I & $2(5,4 \%)$ & $1(4,8 \%)$ & $3(3,8 \%)$ & $2(3,2 \%)$ & $1(2,7 \%)$ & $1(4 \%)$ & $1(4,2 \%)$ & \\
\hline
\end{tabular}

Para a detecção dos anticorpos anti Dsg 1, valores acima de $20 \mathrm{U} / \mathrm{mL}$ foram considerados positivos (+), 14 a $20 \mathrm{U} / \mathrm{mL}$, indeterminados (I), e abaixo de 14 $\mathrm{U} / \mathrm{mL}$, negativos ou anticorpos não detectáveis (-). Para a detecção dos anticorpos IgG anti Dsg 3, valores acima a $20 \mathrm{U} / \mathrm{mL}$ foram considerados positivos, 9 a $20 \mathrm{U} / \mathrm{mL}$, indeterminados, e abaixo de $9 \mathrm{U} / \mathrm{mL}$, negativos ou anticorpos não detectáveis.

Para anti-Dsg1: prevalência de anticorpos no grupo PF vs demais grupos individualmente $(\mathrm{p}<0,0001)$; prevalência no grupo $\mathrm{PV}$ vs $\mathrm{FPF}$ ( $\mathrm{p}<0,003$ ); prevalência no grupo PV vs demais grupos individualmente ( $<<0,0001)$. Demais comparações: $\mathrm{p}>0,05$ (Fisher). Para anti-Dsg3: prevalência no grupo PV vs demais grupos individualmente ( $\mathrm{p}<0,0001)$. Demais comparações: $\mathrm{p}>0,05$ (Fisher).

Anti-Dsg1: ELISA para deteç̧ão de anticorpos anti desmogleína 1, Anti-Dsg3: ELISA para detecção de anticorpos anti desmogleína 3, LTA: Leishmaniose tegumentar Americana, PV: pênfigo vulgar, PF: pênfigo foliáceo, Controles vizinhos: vizinhos dos pacientes com pênfigo, FPF: familiares de pacientes com PF, FPV: familiares de pacientes com PV. 
Os valores em Index Value (U/mL) da quantificação de anticorpos anti-Dsg1 entre os grupos resultaram significativamente maiores para os grupos PF (mediana: 144,4) e PV $(27,8)$ que para os demais: 2,9 para LTAc, 2,3 para LTAm e 1,5 para os controles. $(p<0.0001)$, sem diferença entre esses 3 últimos $(\mathrm{p}>0,05)$.

$\mathrm{Na}$ quantificação de anticorpos anti-Dsg3, os valores $(\mathrm{U} / \mathrm{mL})$ foram significativamente maiores para o grupo PV (mediana de 138,8) do que os demais: medianas de 2,0 para LTA cutânea, 1,7 para LTA mucosa; 1,5 para controles e 0,8 para PF (p < 0.0001) (Figura 5).

Os controles foram reunidos num único grupo por não apresentarem diferença estatística entre si.

Os resultados mostraram que a resposta humoral às desmogleínas diferiu entre os grupos pênfigos e os demais, mas não houve diferença significativa entre o grupo LTA e os controles.

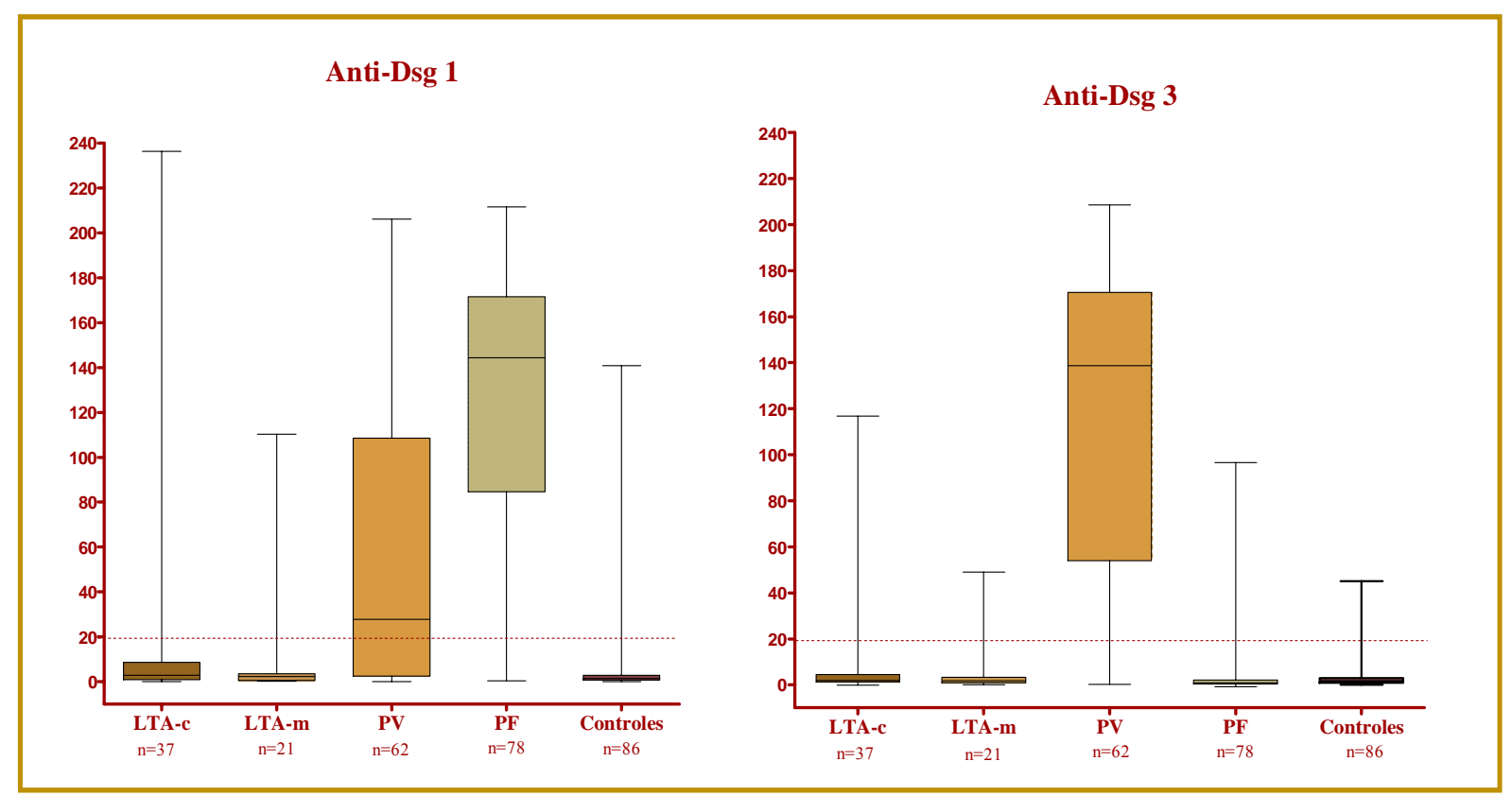

Figura 5. Análise das leituras a $450 \mathrm{~nm}$ do ELISA anti-desmogleína 1 e 3 conforme os grupos avaliados, em Unidade de valor $/ \mathrm{mL}(\mathrm{U} / \mathrm{mL})$. Os boxes representam valores entre $25 \%$ e $75 \%$. As barras representam valor mínimo e máximo. A linha horizontal dentro dos boxes representa a mediana dos valores. A linha tracejada: cut-off para limiar de normalidade.

LTAc: Leishmaniose tegumentar Americana forma cutânea localizada, LTAm: Leishmaniose tegumentar Americana forma mucosa, PV: pênfigo vulgar, PF: pênfigo foliáceo, controles: vizinhos dos pacientes com pênfigo, familiares de pacientes com PF e familiares de pacientes com PV. 


\subsection{Resultado do ensaio ELISA in house para determinação dos anticorpos contra L. braziliensis} (objetivo ii)

A prevalência de anticorpos contra L. braziliensis no ensaio ELISA, como esperada, foi maior no grupo LTA, com positividade em 73\% (27/37) para o grupo LTAc e em 62\% (13/21) para o grupo LTAm, que nos demais: positividade em 10,8\% (4/37) no grupo de controles vizinhos de pacientes com pênfigo (dos quais, um indivíduo teve também resultado ELISA anti-Dsg1 positivo, com título baixo), em 4\% (1/25) no grupo de FPF (indivíduo com resultado ELISA anti-Dsg1 positivo, com título alto), em 4\% (2/51) no grupo dos controles BS, em 1,6\% (1/62) do grupo PV (paciente com resultado ELISA anti-Dsg3 positivo, com título baixo) e em 1,3\% (1/78) do grupo PF (paciente com resultado ELISA anti-Dsg1 positivo, com título alto) (Tabela 8). A prevalência foi significativamente diferente quando comparados o grupo LTAc com cada um dos grupos $(\mathrm{p}<0,0001)$, assim como o grupo LTAm com cada um dos demais $(\mathrm{p}<0,0001)$. Não houve diferença significativa entre as prevalências de anticorpos quando comparados os demais grupos entre si $(\mathrm{p}>0,05)$. 
Tabela 8. Distribuição dos resultados ELISA anti- L. braziliensis conforme os grupos avaliados. Cut off (média + 2DP): DO 0,192.

\begin{tabular}{|c|c|c|c|c|c|c|c|c|c|c|}
\hline & \multicolumn{3}{|c|}{ LTA $(n=58)$} & \multirow[b]{2}{*}{$\begin{array}{c}\mathrm{PF} \\
(\mathrm{n}=78)\end{array}$} & \multirow[b]{2}{*}{$\begin{array}{c}\mathrm{PV} \\
(\mathrm{n}=62)\end{array}$} & \multirow[b]{2}{*}{$\begin{array}{l}\text { Controles vizinhos } \\
\qquad(\mathrm{n}=37)\end{array}$} & \multirow[b]{2}{*}{$\begin{array}{l}\text { FPF } \\
(n=25)\end{array}$} & \multirow[b]{2}{*}{$\begin{array}{l}\text { FPV } \\
(n=24)\end{array}$} & \multirow[b]{2}{*}{$\begin{array}{l}\text { Controles } \\
\text { BS }(n=51)\end{array}$} & \multirow[b]{2}{*}{ Valor do F } \\
\hline & & $\begin{array}{l}\text { Cutânea } \\
(n=37)\end{array}$ & $\begin{array}{l}\text { Mucosa } \\
(n=21)\end{array}$ & & & & & & & \\
\hline \multirow{2}{*}{$\begin{array}{c}\text { Anti- } L . \\
\text { braziliensis }\end{array}$} & + & $27(73 \%)$ & $13(62 \%)$ & $1 \quad(1,3 \%)$ & $1(1,6 \%)$ & $4 \quad(10,8 \%)$ & $1 \quad(4 \%)$ & 0 & $2(4 \%)$ & \multirow{2}{*}{$<0,0001$} \\
\hline & - & $10(27 \%)$ & $8(38 \%)$ & $77(98,7 \%)$ & $61(98,4 \%)$ & $33(89,2 \%)$ & $24(96 \%)$ & $24(100 \%)$ & 49 (96\%) & \\
\hline
\end{tabular}

Anti- L. braziliensis: ELISA para detecção de anticorpos contra L. braziliensis; LTA: leishmaniose tegumentar Americana, PV: pênfigo vulgar, PF: pênfigo foliáceo, Controle vizinhos: vizinhos dos pacientes com pênfigo, FPF: familiares de pacientes com PF, FPV: familiares de pacientes com PV, Controles BS: Controles do banco de sangue. 
Os valores (D.O.) da quantificação dos anticorpos anti-L. braziliensis no ELISA in house foram maiores nos grupos LTA, com mediana de 0,32 para LTA cutânea e 0,31 para LTA mucosa, que nos demais: 0,04 para PV, para PF, e para controles. (Figura 6) $(\mathrm{p}<0.0001)$

Os controles foram reunidos num único grupo por não apresentarem diferença estatística entre eles.

Os resultados mostram resposta humoral aos antígenos de leishmania mais elevada no grupo LTA em relação aos demais grupos, mas sem diferença significativa entre os grupos pênfigos e os controles.

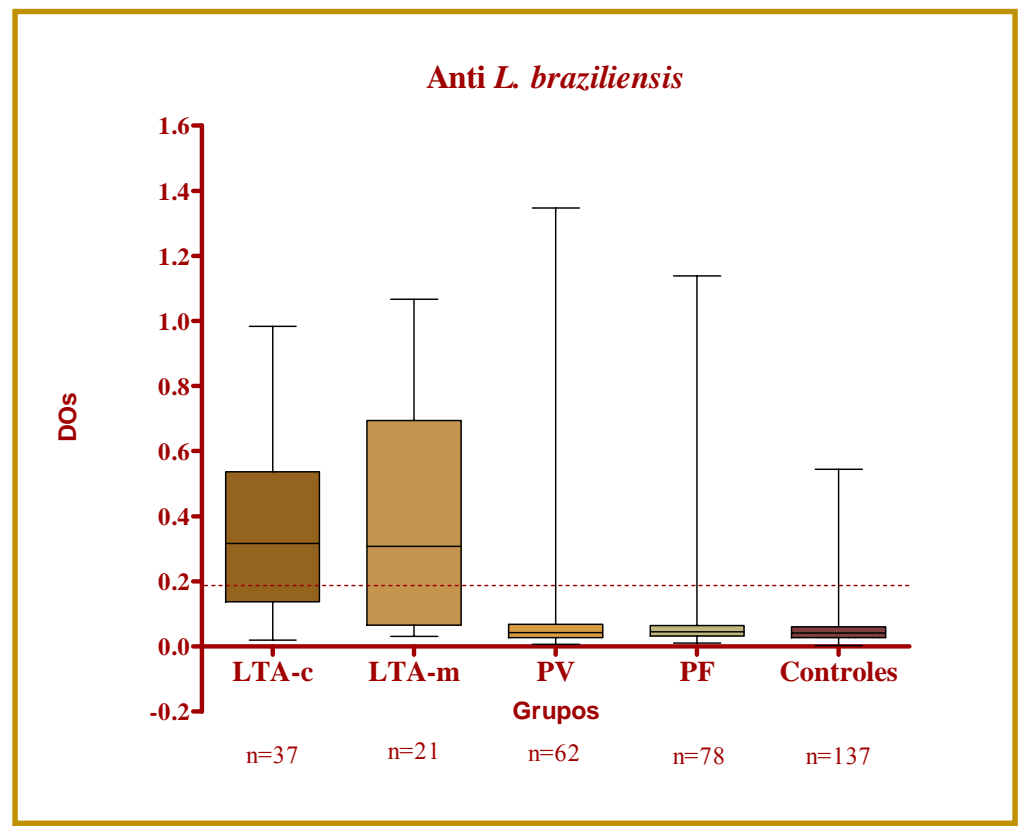

Figura 6. Análise das leituras a $492 \mathrm{~nm}$ do ELISA anti - L. braziliensis conforme os grupos avaliados. Valores em D.O. (densidade óptica). Os boxes representam valores entre $25 \%$ e $75 \%$. As barras representam valor mínimo e máximo. A linha horizontal dentro dos boxes representa a mediana dos valores. A linha tracejada representa o Cut off $=0,192$.

LTAc: Leishmaniose tegumentar Americana forma cutânea locaizada, LTAm: Leishmaniose tegumentar Americana forma mucosa, PV: pênfigo vulgar, PF: pênfigo foliáceo, controles: vizinhos dos pacientes com pênfigo, familiares de pacientes com PF e familiares de pacientes com PV. 
5.3 Correlação dos títulos (D.O.) anti-Desmogleínas e anti-L. braziliensis nos grupos LTA e nos grupos pênfigos (objetivo iii)

A correlação entre os títulos (D.O.) anti-Dsg 1 e 3 com anti-L. braziliensis resultou significante para o grupo LTAc $(\mathrm{r}=0,3834 ; \mathrm{p}=0,0192 ; \mathrm{r}=0,589 ; \mathrm{p}=0,001$, respectivamente). Para o grupo LTAm, a correlação foi significante para a desmogleína $3(r=0,4714 ; p=0,03)$. A correlação entre anticorpos anti-Dsg 1 e anti-L. braziliensis para o grupo LTAm não foi significante.

LTA cutânea

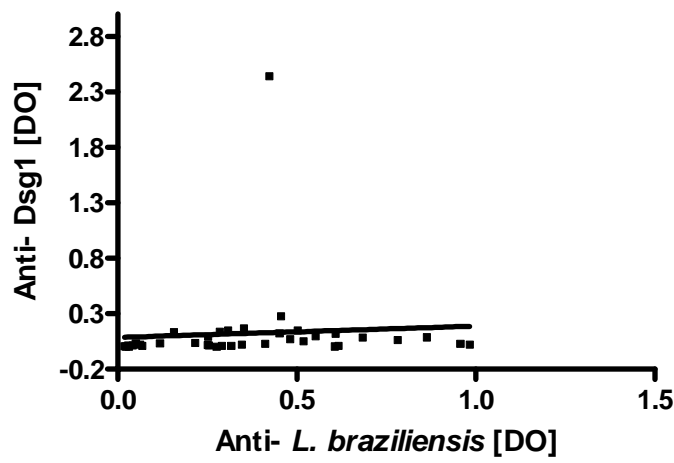

A

Grupo LTA forma mucosa

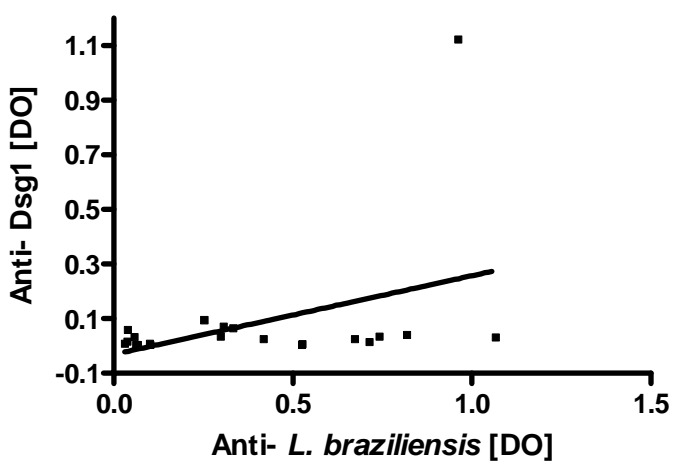

C

Figura 7. Correlação dos títulos (D.O.) anti-Dsg e anti-L. braziliensis nos grupos LTAc e LTAm. A. Anti-Dsg 1 e anti- L. braziliensis no grupo LTA-c ( $\mathrm{r}=0,3834 ; \mathrm{p}=0,0192)$; B. Anti-Dsg 3 e anti- $L$. braziliensis no grupo LTA-c $(\mathrm{r}=0,589 ; \mathrm{p}=0,001)$; C. Anti-Dsg 1 e anti- L. braziliensis no grupo LTA$\mathrm{m}(\mathrm{r}=0,2909 ; \mathrm{p}=0,2) ; \mathbf{D}$. Anti-Dsg 3 e anti- L. braziliensis no grupo LTA-m $(\mathrm{r}=0,4714 ; \mathrm{p}=0,03)$.

A correlação dos títulos (D.O.) anti-Dsg1 e anti-L. braziliensis para o grupo PF não foi significante $(r=0,1508 ; \mathrm{p}=0,876)$. Da mesma forma, a correlação dos títulos (D.O.) anti-Dsg3 e anti- $L$. braziliensis para o grupo PV também não foi significante $(\mathrm{r}=0,1682 ; \mathrm{p}=0,1912)$. 


\subsection{Resultado do Immunoblotting com extrato proteico de epiderme humana e soro de pacientes e controles (objetivo iv)}

Os dados demográficos e laboratoriais das amostras avaliadas neste experimento estão descritos na tabela 9 e os resultados nas figuras seguintes.

Houve marcação da banda de $160 \mathrm{kDa}$ em 3/5 (amostras 87, 296 e 363) pacientes com PF (todos com ELISA anti-Dsg 1 positivo); e da banda de 130kDa em 2/5 (amostras 363 e 482) pacientes com PF (ambos com ELISA anti-Dsg3 negativa).

Houve marcação da banda de 130kDa nos 4 pacientes com PV (todos com ELISA anti-Dsg3 positivo); e da banda de $160 \mathrm{kDa}$ em 1/4 (amostra 124) dos pacientes com PV (este, além de outros 2 que não apresentaram marcação, tiveram ELISA anti-Dsg1 positivo).

Houve reconhecimento da banda de $150 \mathrm{kDa}$ em $4 / 9$ pacientes com pênfigo (todos com ELISA anti-Dsg 2 positivo) e em 1 paciente com LTA (ELISA anti-Dsg2 não realizado).

Não houve marcação em 2 dos 3 controles (ambos com ELISA anti-Dsg 1 e 3 negativo e 1 destes com anti-L. braziliensis positivo e anti-Chagas positivo) e 1 marcou fracamente a banda de 410 $\mathrm{kDa}$ (anti-Dsg 1 e 3 e anti-L. braziliensis negativos).

Dos 6 pacientes com LTA, 4 tinham ELISA anti-Dsg1 e/ou 3 positivos: 1 (amostra 354) teve ELISA anti-Dsg1 positivo (títulos baixos) e marcou a banda de 160kDa; 1 (amostra 465) teve ELISA anti-Dsg3 positivo (títulos baixos) e marcou a banda de 130kDa; e 2 tiveram ambos ELISA anti-Dsg 1 e 3 positivos (títulos altos) e não apresentaram marcação da banda de 130kDa nem da de 160kDa.

Houve marcação da banda de $230 \mathrm{kDa}$ (correspondente ao PM do antígeno BP230) em 4/6 pacientes com LTA, e da banda de $290 \mathrm{kDa}$ em 2/6 pacientes com LTA. Interessantemente, o único paciente com PF e com ELISA anti L.-braziliensis positivo também marcou essas 2 bandas (Figura 12). 
Tabela 9. Dados demográficos e laboratoriais dos pacientes e controles que realizaram Immunoblotting e IFI

\begin{tabular}{|c|c|c|c|c|c|c|c|c|c|c|c|c|c|c|c|}
\hline \multirow{2}{*}{$\begin{array}{l}\text { Id.do } \\
\text { soro }\end{array}$} & \multirow{2}{*}{ Forma clínica } & \multirow{2}{*}{ Gênero } & \multirow{2}{*}{$\begin{array}{l}\text { Idade } \\
\text { (anos) }\end{array}$} & \multicolumn{3}{|c|}{ Anti-Dsg1 } & \multicolumn{3}{|c|}{ Anti-Dsg3 } & \multicolumn{2}{|c|}{ Anti-Dsg2 } & \multicolumn{2}{|c|}{$\begin{array}{c}\text { Anti-Leishmania } \\
\text { braziliensis }\end{array}$} & \multicolumn{2}{|c|}{ Anti-Chagas } \\
\hline & & & & Resultado & D.O. & $\begin{array}{l}\text { Index } \\
\text { value }\end{array}$ & Resultado & D.O. & $\begin{array}{l}\text { Index } \\
\text { value }\end{array}$ & Resultado & D.O. & Result. & D.O. & Resultado & D.O \\
\hline 438 & $\mathrm{PF}$ & $\mathrm{F}$ & 46 & $\mathbf{P}$ & 1,229 & 115,6162 & $\mathrm{~N}$ & 0,009 & 0,519031 & $\mathrm{~N}$ & 0,328 & $\mathrm{~N}$ & 0,047 & N.R. & \\
\hline 484 & $\mathrm{PF}$ & M & 40 & $\mathbf{P}$ & 1,687 & 134,4249 & $\mathrm{~N}$ & 0,009 & 0,703675 & \multicolumn{2}{|l|}{ N.R. } & $\mathrm{N}$ & 0,084 & \multicolumn{2}{|l|}{ N.R. } \\
\hline 363 & $\mathrm{PF}$ & M & 67 & $\mathbf{P}$ & 2,149 & 179,1493 & $\mathrm{~N}$ & 0,001 & 0 & $\mathbf{P}$ & 3,273 & $\mathbf{P}$ & 1,138 & \multicolumn{2}{|l|}{ N.R. } \\
\hline 87 & $\mathrm{PF}$ & $\mathrm{F}$ & 46 & $\mathbf{P}$ & 2,113 & 157,1429 & $\mathrm{I}$ & 0,129 & 9,097421 & $\mathrm{~N}$ & 0,631 & $\mathrm{~N}$ & 0,101 & $\mathbf{P}$ & 7,37 \\
\hline 269 & $\mathrm{PF}$ & $\mathrm{F}$ & 30 & $\mathbf{P}$ & 2,094 & 174,5621 & $\mathrm{~N}$ & 0,011 & 0,819001 & $\mathrm{~N}$ & 0,341 & $\mathrm{~N}$ & 0,095 & $\mathbf{P}$ & 1,63 \\
\hline 117 & PV & M & 28 & $\mathbf{P}$ & 1,147 & 85,26786 & $\mathbf{P}$ & 1,877 & 134,3123 & $\mathrm{~N}$ & 0,632 & $\mathrm{~N}$ & 0,021 & $\mathrm{~N}$ & 0,16 \\
\hline 123 & PV & M & 20 & $\mathbf{P}$ & 1,156 & 85,9375 & $\mathbf{P}$ & 2,358 & 168,7679 & $\mathbf{P}$ & 1,203 & $\mathrm{~N}$ & 0,021 & $\mathrm{~N}$ & 0,28 \\
\hline 124 & $\mathrm{PV}$ & $\mathrm{M}$ & 42 & $\mathbf{P}$ & 1,767 & 131,3988 & $\mathbf{P}$ & 2,086 & 149,2837 & $\mathbf{P}$ & 1,697 & $\mathrm{~N}$ & 0,034 & $\mathrm{~N}$ & 0,24 \\
\hline 384 & $\mathrm{PV}$ & M & 45 & $\mathrm{~N}$ & 0,007 & 0,500417 & $\mathbf{P}$ & 0,779 & 63,71826 & $\mathbf{P}$ & 2,303 & $\mathrm{~N}$ & 0,076 & \multicolumn{2}{|l|}{ N.R. } \\
\hline 533 & CONTROLES & $\mathrm{F}$ & 47 & $\mathrm{~N}$ & 0,02 & 1,113763 & $\mathrm{~N}$ & 0,013 & 0,992556 & \multicolumn{2}{|l|}{ N.R. } & $\mathrm{N}$ & 0,024 & \multicolumn{2}{|l|}{ N.R. } \\
\hline 534 & CONTROLES & M & 72 & $\mathrm{~N}$ & 0,126 & 9,546539 & $\mathrm{~N}$ & 0,046 & 3,722084 & \multicolumn{2}{|l|}{ N.R. } & $\mathrm{N}$ & 0,006 & \multicolumn{2}{|l|}{ N.R. } \\
\hline 595 & CONTROLES & $\mathrm{M}$ & 59 & $\mathrm{~N}$ & 0,005 & 0,301887 & $\mathrm{~N}$ & 0,034 & 2,564103 & \multicolumn{2}{|l|}{ N.R. } & $\mathbf{P}$ & 0,336 & $\mathbf{P}$ & 9,98 \\
\hline 127 & LTAc & M & 54 & $\mathrm{~N}$ & 0,01 & 0,788177 & $\mathrm{~N}$ & 0,009 & 0,604839 & \multicolumn{2}{|l|}{ N.R. } & $\mathbf{P}$ & 0,617 & $\mathrm{~N}$ & 0,55 \\
\hline 296 & LTAm & M & 44 & $\mathrm{~N}$ & 0,031 & 2,857143 & $\mathrm{~N}$ & 0,07 & 6,754032 & \multicolumn{2}{|l|}{ N.R. } & $\mathbf{P}$ & 1,067 & $\mathbf{P}$ & 1,32 \\
\hline 354 & LTAc & M & 65 & $\mathbf{P}$ & 0,277 & 27,0936 & $\mathrm{~N}$ & 0,075 & 7,258065 & \multicolumn{2}{|l|}{ N.R. } & $\mathbf{P}$ & 0,456 & $\mathbf{P}$ & 2,28 \\
\hline 465 & LTAc & $\mathrm{M}$ & 55 & $\mathrm{~N}$ & 0,062 & 4,632588 & $\mathbf{P}$ & 0,334 & 26,11415 & \multicolumn{2}{|l|}{ N.R. } & $\mathbf{P}$ & 0,782 & \multicolumn{2}{|l|}{ N.R. } \\
\hline 138 & LTAc & $\mathrm{M}$ & 47 & $\mathbf{P}$ & 2,439 & 236,3007 & $\mathbf{P}$ & 1,585 & 116,8309 & \multicolumn{2}{|l|}{ N.R. } & $\mathbf{P}$ & 0,424 & $\mathrm{~N}$ & 0,64 \\
\hline 318 & LTAm & $\mathrm{M}$ & 81 & $\mathbf{P}$ & 1,122 & 110,3448 & $\mathbf{P}$ & 0,489 & 48,99194 & \multicolumn{2}{|l|}{ N.R. } & $\mathbf{P}$ & 0,962 & $\mathrm{~N}$ & 0,67 \\
\hline
\end{tabular}

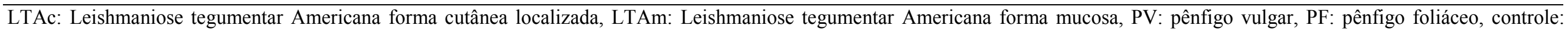
vizinhos dos pacientes com pênfigo, F: feminino, M: masculino, N.R.: Não realizado, P: positivo, N: negativo. 

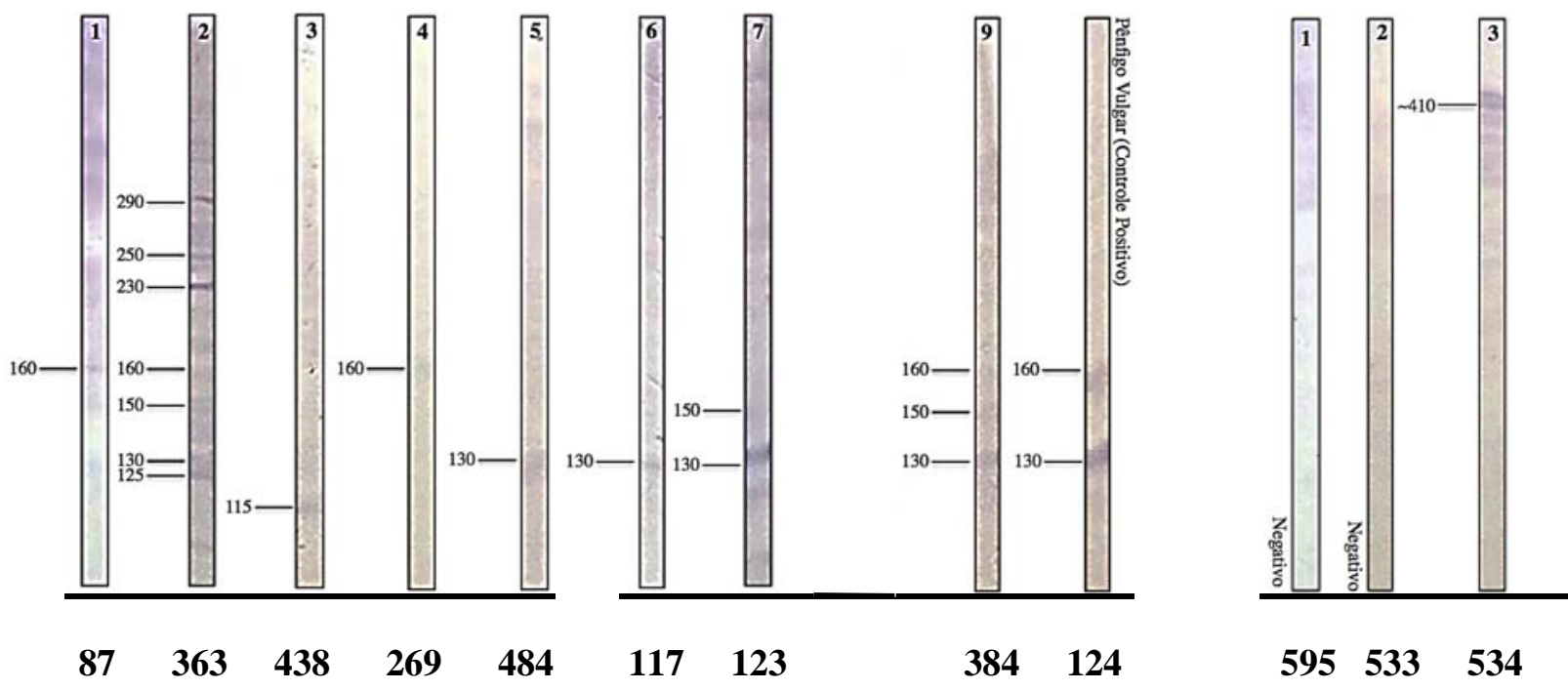

PF

PV

CONTROLES

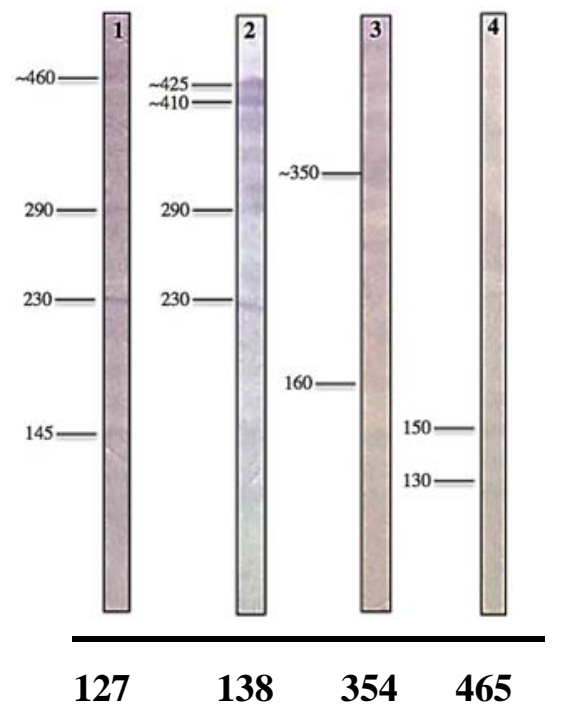

LTAC

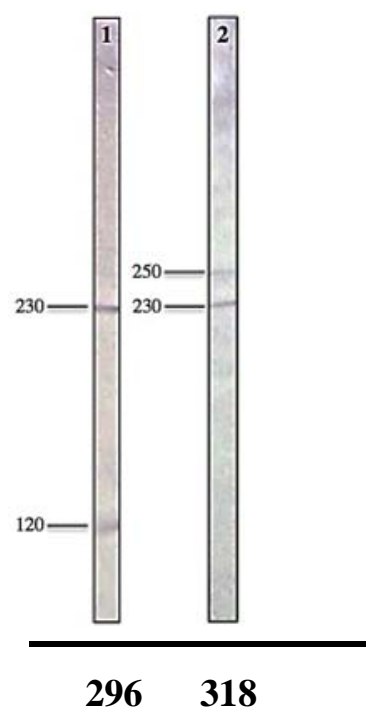

LTAm

Figura 8. Immunoblotting com extrato proteico de epiderme e soro de pacientes e controles (Marcador de PM Precision Plus Protein ${ }^{\mathrm{TM}}$ Dual Color Standards, BioRad). Os PMs dos peptídeos (kDa) estão marcados ao lado de cada fita. Marcação da banda de 160kDa (Dsg1) nas amostras dos pacientes com PF; marcação da banda de 130kDa (Dsg3) nas amostras dos pacientes com PV; detecção da banda de $150 \mathrm{kDa}$ (Dsg2) nas amostras dos pacientes com pênfigos; ausência de marcação na maioria dos controles; reconhecimento de outros peptídeos da epiderme pelos soros do grupo LTA, em especial a banda de $230 \mathrm{kDa}$ (correspondente ao antígeno BP230 do penfigoide bolhoso). 


\subsection{Resultado da Imunofluorescência Indireta com substrato de pele de prepúcio humano e soros}

\section{de pacientes com LTA (objetivo iv)}

Dentre os 6 soros - $127-138-296-318-354-465$ - dos pacientes com LTA avaliados na IFI com substrato epidérmico, um deles, com LTA forma mucosa (318), mostrou resultado positivo na IFI e um outro, também com LTA forma mucosa (296), resultado positivo na IFI salt split, conforme resultado mostrado na Figura 7.
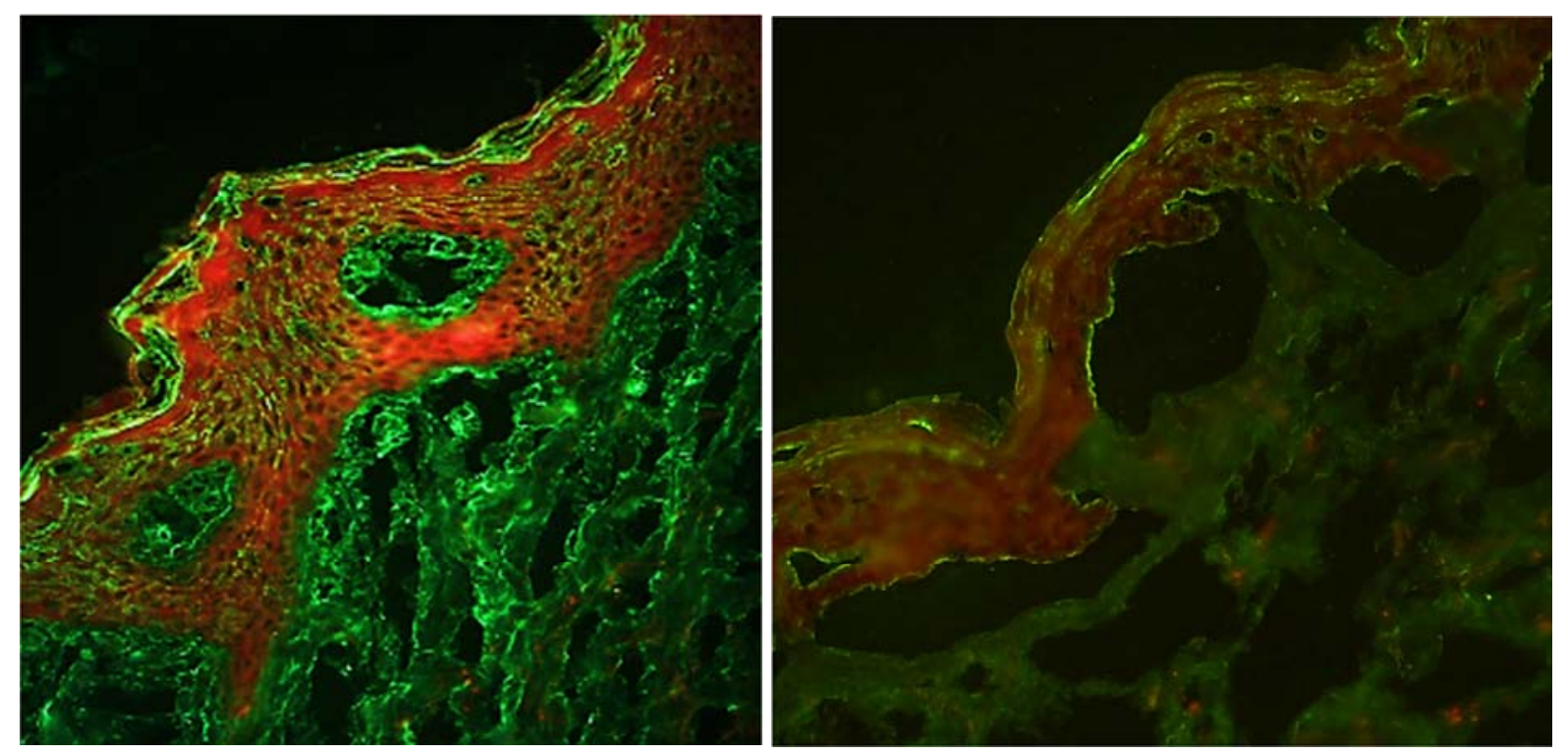

Figura 9. A. Imunofluorescência indireta (IFI) com substrato de pele de prepúcio incubada com soro 1:10 de paciente com LTA forma mucosa (amostra 318 - vide tabela 9) e anti-IgG humana com fluoresceína 1:50. Observar fluorescência granular em torno dos queratinócitos, guardando semelhança à IFI dos pênfigos. B. IFI em substrato de pele facial Salt Split incubada com soro 1:10 de paciente com LTA forma mucosa (amostra 296 - vide tabela 9). Observar: fluorescência no teto da clivagem, guardando semelhança à IFI do penfigóide bolhoso. Cortes corados com Azul de Evans (em vermelho) $[400 \mathrm{x}]$. 


\subsection{Resultado do Immunoblotting com extrato proteico de $L$. (V.) braziliensis e soro de pacientes e controles (objetivo v)}

Todos os soros de LTA apresentaram detecção bem marcada em diversas bandas.

Dentre os dois controles saudáveis (vizinhos), um deles não apresentou marcação e outro mostrou marcação fraca nas bandas $45 \mathrm{kDa}, 95 \mathrm{kDa}, 150 \mathrm{kDa}, 215 \mathrm{kDa}, 330 \mathrm{kDa}$ e $410 \mathrm{kDa}$.

Quanto aos pacientes com pênfigo, dentre os 5 pacientes avaliados ( 3 com PF e 2 com PV), 4 mostraram detecção antigênica. Esses 4 pacientes não apresentaram anticorpos anti- $L$. $(V$.) braziliensis. (Figura 10). As bandas bem marcadas e com detecção repetida nos soros foram: 330 $\mathrm{kDa}, \sim 410 \mathrm{kDa}$ e $>500 \mathrm{kDa}$.

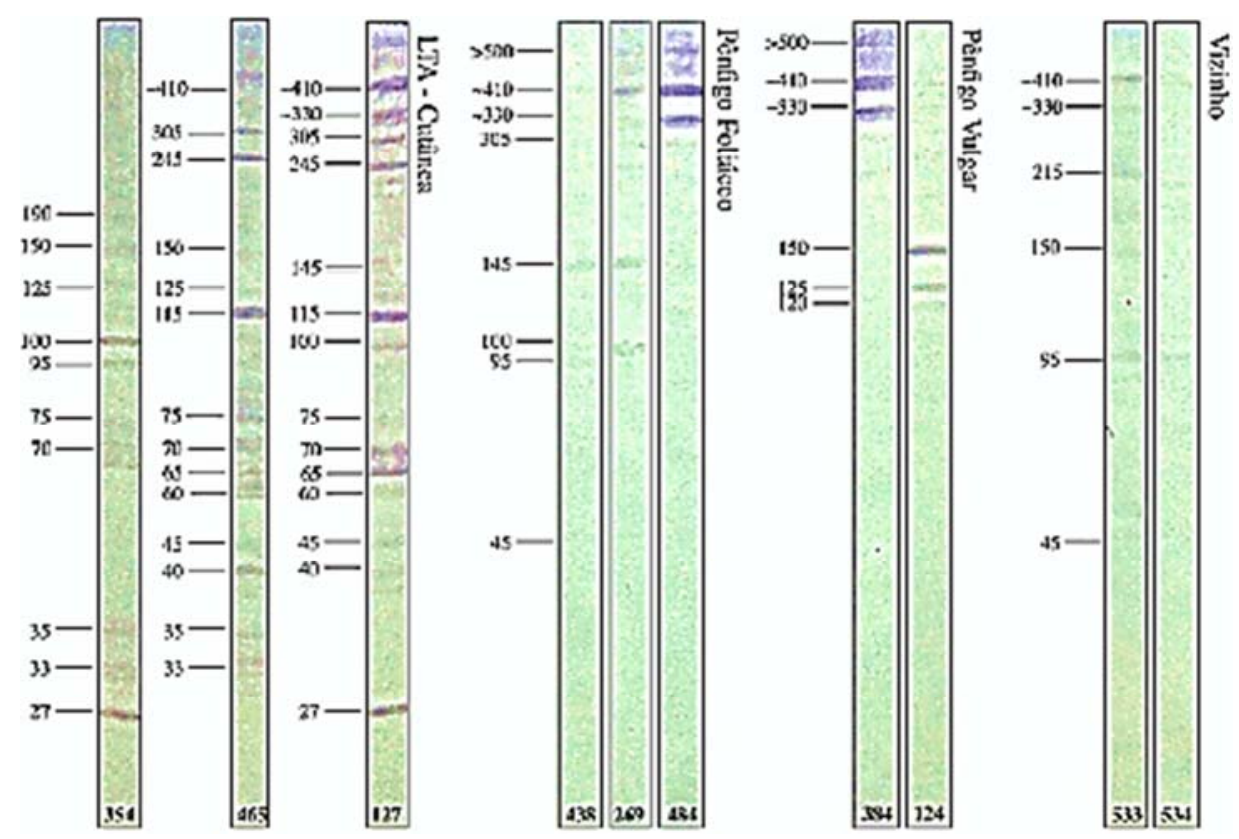

Figura 10. Immunoblotting com extrato proteico de $L$. $(V$.) braziliensis e soro de pacientes e controles, com marcador Precision Plus Protein ${ }^{\mathrm{TM}}$ Dual Color Standards, BioRad. Os PMs dos peptídeos (kDa) estão marcados ao lado de cada fita. Observar marcação dos peptídeos de $330 \mathrm{kDa}, 410 \mathrm{kDa}$ e de PM maior que $500 \mathrm{kDa}$. 


\subsection{Resultado do exame sorológico para determinação dos anticorpos contra T. cruzi (objetivo vi)}

A pesquisa de anticorpos contra $T$. cruzi foi incitada pela necessidade de, conhecida a possibilidade de reação cruzada entre os antígenos de Leishmania spp. e de $T$. cruzi, conhecermos a resposta da população estudada a estes anticorpos. Dessa forma, será apresentado aqui, além dos resultados da sorologia para Chagas para os grupos estudados, a comparação destes resultados com os do ELISA anti-L. braziliensis.

A prevalência da detecção de anticorpos no exame sorológico foi discretamente maior no grupo LTA (12,5\% no grupo LTAc e 5,9\% no grupo LTAm), seguida pelo grupo PF (5\%), FPF (4,5\%) e controles vizinhos $(4 \%)$, mas tal diferença não foi significativa $(P=0.66)$. Não houve resultado positivo nos grupos PV e FPV (Tabela 10)

Tabela 10. Distribuição dos Resultados do Exame sorológico anti- $T$. cruzi conforme os grupos avaliados

\begin{tabular}{|c|c|c|c|c|c|c|c|c|c|}
\hline & & \multicolumn{2}{|c|}{ LTA } & \multirow{2}{*}{$\begin{array}{c}\mathrm{PF} \\
(\mathrm{n}=40)\end{array}$} & \multirow{2}{*}{$\begin{array}{c}\mathrm{PV} \\
(\mathrm{n}=18)\end{array}$} & \multirow{2}{*}{$\begin{array}{l}\text { Controles } \\
\text { vizinhos } \\
(n=25)\end{array}$} & \multirow{2}{*}{$\begin{array}{c}\text { FPF } \\
(n=22)\end{array}$} & \multirow{2}{*}{$\begin{array}{c}\text { FPV } \\
(n=22)\end{array}$} & \multirow{2}{*}{$\begin{array}{l}\text { Valor } \\
\text { do P }\end{array}$} \\
\hline & & $\begin{array}{c}\text { Cutânea } \\
(\mathrm{n}=32)\end{array}$ & $\begin{array}{c}\text { Mucosa } \\
(n=17)\end{array}$ & & & & & & \\
\hline \multirow{2}{*}{$\begin{array}{l}\text { Anti- } \\
\text { T. cruzi }\end{array}$} & + & $\begin{array}{c}4 \\
(12,5 \%)\end{array}$ & $\begin{array}{c}1 \\
(5,9 \%)\end{array}$ & $\begin{array}{c}2 \\
(5 \%)\end{array}$ & 0 & $\begin{array}{c}1 \\
(4 \%)\end{array}$ & $\begin{array}{c}1 \\
(4,5 \%)\end{array}$ & 0 & \multirow{2}{*}{0,66} \\
\hline & - & $\begin{array}{c}28 \\
(87,5 \%)\end{array}$ & $\begin{array}{c}16 \\
(94,1 \%)\end{array}$ & $\begin{array}{c}38 \\
(95 \%)\end{array}$ & $\begin{array}{c}18 \\
(100 \%)\end{array}$ & $\begin{array}{c}24 \\
(96 \%)\end{array}$ & $\begin{array}{c}21 \\
(95,5 \%)\end{array}$ & $\begin{array}{c}22 \\
(100 \%)\end{array}$ & \\
\hline
\end{tabular}

LTA: leishmaniose tegumentar Americana, PV: pênfigo vulgar, PF: pênfigo foliáceo, Controle vizinhos: vizinhos dos pacientes com pênfigo, FPF: familiares de pacientes com PF, FPV: familiares de pacientes com $\mathrm{PV},+$ : positivo, -: negativo

Os valores $(\mathrm{S} / \mathrm{CO})$ da quantificação de anticorpos anti-T. cruzi entre os grupos resultaram maiores nos grupos LTA, com mediana de 0,45 no grupo LTAc e 0,34 no LTAm, seguidos dos pênfigos, com mediana de 0,14 para ambos os grupos $\mathrm{PV}$ e PF, e dos controles, com mediana de 0,05 no grupo FPV, 0,06 no FPF e 0,07 nos controles vizinhos ( $<<0,0001)$. 
Os resultados mostram resposta humoral aos antígenos de T. cruzi mais elevada no grupo LTA em relação aos demais grupos, mas sem diferença significativa entre os grupos pênfigos e os controles (Figura 11).

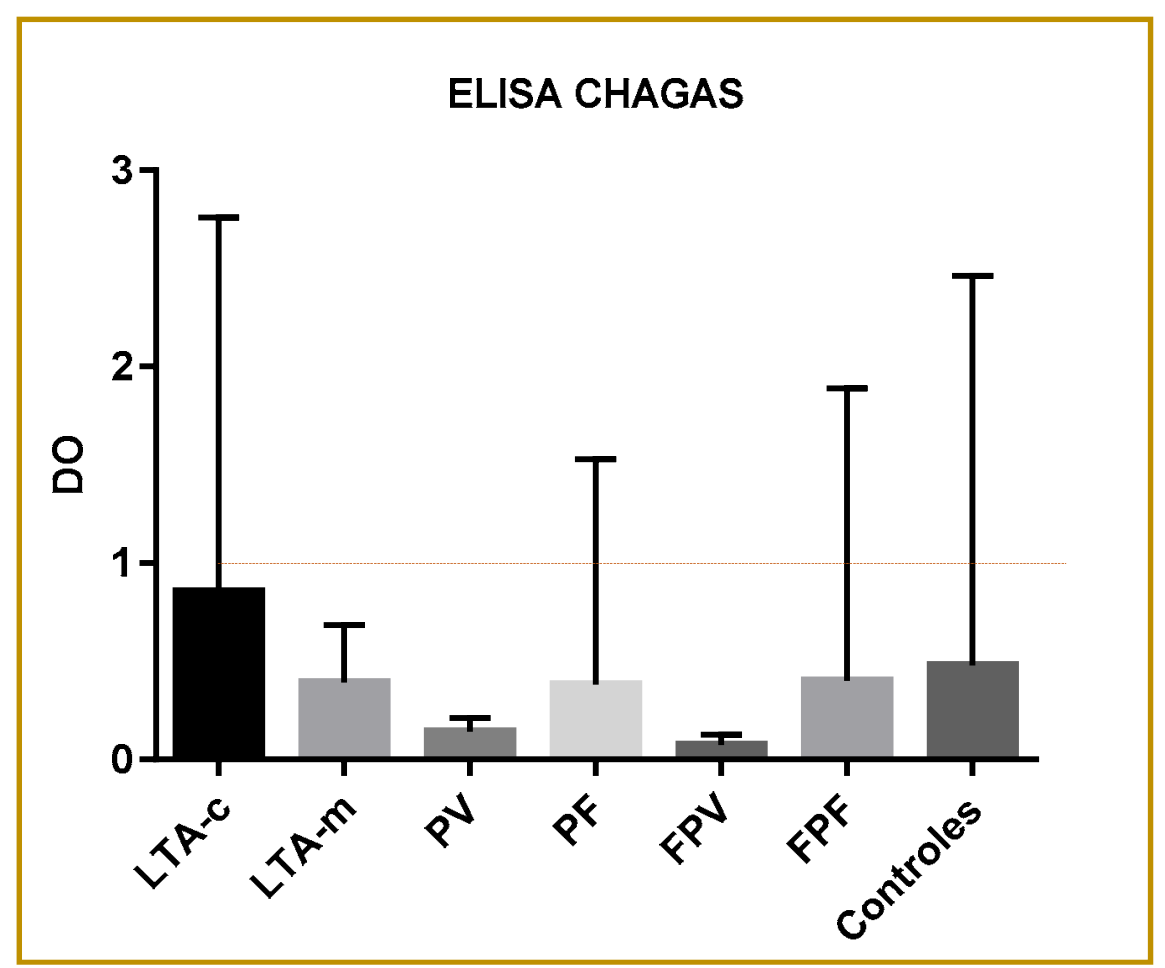

Figura 11. Análise das leituras (Índice $\mathrm{S} / \mathrm{CO}$ ) do exame sorológico anti-T. cruzi (S/CO) segundo os grupos avaliados. Os boxes representam valores das medianas. As barras representam valor mínimo e máximo. A linha horizontal tracejada representa o cut off $=1$.

LTAc: Leishmaniose tegumentar Americana forma cutânea localizada, LTAm: Leishmaniose tegumentar Americana forma mucosa, PV: pênfigo vulgar, PF: pênfigo foliáceo, FPV: familiares de pacientes com PV, FPF: familiares de pacientes com PF, controles: vizinhos dos pacientes com pênfigo.

\subsection{Resultado da Reação Intradérmica de Montenegro (objetivo vii)}

Os pacientes com PV $(n=4)$ e com $P F(n=2)$ avaliados tiveram resultado negativo conforme a leitura realizada após 48 horas da aplicação do teste. A idade dos mesmos variou de 18 a 60 anos, a média do tempo de doença foi de 3 anos e 9 meses, e todos estavam há no mínimo 15 meses sem uso de qualquer droga imunossupressora. Apenas 2 estavam em atividade da doença. 
Tabela 11. Dados demográficos, clínicos e laboratoriais dos pacientes com pênfigo que realizaram teste de Montenegro

\begin{tabular}{|c|c|c|c|c|c|c|c|c|c|}
\hline Identificaçao & Procedência & $\begin{array}{l}\text { Forma } \\
\text { clínica }\end{array}$ & Gênero & $\begin{array}{l}\text { Idade } \\
\text { (anos) }\end{array}$ & Tempo de doença & Anti-Dsg 1 & Anti-Dsg 3 & $\begin{array}{c}\text { Anti-L. } \\
\text { braziliensis }\end{array}$ & $\begin{array}{c}\text { Tempo sem } \\
\text { imunossupressor }\end{array}$ \\
\hline 1 & Sertãozinho/SP & PV & & 58 & 5 anos e 10 meses & Negativo & Positivo & Negativo & 2 anos e 7 meses \\
\hline 2 & Ribeirão Preto/SP & PV & & 55 & 5 anos & Positivo & Positivo & Negativo & 4 anos \\
\hline 3 & Batatais/SP & $\mathrm{PF}$ & & 18 & 5 anos & Positivo & Negativo & Negativo & 2 anos e 5 meses \\
\hline 4 & Franca/SP & PV & & 51 & 2 anos & Positivo & Positivo & N.R. & 1 ano e 4 meses \\
\hline 5 & Ribeirão Preto/SP & $\mathrm{PF}$ & & 60 & 6 meses & Negativo & Negativo & N.R. & Virgem de tratamento \\
\hline 6 & Ribeirão Preto/SP & PV & & 47 & 4 anos & Negativo & Positivo & Negativo & 2 anos e 4 meses \\
\hline
\end{tabular}

PV: pênfigo vulgar, PF: pênfigo foliáceo, M: masculino, F: feminino, N.R.: não realizado. 


\subsection{Estudo $H L A$}

\subsubsection{Frequência dos alelos $H L A-D R$ e $-D Q$ nos grupos estudados (objetivo viii)}

Pacientes com pênfigo, LTA e Controles BS tiveram os alelos $H L A-D R B 1, D Q A 1$ e $D Q B 1$ determinados, e a frequência desses alelos foi comparada entre os grupos.

Para o locus $H L A-D R B 1$, os alelos identificados com frequência significativamente diferente entre os grupos foram: *01:02 (mais frequente no grupo PF que no LTA total $-21.51 \%$ vs. $2.68 \%$ ), *04:02 (mais frequente no grupo PV que no LTA total - 25.61\% vs. 3.57\%), *07:01 (mais frequente no grupo LTA total que no PV $-13.39 \%$ vs. $3.05 \%$ ), $\mathrm{e}^{*} 11: 01$ (mais frequente no grupo LTA total que no PF $-9.82 \%$ vs. $0.58 \%$ ) (Tabela 12 ).

Para o locus $H L A-D Q A 1$, os alelos identificados com frequência significativamente diferente entre os grupos foram: $* 01$ (mais frequente nos controles que no LTA total - $28.96 \%$ vs. $15.18 \%$ - e no LTAc $-28.96 \%$ vs. $10 \%$, e mais frequente no PF quando comparado ao LTA total - $40.7 \%$ vs. $15.18 \%$, e $* 01: 02$ (mais frequente nos grupos LTA total - 19.64\%, LTAc - $17.14 \%$, e LTAm $-23.81 \%$ que nos grupos controles - 5.91\% e PV - 4.88\%. (Tabela 13).

Para o locus $H L A-D Q B 1$, o único alelo identificado com frequência significativamente diferente entre os grupos foi o *03:02 (mais frequente no grupo PV que no LTA total $-31.1 \%$ vs. $11.61 \%)$ (Tabela 14). 
Tabela 12. Análise da frequência dos alelos $H L A-D R B 1$ entre os grupos estudados. Valores de $\mathrm{p} \leq 0,001$ foram considerados estatisticamente significativos e destacados por cor: alelos de resistência em amarelo e de suscetibilidade em verde.

\begin{tabular}{|c|c|c|c|c|c|c|c|c|c|c|c|}
\hline $\begin{array}{l}\text { Alelos } \\
\text { HLA- } \\
\text { DRB1* }\end{array}$ & $\begin{array}{l}\text { Controles } \\
(n=1592)\end{array}$ & $\begin{array}{c}\text { LTA } \\
\text { TOTAL } \\
(\mathrm{n}=56) \\
\end{array}$ & $\begin{array}{c}\text { LTA } \\
\text { cutânea } \\
(\mathrm{N}=35)\end{array}$ & $\begin{array}{c}\text { LTA } \\
\text { mucosa } \\
(\mathrm{N}=21)\end{array}$ & $\begin{array}{c}\text { PÊNFIGO } \\
\text { FOLIÁCEO } \\
(\mathrm{N}=\mathbf{8 6})\end{array}$ & $\begin{array}{c}\text { PÊNFIGO } \\
\text { VULGAR } \\
(\mathrm{N}=82)\end{array}$ & $\begin{array}{c}\text { Controles vs. LTA } \\
\text { total FISHER, OR } \\
\text { (95\%IC) }\end{array}$ & $\begin{array}{c}\text { Controles vs. LTA } \\
\text { cutanea FISHER, OR } \\
(95 \% I C)\end{array}$ & $\begin{array}{c}\text { Controles vs. LTA } \\
\text { mucosa FISHER, OR } \\
(95 \% I C)\end{array}$ & $\begin{array}{c}\text { LTA total vs. PF } \\
\text { FISHER, OR }(95 \% I C)\end{array}$ & $\begin{array}{c}\text { LTA total vs. PV } \\
\text { FISHER, OR }(95 \% I C)\end{array}$ \\
\hline 01:01 & $150(4.71)$ & $7(6.25)$ & $3(4.29)$ & $4(9.52)$ & $23(13.37)$ & $6(3.66)$ & & & & 0,07 & \\
\hline 01:02 & $113(3.55)$ & $3(2.68)$ & $2(2.86)$ & $1(2.38)$ & $37(21.51)$ & $3(1.83)$ & & & & $\begin{array}{c}\mathrm{P}=0.000002, \mathrm{OR}=9.9 \\
(2.9 \text { a } 33.1)\end{array}$ & \\
\hline 01:03 & $22(0.69)$ & $1(0.89)$ & 0 & $1(2.38)$ & $1(0.58)$ & 0 & & & & & \\
\hline 03:01 & $247(7.76)$ & $6(5.36)$ & $4(5.71)$ & $2(4.76)$ & $10(5.81)$ & $4(2.44)$ & & & & & \\
\hline 03:02 & $25(0.79)$ & 0 & 0 & 0 & $3(1.74)$ & $2(1.22)$ & & & & & \\
\hline 04 & 0 & 0 & 0 & 0 & $2(1.16)$ & 0 & & & & & \\
\hline 04:01 & $79(2.48)$ & 0 & 0 & 0 & $3(1.74)$ & $2(1.22)$ & & & & & \\
\hline 04:02 & $65(2.04)$ & $4(3.57)$ & $4(5.71)$ & 0 & $4(2.33)$ & $42(25.61)$ & & $\begin{array}{c}\mathrm{P}=0.059, \mathrm{OR}=2.90(1.02 \\
\text { a } 8.21)\end{array}$ & & & $\begin{aligned} \mathrm{P}= & 0.000003, \mathrm{OR}=9.2 \\
& (3.22 \mathrm{a} 26.76))\end{aligned}$ \\
\hline 04:03 & 38 (1.19) & $1(0.89)$ & $1(1.43)$ & 0 & $2(1.16)$ & $4(2.44)$ & & & & & \\
\hline 04:04 & $88(2.76)$ & $4(3.57)$ & $3(4.29)$ & $1(2.38)$ & $10(5.81)$ & $5(3.05)$ & & & & & \\
\hline 04:05 & $63(1.98)$ & $3(2.68)$ & $1(1.43)$ & $2(4.76)$ & $4(2.33)$ & $1(0.61)$ & & & & & \\
\hline 04:06 & $8(0.25)$ & 0 & 0 & 0 & $1(0.58)$ & 0 & & & & & \\
\hline 04:07 & $27(0.85)$ & $1(0.89)$ & $1(1.43)$ & 0 & $1(0.58)$ & 0 & & & & & \\
\hline 04:08 & $21(0.66)$ & $1(0.89)$ & 0 & $1(2.38)$ & $2(1.16)$ & 0 & & & & & \\
\hline 04:10 & $2(0.06)$ & $1(0.89)$ & $1(1.43)$ & 0 & 0 & 0 & & 0.06 & & & \\
\hline 04:11 & $54(1.70)$ & 0 & 0 & 0 & $7(4.07)$ & $2(1.22)$ & & & & & \\
\hline 07:01 & $342(10.74)$ & 15 (13.39) & $9(12.86)$ & $6(14.29)$ & $6(3.49)$ & $5(3.05)$ & & & & $\begin{array}{c}\mathrm{P}=0.002, \mathrm{OR}=0.23 \\
\quad(0.08 \text { a } 0.62)\end{array}$ & $\begin{array}{c}\mathrm{P}=0.001, \mathrm{OR}=0.020 \\
\quad(0.07 \text { a } 0.57)\end{array}$ \\
\hline 08:01 & $71(2.23)$ & $5(4.46)$ & $4(5.71)$ & $1(2.38)$ & 0 & $2(1.22)$ & & 0.07 & & & \\
\hline 08:02 & $34(1.07)$ & $1(0.89)$ & 0 & $1(2.38)$ & $3(1.74)$ & $1(0.61)$ & & & & & \\
\hline 08:03 & $10(0.31)$ & $1(0.89)$ & $1(1.43)$ & 0 & 0 & 0 & & & & & \\
\hline 08:04 & $42(1.32)$ & $1(0.89)$ & $1(1.43)$ & 0 & $2(1.16)$ & $13(7.93)$ & & & & & $\begin{array}{l}\mathrm{P}=0.009, \mathrm{OR}=9.55 \\
\quad(1.23 \mathrm{a} 74.13)\end{array}$ \\
\hline 08:07 & $25(0.79)$ & 0 & 0 & 0 & $1(0.58)$ & 0 & & & & & \\
\hline 09:01 & $41(1.29)$ & $2(1.79)$ & $2(2.86)$ & 0 & $4(2.33)$ & 0 & & & & & \\
\hline $10: 01$ & $43(1.35)$ & $4(3.57)$ & $1(1.43)$ & $3(7.14)$ & $1(0.58)$ & $1(0.61)$ & & & $\begin{array}{c}\mathrm{P}=0.02, \mathrm{OR}=5.6(91.6 \mathrm{a} \\
18.88)\end{array}$ & 0.08 & \\
\hline 11:00 & 0 & 0 & 0 & 0 & 0 & $1(0.61)$ & & & & & \\
\hline 11:01 & $258(8.10)$ & $11(9.82)$ & $5(7.14)$ & $6(14.29)$ & $1(0.58)$ & $9(5.49)$ & & & & $\begin{aligned} \mathrm{P}= & 0.0002, \mathrm{OR}=0.05 \\
& (0.006 \text { a } 0.42)\end{aligned}$ & \\
\hline
\end{tabular}




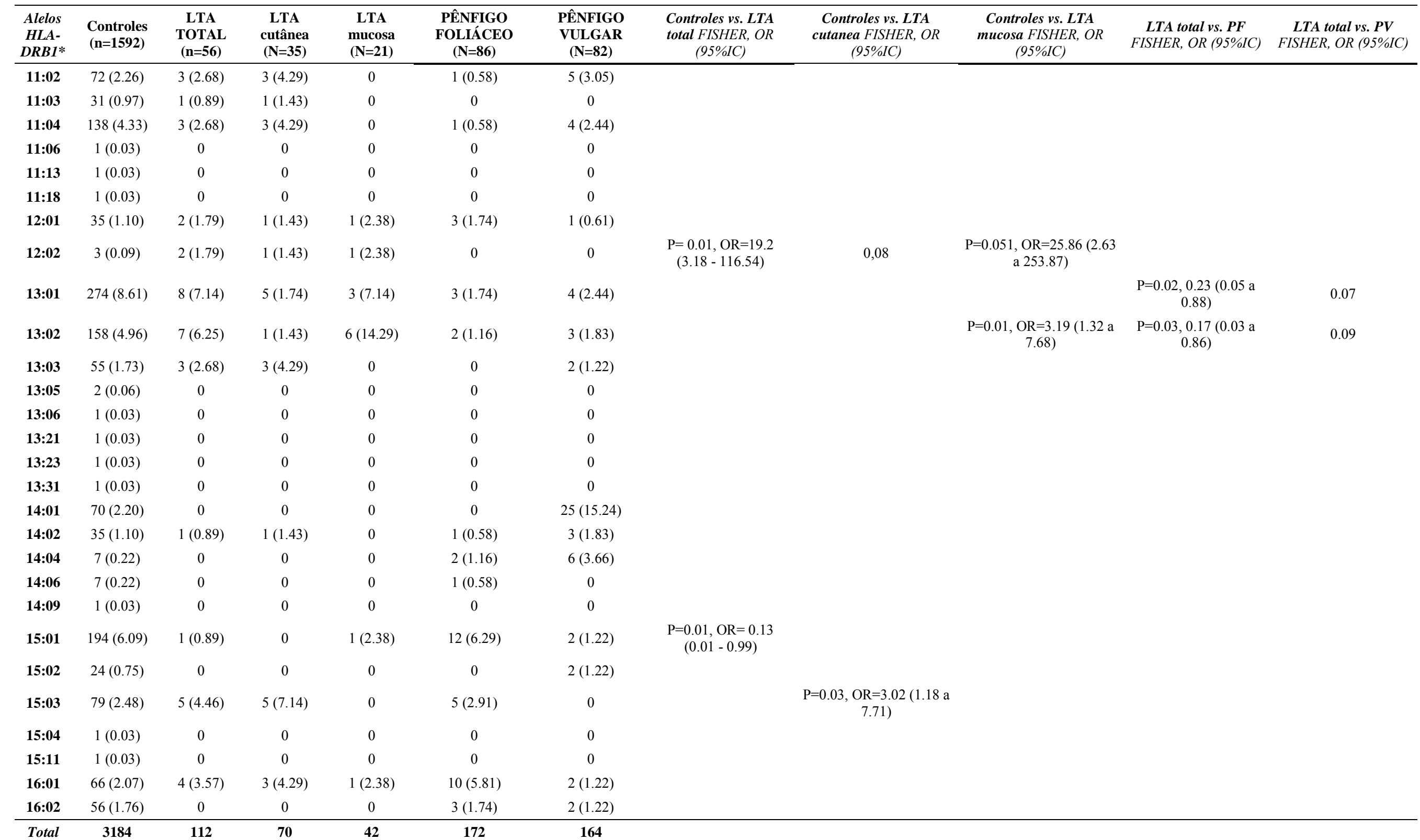


Tabela 13. Análise da frequência dos alelos $H L A-D Q A 1$ entre os grupos estudados. Valores de $\mathrm{p} \leq 0,001$ foram considerados estatisticamente significativos e destacados por cor: alelos de resistência em amarelo e de suscetibilidade em verde.

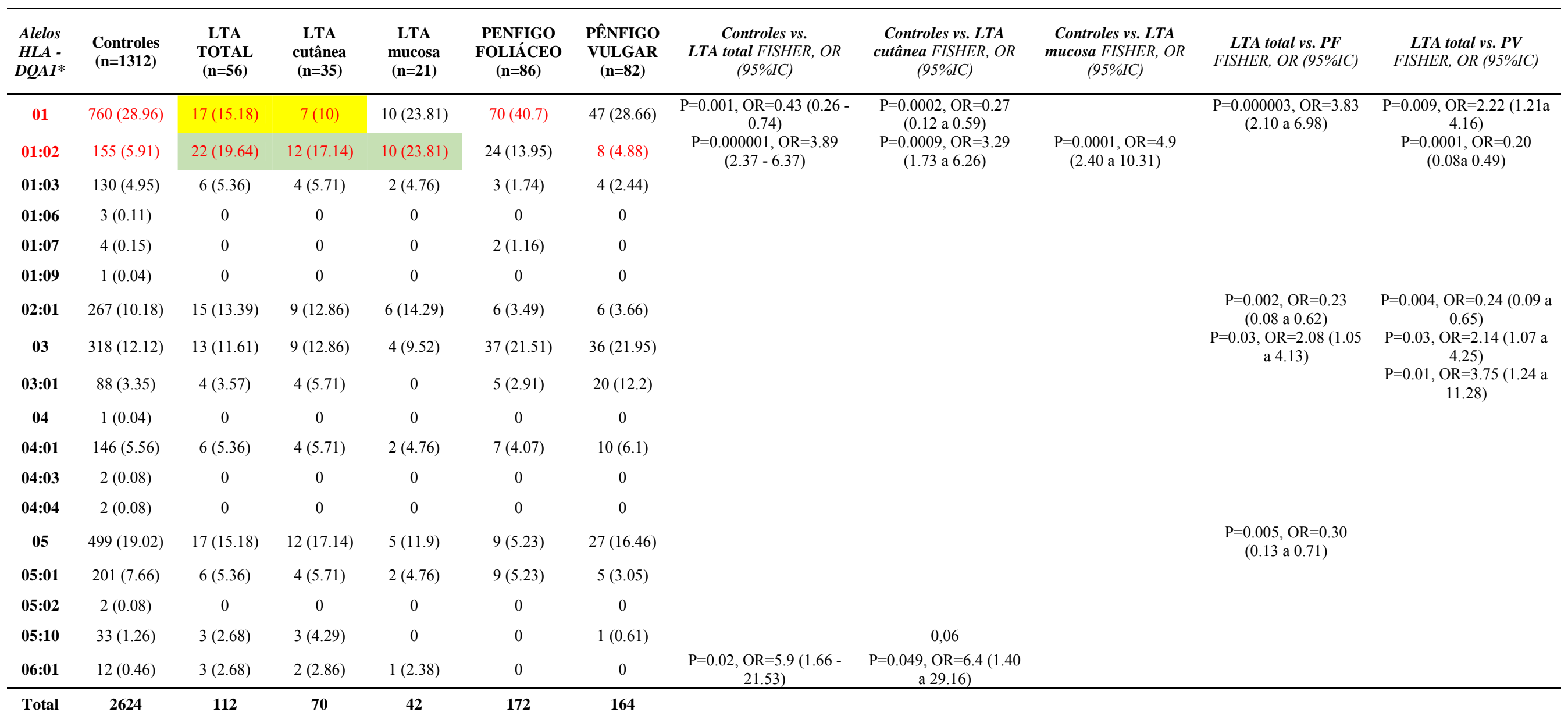


Tabela 14. Análise da frequência dos alelos $H L A-D Q B 1$ entre os grupos estudados. Valores de $\mathrm{p} \leq 0,001$ foram considerados estatisticamente significativos e destacados por cor: alelos de resistência em amarelo.

\begin{tabular}{|c|c|c|c|c|c|c|c|c|c|c|c|}
\hline $\begin{array}{c}\text { Alelos } \\
\text { HLA- } \\
\text { DQB1* }\end{array}$ & $\begin{array}{l}\text { Controles } \\
(n=1411)\end{array}$ & $\begin{array}{c}\text { LTA } \\
\text { TOTAL } \\
(\mathbf{n}=56) \\
\end{array}$ & $\begin{array}{c}\text { LTA } \\
\text { cutânea } \\
(\mathbf{n}=35)\end{array}$ & $\begin{array}{c}\text { LTA } \\
\text { mucosa } \\
(\mathrm{n}=21) \\
\end{array}$ & $\begin{array}{c}\text { PÊNFIGO } \\
\text { FOLIÁCEO } \\
(\mathbf{n}=86) \\
\end{array}$ & $\begin{array}{c}\text { PÊNFIGO } \\
\text { VULGAR } \\
(\mathrm{n}=82)\end{array}$ & $\begin{array}{c}\text { Controles vs. } \\
\text { LTA total FISHER, OR } \\
(95 \% I C) \\
\end{array}$ & $\begin{array}{c}\text { Controles vs. } \\
\text { LTA cutânea FISHER, } \\
\text { OR (95\%IC) } \\
\end{array}$ & $\begin{array}{c}\text { Controles vs. LTA mucosa } \\
\text { FISHER, OR (95\%IC) }\end{array}$ & $\begin{array}{c}\text { LTA total vs. PF } \\
\text { FISHER, OR }(95 \% I C)\end{array}$ & $\begin{array}{c}\text { LTA total vs. PV } \\
\text { FISHER, OR (95\%IC) }\end{array}$ \\
\hline 02:01 & $233(8.26)$ & $6(5.36)$ & $4(5.71)$ & $2(4.76)$ & $9(5.23)$ & $4(2.44)$ & & & & & \\
\hline 02:02 & $260(9.21)$ & $13(11.61)$ & $9(12.86)$ & $4(9.52)$ & $6(3.49)$ & $5(3.05)$ & & & & $\mathrm{P}=0.01, \mathrm{OR}=0.27(0.10-0.7)$ & $\mathrm{P}=0.006, \mathrm{OR}=0.23(0.08-0.69)$ \\
\hline 03 & $2(0.07)$ & 0 & 0 & 0 & 0 & $1(0.61)$ & & & & & \\
\hline 03:01 & $626(22.18)$ & $23(20.54)$ & $16(22.86)$ & $7(16.67)$ & $15(8.72)$ & $30(18.29)$ & & & & $\mathrm{P}=0.006, \mathrm{OR}=0.36(0.2-0.7)$ & \\
\hline 03:02 & $297(10.52)$ & $13(11.61)$ & $11(15.71)$ & $2(4.76)$ & $27(15.7)$ & $51(31.1)$ & & & & & $\mathrm{P}=0.0001, \mathrm{OR}=3.43(1.7$ a 6.7$)$ \\
\hline 03:03 & $75(2.66)$ & $4(3.57)$ & $2(2.86)$ & $2(4.76)$ & $4(2.33)$ & $1(0.61)$ & & & & & \\
\hline 03:04 & $3(0.11)$ & 0 & 0 & 0 & 0 & 0 & & & & & \\
\hline 03:05 & $1(0.04)$ & 0 & 0 & 0 & 0 & $1(0.61)$ & & & & & \\
\hline 03:19 & $13(0.46)$ & $1(0.89)$ & $1(1.43)$ & 0 & 0 & $2(1.22)$ & & & & & \\
\hline 04 & 0 & 0 & 0 & 0 & $1(0.58)$ & $1(0.61)$ & & & & & \\
\hline 04:01 & $3(0.11)$ & 0 & 0 & 0 & 0 & 0 & & & & & \\
\hline 04:02 & $170(6.02)$ & $7(6.25)$ & $4(5.71)$ & $3(7.14)$ & $12(6.98)$ & $9(5.49)$ & & & & & \\
\hline 05 & 0 & 0 & 0 & 0 & $7(4.07)$ & $22(13.41)$ & & & & & \\
\hline 05:01 & $328(11.62)$ & $20(17.86)$ & $9(12.86)$ & $11(26.19)$ & $59(34.3)$ & $10(6.1)$ & $\mathrm{P}=0.05, \mathrm{OR}=1.65(1-3)$ & & $\mathrm{P}=0.01, \mathrm{OR}=2.69(1.3-5.4)$ & $\mathrm{P}=0.002, \mathrm{OR}=2.40(1.3-4)$ & $\mathrm{P}=0.002, \mathrm{OR}=0.29(0.13-0.7)$ \\
\hline 05:02 & $91(3.22)$ & $8(7.14)$ & $6(8.57)$ & $2(4.76)$ & $11(6.4)$ & $3(1.83)$ & $\mathrm{P}=0.05, \mathrm{OR}=2.3(1.1-5)$ & $\mathrm{P}=0.02, \mathrm{OR}=2.81(12-6)$ & & & $\mathrm{P}=0.05, \mathrm{OR}=0.24(0.06$ a 0.9$)$ \\
\hline 05:03 & $69(2.45)$ & 0 & 0 & 0 & $1(0.58)$ & $11(6.71)$ & & & & & \\
\hline 05:05 & $1(0.04)$ & 0 & 0 & 0 & 0 & 0 & & & & & \\
\hline 06 & $8(0.28)$ & 0 & 0 & 0 & 0 & 0 & & & & & \\
\hline 06:01 & $19(0.67)$ & 0 & 0 & 0 & 0 & $3(1.83)$ & & & & & \\
\hline 06:02 & $263(9.32)$ & $7(6.25)$ & $5(7.14)$ & $2(4.76)$ & $16(9.3)$ & $3(1.83)$ & & & & & 0.09 \\
\hline 06:03 & $226(8.01)$ & $5(4.46)$ & $3(4.29)$ & $2(4.76)$ & $3(1.74)$ & $4(2.44)$ & & & & & \\
\hline 06:04 & $99(3.51)$ & $3(2.68)$ & 0 & $3(7.14)$ & $1(0.58)$ & $3(1.83)$ & & & & & \\
\hline 06:05 & 0 & $1(0.89)$ & 0 & $1(2.38)$ & 0 & 0 & & & & & \\
\hline 06:09 & $29(1.03)$ & $1(0.89)$ & 0 & $1(2.38)$ & 0 & 0 & & & & & \\
\hline 06:11 & $5(0.18)$ & 0 & 0 & 0 & 0 & 0 & & & & & \\
\hline 16:02 & $1(0.04)$ & 0 & 0 & 0 & 0 & 0 & & & & & \\
\hline Total & 2822 & 112 & 70 & 42 & 172 & 164 & & & & & \\
\hline
\end{tabular}




\subsubsection{Associação dos alelos HLA de suscetibilidade ou de resistência à LTA, PF e PV (objetivo ix)}

Para a análise de associação dos alelos entre ambas as doenças, considerou-se:

i. A análise do grupo LTA versus grupo controle para os alelos de suscetibilidade à LTA, e

ii. As análises do grupo LTA versus grupo PF; e grupo LTA versus grupo PV para os alelos de suscetibilidade à LTA e/ou aos pênfigos.

\section{Para o locus HLA-DRBI (Tabela 15):}

O alelo $H L A-D R B 1^{*} 11: 01$ resultou de suscetibilidade no grupo LTA quando comparado ao grupo $\mathrm{PF}[\mathrm{P}=0.0002, \mathrm{OR}=18$ (2.37 a 146.3) . Este alelo não é relacionado aos pênfigos (dados não publicados) nem à LTA quando comparados ao grupo controle.

O alelo $H L A-D R B 1 * 01: 02$ resultou de resistência no grupo LTA quando comparado ao grupo $\mathrm{PF}[\mathrm{P}=0.000002, \mathrm{OR}=0.10(0.03$ a 0.33$)]$, porém, não apresentou diferença quanto aos controles. No $\mathrm{PF}$, este alelo é de suscetibilidade quando comparado ao grupo controle (dados não publicados). Portanto, o grupo LTA se comporta de forma semelhante ao grupo controle.

O alelo $H L A-D R B 1 * 07: 01$ resultou de suscetibilidade no grupo LTA quando comparado ao grupo $\mathrm{PV}[\mathrm{P}=0.001, \mathrm{OR}=4.9(1.7$ a 13.9$)]$, porém, não apresentou diferença quanto ao grupo controle. Nos grupos PV e PF, esse alelo é de resistência qdo comparado ao grupo controle (dados não publicados). Portanto, o grupo LTA se comporta de forma semelhante ao grupo controle.

O alelo $H L A-D R B 1 * 04: 02$ resultou de resistência no grupo LTA quando comparado ao grupo $\mathrm{PV}[\mathrm{P}=0.000003, \mathrm{OR}=0.10(0.04$ a 0.31$)]$, porém, não apresentou diferença quanto ao grupo controle. No PV, este alelo é de suscetibilidade quando comparado ao grupo controle (dados não publicados). Portanto, o grupo LTA se comporta de forma semelhante ao grupo controle. 
Tabela 15. Associação dos alelos $H L A-D R B 1$ à suscetibilidade ou resistência às doenças estudadas.

\begin{tabular}{|c|c|c|c|}
\hline & \multirow{2}{*}{ HLA-DRB1 } & \multicolumn{2}{|c|}{ LTA } \\
\hline & & Suscetibilidade & Resistência \\
\hline \multirow{2}{*}{$\mathrm{PF}$} & Suscetibilidade & NI & *01:02 \\
\hline & Resistência & $* 11: 01$ & NI \\
\hline \multirow{2}{*}{ PV } & Suscetibilidade & NI & *04:02 \\
\hline & Resistência & $* 07: 01$ & NI \\
\hline
\end{tabular}

NI: não identificado

Para o locus HLA-DQA1 (Tabela 16):

O alelo $H L A-D Q A 1 * 01: 02$ resultou de suscetibilidade nos grupos LTA total, LTAc e LTAm, quando comparado aos grupos controle $[\mathrm{P}=0.000001, \mathrm{OR}=3.89$ (2.37 - 6.37); $\mathrm{P}=0.0009, \mathrm{OR}=3.29$ (1.73 a 6.26); $\mathrm{P}=0.0001, \mathrm{OR}=4.9$ (2.40 a 10.31), respectivamente $]$ e $\mathrm{PV}[\mathrm{P}=0.0001, \mathrm{OR}=4.76$ (2.04 a 11.15)] . Este alelo não é relacionado ao PV quando comparado aos controles (dados não publicados). É relacionado à suscetibilidade ao $\mathrm{PF}$ quando comparado ao grupo controle (dados não publicados). Portanto, o grupo LTA se comporta de forma semelhante ao grupo PF.

$\mathrm{O}$ alelo $H L A-D Q A 1 * 01$ resultou de resistência nos grupos LTA [P=0.001, OR=0.43 $(0.26-0.74)]$ e LTAc $[\mathrm{P}=0.0002, \mathrm{OR}=0.27$ (0.12 a 0.59)], quando comparado aos grupos controle e $\mathrm{PF}[\mathrm{P}<0.001$, $\mathrm{OR}=0.26(0.14-0.47)]$. No PF, este alelo é de susceptibilidade, quando comparado aos controles (dados não publicados). Portanto, o grupo LTA se comporta de forma semelhante ao grupo controle.

Tabela 16. Associação dos alelos $H L A-D Q A 1$ à suscetibilidade ou resistência às doenças estudadas.

\begin{tabular}{cccc}
\hline \multirow{2}{*}{ HLA-DQA1 } & \multicolumn{2}{c}{ LTA } \\
\cline { 2 - 4 } PF & Suscetibilidade & Resistência \\
\cline { 2 - 4 } & Resistência & NI & $* 01$ \\
\hline \multirow{2}{*}{ PV } & Suscetibilidade & NI & NI \\
\cline { 2 - 3 } & Resistência & $* 01: 02$ & NI \\
\hline NI: não identificado & &
\end{tabular}


Para o locus $H L A-D Q B 1$ (Tabela 17):

O alelo $H L A-D Q B 1^{*}$ 03:02 resultou de resistência no grupo LTA, qdo comparado ao grupo PV $[\mathrm{P}=0.0001, \mathrm{OR}=0.29(0.1-0.5)]$, porém, não apresentou diferença quanto ao grupo controle. Esse alelo é de suscetibilidade no grupo PV, quando comparado ao grupo controle (dados não publicados). Portanto, o grupo LTA se comporta de forma semelhante ao grupo controle.

Tabela 17. Associação dos alelos $H L A-D Q B 1$ à suscetibilidade ou resistência às doenças estudadas.

\begin{tabular}{|c|c|c|c|}
\hline & \multirow{2}{*}{ HLA-DQB1 } & \multicolumn{2}{|c|}{ LTA } \\
\hline & & Suscetibilidade & Resistência \\
\hline \multirow{2}{*}{$\mathrm{PF}$} & Suscetibilidade & NI & NI \\
\hline & Resistência & NI & NI \\
\hline \multirow{2}{*}{ PV } & Suscetibilidade & NI & *03:02 \\
\hline & Resistência & NI & NI \\
\hline
\end{tabular}

NI: não identificado 


\section{DISCUSSÃo}

Diante da citada associação que vem sendo investigada entre pênfigos e LTA, tivemos por objetivo, neste estudo, investigar se há relação imunogenética capaz de fundamentar a coendemicidade de ambas doenças na região nordeste do estado de São Paulo.

\section{Relação Imunológica}

\section{ELISA anti-Dsg 1 e 3}

Partindo da hipótese de que a exposição aos antígenos da leishmania poderia ser um fator ambiental desencadeador dos pênfigos, iniciamos a busca por um link imunológico, pesquisando a resposta humoral dos pacientes com LTA às desmogleínas através de ensaio ELISA anti-Dsg 1 e 3. As altas prevalências de resposta humoral à Dsg1 encontradas nos pacientes com PF $(84,6 \%)$ e com PV $(54,8 \%)$ são consistentes com a literatura, como descrito por Amagai et al., em 1999 (anti-Dsg1 em 89,6\% para PF e 55,6\% para PV), por Kallel Sellami et al., em 2004 (anti-Dsg1 em 90\% para PF e 50\% para PV) e Vargas et al., 2006 (anti-Dsg1 em 95\% dos pacientes com PF). Houve diferença significativa entre a resposta humoral dos grupos pênfigos e os demais, mas não entre os grupos LTA e controles, nem em relação à frequência de positividade nem à distribuição dos valores de Index Value das amostras.

Zaara et al. (2012), utilizando o mesmo kit comercial ELISA anti-Dsg 1 e 3 (MBL, Nagoya, Japan), mostraram frequência de positividade do ELISA anti-Dsg1 entre os pacientes com LTA um pouco maior $(8 / 30-13,3 \%)$ do que a aqui apresentada $(2 / 37-5,4 \%$ para LTAc e $1 / 21-4,8 \%$ para LTAm), mas também sem diferença significativa para o Index Value entre pacientes e controles. Já em estudo anterior, Diaz et al. (2004) mostraram positividade mais elevada, de 43\% no grupo total de LTA (88 pacientes de países diversos) e ainda maior (73\%) quando considerada apenas a população brasileira. Tais valores causam estranheza, e associados à inexistência de quadro clínico de pênfigo em qualquer desses indivíduos, incitam questionamento sobre a técnica utilizada (ELISA in house com antígenos recombinantes sintéticos) e quanto à possibilidade de reação cruzada entre a Dsg1 e os 
antígenos da leishmania, sendo necessária, para elucidação, adsorção prévia desses soros de LTA com antígenos de leishmania.

No que diz respeito à resposta humoral à Dsg3, os achados para os grupos PV (83,9\% de positividade) e PF (6,4\% de positividade) são também compatíveis com os descritos na literatura [Amagai et al., 1998 (anti-Dsg3 em 85,2\% para PV e 4,2\% para PF) e Kallel Sellami et al., 2007 (antiDsg3 em 10,2\% dos pacientes com PF)], e mostram diferença significativa entre o grupo PV com os demais. Guardando semelhança ao ocorrido para os resultados da Dsg1, não houve diferença entre o grupo LTA e os controles. Essa pesquisa de anticorpos contra Dsg3 em pacientes com LTA é inédita e resultou em 5,2\% de positividade. Kallel Sellami et al., 2007, descreveram, em pacientes com leishmaniose visceral, 17,3\% de positividade anti-Dsg3, mas todos fracamente positivos (valores de Index Value entre 7 e 20, considerados indeterminados pelas instruções do fabricante). Nenhum paciente com leishmaniose visceral apresentou Index value acima de 20 (cut off recomendado pelo fabricante e utilizado em nossos resultados).

Assim, para a resposta humoral a ambos antígenos - Dsg 1 e 3 - o grupo de pacientes com LTA se comportou semelhante aos controles.

E analisando, em destaque, os 4 casos de LTA que apresentaram anticorpos anti-Dsg positivos, estes não apresentaram evolução fora do padrão, tendo sido acompanhados com boa resposta ao tratamento com antimonial e cura, com alta do ambulatório.

\section{ELISA anti-L.braziliensis}

Zaraa et al., na Tunísia, em 2012, estudaram a resposta humoral contra Dsg1 e contra extratos de glândulas salivares (EGS) do Phlebotomus papatasi em 31 pacientes com PF e em 31 controles, e em 60 com LTA e 60 controles. As prevalências de anti-EGS e de anti-Dsg1 foram significantemente maiores no grupo PF que no seu controle. Para os grupos LTA e seu controle, não houve diferença estatística para a prevalência de anti-EGS (alta em ambos), mas a prevalência de anti-Dsg1 foi estatisticamente maior no grupo LTA. Assim, os autores sugerem que os pacientes com contato com o parasito leishmania são mais propensos a desenvolverem anti-Dsg1 do que os indivíduos que apresentam altos títulos de anti-EGS, mas sem exposição ao parasito. 
Essa inferência foi feita partindo do princípio que os controles de LTA, com altos títulos antiEGS, teriam tido contato com $P$. papatasi, mas, por não apresentarem doença clínica, não teriam tido contato com o parasito. No entanto, a não avaliação de anticorpos anti-leishmania nesses indivíduos não permite a afirmativa de que os mesmos não tiveram tal contato.

Assim, objetivando responder melhor a esse questionamento, pesquisamos a resposta humoral dos pacientes com pênfigos aos antígenos de L.braziliensis através de ensaio ELISA e Immunoblotting. A escolha da L. (Viannia) braziliensis como antígeno baseou-se no fato de ser essa a espécie mais frequente na etiologia da LTA na referida região geográfica (LUZ et al., 2009; SOARES et al., 2015). A pesquisa de anticorpos anti-L. braziliensis nos pacientes com pênfigos é inédita, e não se mostrou, no ELISA, significativamente diferente da do grupo controle (1,3\% para $\mathrm{PF}, 1,6 \%$ para PV e 5,1\% para controles). Diaz et al. (2004) relataram ausência de anticorpos contra Leishmania sp. em 40 pacientes com PF e em 10 controles de área endêmica, por imunofluorescência indireta. De modo semelhante, Kallel Sellami et al. (2007) mostraram que a prevalência de anticorpos contra antígenos parasitários de hidatidose e de leishmaniose visceral em pacientes com PF não diferiu significativamente dos controles. O que também foi descrito, mais recentemente, por Mortazavi et al. (2015) em relação à pesquisa de soropositividade para anticorpos contra antígenos de Leishmania major, assim como de Toxoplasma gondii e Epstein-Barr vírus.

Analisando, em destaque, os 2 casos de pênfigo (1 paciente com PF e 1 com PV) que tiveram ELISA anti-L. braziliensis positivo, percebeu-se que ambos tiveram pênfigo de difícil controle e que se mantêm em seguimento até o presente momento (aproximadamente 15 anos para ambos) sem nunca terem tido lesão sugestiva de LTA.

\section{Correlação entre os títulos anti-Dsg 1 e 3 e anti-L.braziliensis}

A correlação positiva e significante entre os títulos anti-Dsg 1 e 3 com anti-L. braziliensis para o grupo LTAc poderia suscitar sobre relação cruzada antigênica; porém, a correlação não significante entre os títulos de anti-Dsg 1 e 3 e anti-L. braziliensis para os grupos PF e PV respectivamente, argumenta contra a existência de reação cruzada entre esses ensaios, descartando a necessidade de adsorção. Não há na literatura consultada comparação semelhante. 


\section{Immunoblotting com extrato de epiderme}

Em relação ao IB com extrato proteico de epiderme, a detecção da banda de 130kDa em todos os pacientes com PV (4/4) e da banda de $160 \mathrm{kDa}$ na maioria dos pacientes com PF (3/5), bem como a não detecção de bandas pelos pacientes controles saudáveis $(0 / 3)$, são resultados condizentes com o esperado para o conhecimento da fisiopatologia dos pênfigos, e que confirmam a adequação do extrato proteico utilizado.

O reconhecimento da banda de $150 \mathrm{kDa}$ nos pacientes com pênfigo ocorreu exatamente naqueles que possuem ELISA anti-Dsg 2 positivo (dados não publicados). Esse resultado é interessante já que anticorpos contra esta desmogleína já tenham sido demonstrados em pacientes com pênfigos. Flores et al., 2012, identificaram $42 \%$ de positividade de anti-Dsg2 em pacientes com PF endêmico.

A deteç̧ão dos peptídeos de $130 \mathrm{kDa}$ e de $160 \mathrm{kDa}$ nos pacientes com LTA e anti-Dsg 1/3 positivos pode representar uma confirmação da existência de resposta imune humoral contra as desmogleínas nestes indivíduos, ou um reconhecimento das desmogleínas pelos anticorpos antileishmania por reação cruzada. A ausência de deteç̧ão dessas bandas pelos soros do grupo LTA com ELISA para L. braziliensis positivo, mas para desmogleínas negativo, advoga contra a existência de reação cruzada entre esses antígenos. Kallel Sellami et al., 2007, mostraram ausência de detecção proteica no IB com extrato de epiderme pelo soro de pacientes com leishmaniose visceral (com ELISA anti-Dsg 1 e/ou 3 positivos). De todo modo, o reconhecimento dos soros dos pacientes com LTA por outros peptídeos epidérmicos sugere a possibilidade de reconhecimento de proteínas da epiderme menos tradicionais que as apontadas como alvos nos pênfigos, como é o caso do recohecimento da banda de 230kDa, relacionada na literatura ao penfigoide bolhoso (antígeno BP230). Estudos com amostragem maior de pacientes com LTA são necessários para essa investigação.

Interessante ainda destacar que os soros de indivíduos controles com ELISA anti-Dsg negativo e com sorologia para Chagas positiva não mostrou reconhecimento de peptídeos no IB, defendendo a inexistência de reação cruzada entre os antígenos de T. cruzi e a epiderme. 


\section{Imunofluorescência Indireta}

À IFI, o reconhecimento de antígenos intercelulares (1/6 pacientes) e de antígenos da zona da membrana basal (1/6 pacientes) por soros de pacientes com LTA é interessante. Um dos pacientes da forma mucosa (soro 318) apresentou IFI semelhante aos pênfigos, confirmando o resultado positivo do ELISA anti-Dsg 1 e 3. O ELISA resultou positivo para anti-L. V. braziliensis e negativo para Chagas. Já no IB, o soro desse paciente reconheceu as bandas de 230kDa (BP230 ou BPAg1) e de 250kDa. Embora a banda de $230 \mathrm{kDa}$ seja descrita no penfigoide bolhoso, na IFI (salt Split), não houve marcação fluorescente da zona da membrana basal.

O outro paciente com LTA forma mucosa (soro 296) apresentou IFI (salt Split) positiva no teto da clivagem, semelhante ao penfigoide bolhoso. Esse paciente apresentou ELISA negativo para anti-Dsg 1 e 3; e positividade para anti- L. V. braziliensis e Chagas. Já no IB, houve reconhecimento das bandas de 180kDa (BPAg2) e de 230kDa, ambos peptídeos marcadores do penfigoide bolhoso, justificando o resultado da IFI.

Diante dos resultados da IFI salt Split e do IB, procedeu-se ao ELISA para anti-BP 180 e 230 (resultados não mostrados) com as amostras dos 6 pacientes com LTA (4 da forma cutânea e 2 da forma mucosa). Dos 6 pacientes, os soros citados acima - 318 e 296 - resultaram positivos para BP180 e BP230.

Chama a atenção que somente os soros dos pacientes com a forma mucosa da LTA mostraram positividade na IFI. Também foram os únicos que mostraram positividade para anti-BP 180 e 230 . Como a população idosa pode apresentar anticorpos anti-BP positivos, conferimos as idades desses pacientes. O paciente com IFI salt Split positiva tinha 44 anos, e aquele que apresentou IFI semelhante aos pênfigos, 81 anos. Assim, concluímos que os pacientes com LTA podem se comportar de forma semelhante aos controles; possuem anticorpos contra Dgs 1 e 3; e ou contra BP 180 e 230, sem, contudo, manisfetarem a doença.

Kallel Sellami et al. (2007) discutem a diferença de resultados entre o ELISA e a IFI, justificada pela sensibilidade e especificidade diferentes para cada técnica. 
Os resultados apresentados no ensaio ELISA, no Immunoblotting e na IFI, diferindo na capacidade de detecção de anticorpos entre os pacientes, mostram que tais técnicas são importantes e complementares na pesquisa da resposta imune.

\section{Immunoblotting com extrato de $L$. $(V$.) braziliensis}

O IB com extrato proteico de $L$. $(V$.) braziliensis demonstrou detecção bem marcada nos soros de LTA, e negativa ou muito fraca nos controles saudáveis, reiterando a validade do experimento. $\mathrm{O}$ reconhecimento de peptídeos de $L$. (V.) braziliensis pelos soros de PF e PV pode significar que: anticorpos anti-Dsg 1 ou 3 estejam reconhendo peptídeos de $L$. (V.) braziliensis por reação cruzada; os pacientes com PF e PV foram expostos ao parasito e produziram anticorpos específicos contra peptídeos de L. (V.) braziliensis; ou ainda uma reação inespecífica.

A detecção da banda de 150kDa ocorreu em dois soros de LTA e com um soro de PV. Como citado acima, este é o peso molecular, na epiderme, da Dsg2. Interessantemente, este paciente com PV apresenta ELISA anti-Dsg2 positivo (resultados não publicados). Esses dados levam ao seguinte questionamento: um peptídeo de $L$. $(V$.) braziliensis de $150 \mathrm{kDa}$, mas completamente diferente do peptídeo da epiderme, está sendo reconhecido por anticorpo anti-Dsg2, configurando mimetismo antigênico; um peptídeo de L. $(V$.) braziliensis de $150 \mathrm{kDa}$ está sendo reconhecido por outro anticorpo diferente daquele anti-Dsg2, configurando uma reação específica contra $L$. (V.) braziliensis; ou ainda um peptídeo de L. (V.) braziliensis similar à Dsg2 está sendo reconhecido por anticorpo anti-Dsg2 (mimetismo antigênico e mimetismo molecular). Estudo com mairo amostragem e sequenciamento desse peptídeo contribuiriam para elucidar tal questão.

\section{Exame sorológico para T. cruzi}

Para afastar a possibilidade de reações cruzadas como fatores confudidores, pesquisamos a resposta humoral dos pacientes com pênfigos ao $T$. cruzi, que tem conhecida semelhança antigênica à leishmania, através de exame sorológico para Chagas. A sorologia para Chagas gerou positividade maior no grupo LTAc (12,5\%), mas a diferença não foi estatísticamente significativa entre os grupos LTAm (5,9\%), pênfigos (5\% no grupo PF e $0 \%$ no PV) e controles $(4,5 \%$ no grupo FPF e $4 \%$ nos 
vizinhos controles). Além disso, os 2 únicos pacientes com PF que tiveram positividade na sorologia para Chagas, apresentaram ELISA anti-L. braziliensis negativo, falando contra a possibilidade de reação cruzada entre os 2 testes.

Souza et al. (2012), pesquisando reatividade ao T. cruzi em população de área endêmica para FS (pacientes e controles), mostraram resposta humoral em 2,5\% dos pacientes e em 3,3\% dos controles, resultados concordantes com os nossos.

\section{Teste de Montenegro}

Ainda, pesquisamos a resposta imune celular à leishmania, através do TIM. O resultado negativo nos 6 indivíduos avaliados demonstra ausência de resposta imunecelular dos pacientes com pênfigos ao antígeno de Leishmania sp., resultado válido considerando que todos os pacientes tinham mais de 6 meses de tempo de doença, tempo necessário para a positivação do teste, e que todos os indivíduos foram testados sem corticoides ou imunossupressores por no mínimo 15 meses. Esse resultado sugere que os mesmos não tiveram contato prévio com o parasito, o que foi corroborado pelo ELISA anti-L. braziliensis negativo nos 4/6 pacientes testados.

\section{Relação genética}

\section{Estudo HLA}

Investigamos a relação genética entre LTA e pênfigos, através da caracterização dos alelos $H L A$ de classe II $-D R$ e $-D Q$. Inicialmente, verificamos a frequência dos alelos no grupo LTA em relação aos controles. A seguir, verificamos a associação destes com os alelos relevantes para os pênfigos.

Não há na literatura consultada nenhum relato de associação de ambas as doenças - pênfigos e LTA - em um mesmo indivíduo, assim como também não a temos observado na região do estudo, com toda a vivência clínica nos ambulatórios de referências da Dermatologia do HC para ambas as doenças (ambulatório de dermatoses autoimunes, e ambulatório de dermatoses granulomatosas), sendo aregião nordeste do estado de São Paulo, endêmcica para ambas as dermatoses. Este fato incita a hipótese de 
que não haja alelos $H L A$ que predisponham tanto à LTA, quanto ao pênfigo. Ginel et al. (1993) descreveram um caso de pênfigo foliáceo canino associado à leishmaniose. E Maleb et al. (2011) descreveram um caso isolado de paciente com pênfigo em tratamento imunossupressor, que posteriormente recebeu o diagnóstico de leishmaniose visceral por investigação laboratorial ocasional.

Concordando com o referido acima, os dados encontrados no presente estudo mostram associações opostas para LTA e pênfigos. Identificamos associação de resistência para LTA e suscetibilidade para pênfigo (PF e/ou PV) em 4 alelos $(D R B 1 * 01: 02$ e *04:02, DQA1*01 e $D Q B 1^{*}$ 03:02); e de suscetibilidade para LTA e de resistência para pênfigo (PF e/ou PV) em 3 alelos $(D R B 1 * 11: 01$ e *07:01 e $D Q A 1 * 01: 02)$.

No que se refere à literatura vigente, a associação $H L A$ é bem menos estudada na LTA que nos pênfigos, e apenas conta com 2 trabalhos na literatura.

Assim, discutindo os alelos aqui identificados como de resistência para LTA e suscetibilidade para pênfigos, temos: para o alelo $D R B 1^{*} 01: 02$, a suscetibilidade para PF foi também descrita em estudos anteriores (MORAES et al., 1991 e PAVONI et al., 2003) e em estudo recente do nosso grupo (dados não publicados); para o alelo $D R B 1^{*} 04: 02$, suscetibilidade para PV foi também identificada por Weber et al. (2011) e por nosso grupo (dados não publicados); para o alelo $D Q A 1^{*} 01$, suscetibilidade para PF é corroborada por resultados do nosso grupo (dados não publicados) e é inédita na literatura; e para o alelo $D Q B 1 * 03: 02$, suscetibilidade para PF foi apontada anteriormente por Moraes et al. (1997), suscetibilidade para PV foi identificada por nosso grupo (dados não publicados), e, das aqui identificadas, é a única associação com LTA discutida na literatura. No entanto, o estudo é muito antigo e a caracterização realizada foi apenas em baixa definição $(D Q B 1 * 03)$, não especificando se a associação de suscetibilidade encontrada foi para $D Q B 1 * 03: 01$, *3:02 ou *03:03 (PETZLERLER et al., 1991).

Em relação aos descritos como de suscetibilidade para LTA e resistência para pênfigos, temos: para o alelo $D R B 1^{*} 11: 01$, resistência para PF foi também descrita previamente (PAVONI et al., 2003); para o alelo $D R B 1 * 07: 01$, resistência para PF foi descrita anteriormente (PAVONI et al., 2003) e resistência para PF e PV identificada em outro estudo recente do nosso grupo (dados não publicados); e apenas para o alelo $D Q A 1^{*} 01: 02$ a associação de suscetibilidade para LTA (em relação 
ao PV) aqui apontada não foi corroborada como oposta em relação ao pênfigo e coincidiu com suscetibilidade também para PF nos dados do estudo do nosso grupo (dados não publicados).

Assim, nossos achados sugerem que, embora LTA, PF e PV compartilhem região de endemicidade, não há indícios de que a exposição aos antígenos da leishmania possa ter desencadeado a produção de anticorpos contra as desmogleínas, favorecendo o desenvolvimento do pênfigo. 


\section{CONCLUSÕES}

1. Os pacientes com LTA têm resposta humoral às desmogleínas 1 e 3 semelhante aos controles.

2. Os pacientes com pênfigo têm resposta humoral e celular aos antígenos de L. (V.) braziliensis semelhante aos controles.

3. Há reconhecimento de peptídeos da epiderme humana por soro de pacientes com LTA.

4. Há reconhecimento de peptídeos de L. (V.) braziliensis por soro dos pacientes com pênfigo;

5. Pacientes com pênfigos têm resposta humoral aos antígenos de Trypanosoma cruzi semelhante aos controles.

6. Pacientes com LTA e pênfigo apresentam associações opostas de alelos $H L A$ de classe II -DR e $-D Q$ de suscetibilidade ou resistência.

\subsection{Conclusão Final}

Os resultados imunológicos mostram que o parasito $L$. $(V$.) braziliensis não está implicado na patogênese dos pênfigos, e o estudo genético corrobora a observação clínica da ausência da associação de ambas as doenças na região do estudo. 


\section{REFERÊNCIAS}

Abréu-Vélez AM, Reason IIM, Howard MS, Roselino AM. Endemic pemphigus foliaceus over a century: Part I. North Am J Med Sci. 2010;2:51-9.

Abréu-Vélez AM, Roselino AM, Howard MS, Reason IIM. Endemic pemphigus over a century: Part II. North Am J Med Sci. 2010;2:114-20.

Aires JM, Chociay MF, Nascimento MMP, Figueiredo JFC, Roselino AM. Maxadilan (MAX) salivary protein of Lutzomyia longipalpis: detection of antibodies anti-MAX in American tegumentar leishmaniasis (ATL), and genetic and protein expression of MAX in Lutzomyia neivai. An Bras Dermatol. 2005;80:S333-S338.

Alberto FL, Cruz AK, Almeida AM, Roselino AMF. Leishmania amazonensis no interior do Estado de São Paulo. Anais do 48․ C.B.D., p. 162, Curitiba, PR, 1993;

Amagai M. Autoimmune and infectious skin diseases that target desmogleins. Proc Jpn Acad Ser B Phys Biol Sci. 2010;86(5):524-37.

Amagai M, Komai A, Hashimoto T, Shirakata Y, Hashimoto K, Yamada T, Kitajima Y, Ohya K, Iwanami $\mathrm{H}$, Nishikawa $\mathrm{T}$. Usefulness of enzyme-linked immunosorbent assay using recombinant desmogleins 1 and 3 for serodiagnosis of pemphigus. Br J Dermatol. 1999 Feb;140 (2):351-7

Ambiel MV, Roselino AM. Prevalência da Síndrome metabólica em pacientes com pênfigos. In: $65^{\circ}$. Congresso da Sociedade Brasileira de Dermatologia, no Rio de Janeiro, 2010.

Aoki V, Sousa JX Jr, Diaz LA; Cooperative Group on Fogo Selvagem Research. Pathogenesis of endemic pemphigus foliaceus. Dermatol Clin. 2011 Jul;29 (3):413-8.

Aoyama, Y.; Owada, M. K.; Kitajima, Y. A pathogenic autoantibody, pemphigus vulgaris-IgG, induces phosphorylation of desmoglein 3 , and its dissociation from plakoglobin in cultured keratinocytes. Eur J Immunol, v. 29, n. 7, p. 2233-40, Jul 1999.

Artega LA, Prisayanh OS, Warren SJP, Lui Z, Diaz LA, Lin MS. A subset of pemphigus foliaceus patients exhibits pathogenic autoantibodies against both anti-desmoglein-1 and desmoglein-3. J Invest Dermatol. 2002;118(5):806-11.

Assumpção TC, Eaton DP, Pham VM, Francischetti IM, Aoki V, Hans-Filho G, Rivitti EA, Valenzuela JG, Diaz LA, Ribeiro JM. An insight into the sialotranscriptome of Triatoma matogrossensis, a kissing bug associated with fogo selvagem in South America. Am J Trop Med Hyg. 2012 Jun;86(6):1005-14. 
Barroso-Freitas AP, Passos SR, Mouta-Confort E, Madeira MF, Schubach AO, Santos GP, Nascimento LD, Marzochi MC, Marzochi KB. Accuracy of an ELISA and indirect immunofluorescence for the laboratory diagnosis of American tegumentary leishmaniasis. Trans $\mathrm{R}$ Soc Trop Med Hyg. 2009 Apr;103(4):383-9. doi: 10.1016/j.trstmh.2008.12.019. Epub 2009 Feb 10 .

Berkowitz P, Hu P, Warren S, Liu Z, Diaz LA, Rubenstein DS. p38MAPK inhibition prevents disease in pemphigus vulgaris mice. Proc Nati Acad Sci U S A. 2006;103(34):12855-12860.

Berkowitz P, Chua M, Liu Z, Diaz LA, Rubenstein DS. Autoantibodies in the autoimmune disease pemphigus foliaceus induce blistering via p38 mitogen-activated protein kinase-dependent signaling in the skin. Am J Pathol. 2008;173(6):1628-1636.

Beutner EH, Jordon RE, Chorzelski TP. The immunopathology of pemphigus and bullous pemphigoid. J. Invest Dermatol. 1968;51:63-80.

Caballero ZC, Sousa OE, Marques WP, Saez-Alquezar A, Umezawa ES. Evaluation of serological tests to identify Trypanosoma cruzi infection in humans and determine cross-reactivity with Trypanosoma rangeli and Leishmania spp. Clin Vaccine Immunol. 2007 Aug;14(8):1045-9. Epub 2007 May 23.

Caldelari R, De Bruin A, Baumann D, et al. A central role for the armadillo protein plakoglobin in the autoimmune disease pemphigus vulgaris. J Cell Biol. 2001;153(4):823-834.

Campanelli AP, Roselino AM, Cavassani KA, Pereira MS, Mortara RA, Brodskyn CI, Goncalves HS, Belkaid Y, Barral-Netto M, Barral A, Silva JS. CD4+CD25+ T cells in skin lesions of patients with cutaneous leishmaniasis exhibit phenotypic and functional characteristics of natural regulatory T cells. J Infect Dis. 2006 May 1;193(9):1313-22. Epub 2006 Mar 17.

Cataldo JI, de Queiroz Mello FC, Mouta-Confort E, de Fátima Madeira M, de Oliveira Schubach A, da Silva Genestra M, Ribeiro FC, de Fátima Moreira-Venâncio C, Passos SR. Immunoenzymatic assay for the diagnosis of American tegumentary leishmaniasis using soluble and membraneenriched fractions from infectious Leishmania (Viannia) braziliensis. J Clin Lab Anal. 2010;24(5):289-94. doi: 10.1002/jcla.20402.

Cerna M, Fernandez-Viña M, Friedman H, Moraes JR, Moraes ME, Diaz L, Stastny P. Genetic markers for susceptibility to endemic Brazilian pemphigus foliaceus (Fogo Selvagem) in Xavante Indians. Tissue Antigens. 1993 Sep;42(3):138-40.

Cervantes-Landín AY, Martínez I, Schabib M, Espinoza B. High molecular weight proteins of Trypanosoma cruzi reduce cross-reaction with Leishmania spp. in serological diagnosis tests. Biomed Res Int. 2014;2014:365403. doi: 10.1155/2014/365403. Epub 2014 Jul 20.

Chernyavsky AI, Arredondo J, Kitajima Y, Sato-Nagai M, Grando SA. Desmoglein versus nondesmoglein signaling in pemphigus acantholysis: characterization of novel signaling pathways downstream of pemphigus vulgaris antigens. J Biol Chem. 2007;282(18):13804- 13812. 
Chiossi MP, Costa RS, Roselino AM. Dermal dendritic cell number correlates with serum autoantibody titers in Brazilian pemphigus foliaceus patients. Braz J Med Biol Res. 2004 Mar;37(3):337-41.

Chiossi MP, Roselino AM. Endemic Pemphigus foliaceus ("Fogo selvagem"): a series from the Northeastern region of the State of São Paulo, Brazil, 1973-1998. Rev Inst Med Trop SP. 2001 Mar-Apr;43(2):59-62.

Culton DA, Qian Y, Li N, Rubenstein D, Aoki V, Filhio GH, Rivitti EA, Diaz LA. Advances in pemphigus and its endemic pemphigus foliaceus (Fogo Selvagem) phenotype: a paradigm of human autoimmunity. J Autoimmun. 2008 Dec;31(4):311-24.

Delva E, Jennings JM, Calkins CC, Kottke MD, Faundez V, Kowalczyk AP. Pemphigus vulgaris IgGinduced desmoglein-3 endocytosis and desmosomal disassembly are mediated by a clathrin- and dynamin-independent mechanism. J Biol Chem. 2008;283(26):18303-18313.

Desjeux P. Leishmaniasis: current situation and new perspectives. Comp. Immunol. Microbiol. Infect. Dis.27,305-318 (2004).

Diaz LA, Arteaga LA, Hilario-Vargas J, Valenzuela JG, Li N, Warren S, Aoki V, Hans-Filho G, Eaton D, dos Santos V, Nutman TB, de Mayolo AA, Qaqish BF, Sampaio SA, Rivitti EA; Cooperative Group on Fogo Selvagem Research. Anti--desmoglein-1 antibodies in onchocerciasis, leishmaniasis and Chagas disease suggest a possible etiological link to Fogo selvagem. J Invest Dermatol. 2004 Dec;123(6):1045-51.

Diaz LA, Prisayanh PS, Dasher DA, et al. The IgM Anti--Desmoglein 1 Response Distinguishes Brazilian Pemphigus Foliaceus (Fogo Selvagem) from Other Forms of Pemphigus. J Investig Dermatol. 2008;128:667-75.

Diniz JL, Costa MO, Gonçalves DU. Mucocutaneous Leishmaniasis: clinical markers in presumptive diagnosis. Braz J Otorhinolaryngol. 2011 Jun;77(3):380-4.

El-Sayed NM, Myler PJ, Blandin G, Berriman M, Crabtree J, Aggarwal G, Caler E, Renauld H, Worthey EA, Hertz-Fowler C, Ghedin E, Peacock C, Bartholomeu DC, Haas BJ, Tran AN, Wortman JR, Alsmark UC, Angiuoli S, Anupama A, Badger J, Bringaud F, Cadag E, Carlton JM, Cerqueira GC, Creasy T, Delcher AL, Djikeng A, Embley TM, Hauser C, Ivens AC, Kummerfeld SK, Pereira-Leal JB, Nilsson D, Peterson J, Salzberg SL, Shallom J, Silva JC, Sundaram J, Westenberger S, White O, Melville SE, Donelson JE, Andersson B, Stuart KD, Hall N. Comparative genomics of trypanosomatid parasitic protozoa. Science. 2005 Jul 15;309(5733):4049.

Ferreira MP, Roselino AM, Nascimento MM, Aires JM, Figueiredo JF. Sensitivity of an immunoenzymatic test for detection of anti-L. brasiliensis antibodies compared to other tests used for the diagnosis of American cutaneous leishmaniasis. Rev Inst Med Trop Sao Paulo. 2006 JulAug;48(4):215-7. 
Flores G, Qian Y, Díaz LA. The enigmatic autoimmune response in endemic pemphigus foliaceus. Actas Dermosifiliogr. 2009 Dec;100 Suppl 2:40-8.

Freitas SF, Santos SSR, Sampaio RNR, Roselino AM. Imprint of skin samples collected on filter paper substitutes skin biopsy for etiological diagnosis of American tegumentary leishmaniasis by polymerase chain reaction. In: Book Abstracts. 21st World Congress of Dermatology, 2007, Buenos Aires, Argentina. 2007;2:787.

Furtado T. Critérios para diagnóstico da leishmaniose tegumentar Americana. Anais Brasileiros de Dermatologia 65:51-86, 1980.

Garcia FCB, Rodrigues SS, Chociay MF, Medeiros ACR, Roselino AM. Subsidiary methods for the diagnosis of American tegumentar leishmanisis (ATL): comparison of sequencing of DNA and PCR-RFLP for identification of leishmania species in skin samples. Anais Brasileiros de Dermatologia. 2005;80:S339-S344.

Gatti MFC, Zago MA, Roselino AM. Polimorfismo 274C/T e 823C/T do gene NRAMP1/SLC11A1 estão relacionados à leishmaniose tegumentar Americana. An Bras Dermatol. 2008;83:S191.

Gil JF, Hoyos CL, Cimino RO, Krolewiecki AJ, López Quiroga I, Cajal SP, Juárez M, García Bustos MF, Mora MC, Marco JD, Nasser JR. [Role of three ELISA tests using promastigote homogenates of Leishmania braziliensis, L. amazonensis and L. guyanensis in the diagnosis of tegumentary leishmaniasis]. Medicina (B Aires). 2011;71(5):420-8.

Gomes CM, Cesetti MV, de Morais OO, Mendes MS, Roselino AM, Sampaio RN. The influence of treatment on the development of leishmaniasis recidiva cutis: a 17-year case-control study in Midwestern Brazil. J Eur Acad Dermatol Venereol. 2015a Jan; 29 (1):109-14

Gomes CM, de Paula NA, Cesetti MV, Roselino AM, Sampaio RN. Mucocutaneous leishmaniasis: accuracy and molecular validation of noninvasive procedures in a L. (V.) braziliensis-endemic area. Diagn Microbiol Infect Dis 2014a Aug;79: 413-418.

Gomes CM, de Paula NA, de Morais OO, Soares KA, Roselino AM, Sampaio RN. Complementary exams in the diagnosis of American tegumentary leishmaniasis. An Bras Dermatol 2014b Sep-Oct 89: 701-709.

Gonçalves GAP, Brito MMC, Salathiel ASM, Ferraz TS, Alves D, Roselino AMF. Incidência do Pênfigo Vulgar ultrapassa a do Pênfigo Foliáceo (PF) em região endêmica para PF: análise de série histórica de 21 anos. An Bras Dermatol. 2011;86(6) (in press).

Goto H, Lindoso JA. Current diagnosis and treatment of cutaneous and mucocutaneous leishmaniasis. Expert Rev Anti- Infect Ther. 2010 Apr;8(4):419-33. doi: 10.1586/eri.10.19.

Grando SA. Pemphigus autoimmunity: Hypotheses and realities. Autoimmunity. 2012;Early Online:129 ; 
Guedes ACM, Cucé LC, Furtado, T. Avaliação imunológica e histopatólogica de reação de Montenegro. Anais Brasileiros de Dermatologia 65:34S-405, 1990.

Hisamatsu Y, Abreu Velez AM, Amagai M, Ogawa MM, Kanzaki T, Hashimoto T. Comparative study of autoantigen profile between Colombian and Brazilian types of endemic pemphigus foliaceus by various biochemical and molecular biological techniques. J Dermatol Sci. 2003 Jun;32(1):33-41;

James KA, Culton DA, Diaz LA. Diagnosis and clinical features of pemphigus foliaceus. Dermatol Clin. 2011 Jul;29(3):405-12.

Joly P, Sin C. [Pemphigus: a review]. Ann Dermatol Venereol. 2011 Mar;138(3):182-200.

Kallel Sellami M, Ben Ayed M, Mouquet H, Drouot L, Zitouni M, Mokni M, Cerruti M, Turki H, Fezza B, Mokhtar I, Ben Osman A, Zahaf A, Kamoun MR, Joly P, Masmoudi H, Makni S, Tron F, Gilbert D. Anti--desmoglein 1 antibodies in Tunisian healthy subjects: arguments for the role of environmental factors in the occurrence of Tunisian pemphigus foliaceus. Clin Exp Immunol. 2004 July; 137(1): 195-200.

Kallel Sellami M, Zitouni M, Tombari W, Bem Ayed M, Abida O, Laadhar L, Mokni M, Fezza B, Turki H, Mokhtar I, Bem Osman A, Kamoun Mohamed R, Joly P, Tron F, Gilbert D, masmoudi H, Makni S. Anti--desmoglein-1 antibodies are prevalent in Tunisian patientes with hydatidosis and leishmaniasis. Br J Dermatol. 2007;156:575-612.

Kar K. Serodiagnosis of leishmaniasis. Crit Rev Microbiol. 1995;21(2):123-52.Kim OM, Nascimento MMP, Figueiredo JFC, Roselino AM. Similaridade entre proteínas salivares de insetos hematófagos e seu papel na fisiopatogenia do Pênfigo Foliáceo Endêmico. In: $64^{\circ}$ Congresso da Sociedade Brasileira de Dermatologia, Belém, PA, 2009.

Kawasaki Y, Aoyama Y, Tsunoda K, Amagai M, Kitajima Y. Pathogenic monoclonal antibody against desmoglein 3 augments desmoglein 3 and p38 MAPK phosphorylation in human squamous carcinoma cell line. Autoimmunity. 2006;39(7):587-590.

Kim OM, Pepinelli M, Passeri M, Figueiredo JFC, Roselino AM. Soro de pacientes com pênfigo foliáceo (fogo selvagem) reage contra proteínas salivares de inseto hematófago. An Bras Dermatol. 2008;83:S30.

Kim O, Yamashita M; Roselino A. Antibodies against Simulium nigrimanum proteins present similar antigenicity with adhesion molecules of keratinocytes in experimental model. In: 2010 JC Bystryn Pemphigus \& Pemphigoid Meeting: From the bench to the bedside, 2010, Bethesda, MA, USA;

Kim OM. Papel da saliva de insetos hematófagos na fisiopatologia do Pênfigo Foliáceo Endêmico (Fogo Selvagem-FS). 2012. 187 f. Tese (Doutorado) - Faculdade de Medicina de Ribeirão Preto da Universidade de São Paulo. Programa de Pós-Graduação em Clínica Médica. Ribeirão Preto, São Paulo. 2012. 
Klein J, Sato A. The HLA system. First of two parts. N Engl J Med. 2000 Sep 7;343(10):702-9.Klein J, Sato A. The HLA system. Second of two parts. N Engl J Med.2000;14, 343(11):782-6.

Koulu L, Kusumi A, Steinberg MS, Klaus-Kovtun V, Stanley JR. Human antibodies against a desmosomal core protein in pemphigus foliaceus. J Exp Med. 1984;160:1509-18.

LI, N. et al. Involvement of the apoptotic mechanism in pemphigus foliaceus autoimmune injury of the skin. J Immunol, v. 182, n. 1, p. 711-7, Jan 12009.

Luz ZM, Silva AR, Silva Fde O, Caligiorne RB, Oliveira E, Rabello A. Lesion aspirate culture for the diagnosis and isolation of Leishmania spp. from patients with cutaneous leishmaniasis. Mem Inst Oswaldo Cruz. 2009 Feb;104(1):62-6.

Medeiros AC, Rodrigues SS, Roselino AM. Comparison of the specificity of PCR and the histopathological detection of leishmania for the diagnosis of American cutaneous leishmaniasis. Braz J Med Biol Res. 2002 Apr;35(4):421-4.

Medeiros ACR, Roselino AMF. Leishmaniose tegumentar Americana: do histórico aos dias de hoje. Anais Brasileiros de Dermatologia, 74 (4): 329-336, 1999.

Medeiros AR, Silva WA Jr, Roselino AM. DNA sequencing confirms the involvement of Leishmania (L.) amazonensis in American tegumentary leishmaniasis in the state of São Paulo, Brazil. Clinics (Sao Paulo). 2008 Aug;63(4):451-6.

Miyagawa S, Higashimine I, Iida T, Yamashina Y, Fukumoto T, Shirai T. HLA-DRBI*04 and $D R B 1^{*} 14$ alleles are associated with susceptibility to pemphigus among Japanese. J Invest Dermatol. 1997 Nov;109(5):615-8.

Mizoguchi A1, Bhan AK. A case for regulatory B cells. J Immunol. 2006 Jan 15;176(2):705-10.

Montenegro, J. - A cutis-reação na leishmaniose. An. Fac. Med. S. Paulo, 1: 323-330, 1926.

Moraes JR, Moraes ME, Fernandez-Vina D, Diaz LA, Friedman H, Campbell IT, et al. HLA antigens and risk for development of pemphigus foliaceus (folgo selvagem) in endemic area of Brazil. Immunogenetics. 1991;33:388-91.

Moraes ME, Fernandez-Vina M, Lazaro A, Diaz LA, Filho GH, Friedman H, Rivitti E, Aoki V, Stastny P, Moraes JR. An epitope in the third hypervariable region of the DRBI gene is involved in the susceptibility to endemic pemphigus foliaceus (fogo selvagem) in three different Brazilian populations. Tissue Antigens. 1997 Jan;49(1):35-40.

Moreira DS, Nascimento MMP, Figueiredo JFC, Santos SSR, Chociay MF, Roselino AM. Reação sorológica e PCR para Doença de Chagas em leishmaniose tegumentar Americana (LTA). In: Medicina, Ribeirão Preto. 2004;37:21. 
Morita K, Miyachi Y, Furuse M. Tight junctions in epidermis: from barrier to keratinization. Eur J Dermatol. 2011 Jan-Feb;21(1):12-7.

Mortazavi H, Hejazi P, Khamesipour A, Mohebali M, Ehsani AH, Mohammadi Y, Farahani IV, Amirzargar AA. Frequency of seropositivity against infectious agents amongst pemphigus vulgaris patients: a case-control study on Strongyloides stercoralis, Helicobacter pylori, Toxoplasma gondii, Leishmania major, and Epstein-Barr virus. Int J Dermatol. 2015 Jul 14. doi: 10.1111/ijd.12869.

Motta AC, Lopes MA, Ito FA, Carlos-Bregni R, de Almeida OP, Roselino AM. Oral leishmaniasis: a clinicopathological study of 11 cases. Oral Dis. 2007 May;13(3):335-40.

Nogueira MF, Sotto MN, Cucé LC. American tegumentary leishmaniasis: Langerhans cells in Montenegro skin test. Rev Inst Med Trop Sao Paulo. 2008 Sep-Oct;50(5):283-6.

Osada K, Seishima M, Kitajima Y. Pemphigus IgG activates and translocates protein kinase C from the cytosol to the particulate/cytoskeleton fractions in human keratinocytes. J Invest Dermatol. 1997;108(4):482-487.

Pacheco-Tovar MG, Avalos-Díaz E, Vega-Memije E, et al. The final destiny of acantholytic cells in pemphigus is Fas mediated. J Eur Acad Dermatol Venereol. 2009;23(6):697-701.

Pavoni DP, Roxo VM, Marquart Filho A, Petzl-Erler ML. Dissecting the associations of endemic pemphigus foliaceus (fogo selvagem) with $H L A-D R B 1$ alleles and genotypes. Genes Immun. 2003;4:110-6.

Petzl-Erler ML, Santamaria J. Are $H L A$ class II genes controlling susceptibility and resistance to Brazilian pemphigus foliaceus (fogo selvagem)? Tissue Antigens. 1989 Mar;33(3):408-14.

Petzl-Erler ML, Belich MP, Queiroz-Telles F. Association of mucosal leishmaniasis with HLA. Hum Immunol. 1991 Dec;32(4):254-60.

Pohla-Gubo G, Hintner H. Direct and indirect immunofluorescence for the diagnosis of bullous autoimmune diseases. Dermatol Clin. 2011 Jul;29(3):365-72.

Puviani, M. et al. Fas ligand in pemphigus sera induces keratinocyte apoptosis through the activation of caspase-8. J Invest Dermatol, v. 120, n. 1, p. 164-7, Jan 2003.

Qian Y1, Jeong JS, Maldonado M, Valenzuela JG, Gomes R, Teixeira C, Evangelista F, Qaqish B, Aoki V, Hans G Jr, Rivitti EA, Eaton D, Diaz LA. Cutting Edge: Brazilian pemphigus foliaceus anti-desmoglein 1 autoantibodies cross-react with sand fly salivary LJM11 antigen. J Immunol. 2012 Aug 15;189(4):1535-9. doi: 10.4049/jimmunol.1200842. Epub 2012 Jul 13. 
Ribas-Silva RC, Ribas AD, Dos Santos MC, da Silva WV, Lonardoni MV, Borelli SD, Silveira TG. Association between HLA genes and American cutaneous leishmaniasis in endemic regions of Southern Brazil. BMC Infect Dis. 2013 May 2;13:198. doi: 10.1186/1471-2334-13-198.

Ribeiro JM, Valenzuela JG, Pham VM, Kleeman L, Barbian KD, Favreau AJ, Eaton DP, Aoki V, Hans-Filho G, Rivitti EA, Diaz LA. An insight into the sialotranscriptome of Simulium nigrimanum, a black fly associated with fogo selvagem in South America. Am J Trop Med Hyg. 2010 Jun;82(6):1060-75.

Rocha-Alvarez R, Ortega-Loayza AG, Friedman H, Campbell I, Aoki V, Rivitti EA, Dasher D, Li N, Diaz LA; Cooperative Group on Fogo Selvagem Research. Endemic pemphigus vulgaris. Arch Dermatol. 2007 Jul;143(7):895-9.

Rodrigues, D. B. et al. In situ detection of inflammatory cytokines and apoptosis in pemphigus foliaceus patients. Arch Pathol Lab Med, v. 133, n. 1, p. 97-100, Jan 2009.

Rosalba FG, Roselino AM. Identificação de fatores de risco associados à forma mucosa da leishmaniose tegumentar Americana. In: $62^{\circ}$. Congresso da Sociedade Brasileira de Dermatologia, 2007, São Paulo, SP. An Bras Dermatol. 2007;82:S178.

Rosatelli TB, Roselino AM, Dellalibera-Joviliano R, Reis ML, Donadi EA. Increased activity of plasma and tissue kallikreins, plasma kininase II and salivary kallikrein in pemphigus foliaceus (fogo selvagem). Brit J Dermatol. 2005 Apr;152(4):650-7.

Roselino AM, Aires JM, Kim OM, Nascimento MMP, Lerner EA, Figueiredo JFC. Soros de pacientes com pênfigo foliáceo (fogo selvagem) reagem contra maxadilan. Resumos do III Congresso da Sociedade Paulista de Parasitologia. Taubaté-SP, 2006.

Roselino AMF, Almeida AM. Surto com pênfigo Foliáceo Endêmico em Instituição para Menores, Batatais, SP, Brasil, 1988-1990. Medicina, Ribeirão Preto, 28 (1): 44-50, 1995.

Roselino, AMF; Donadi, EA; Deghaide, NHS. HLA-A69 e HLA-DRB1*01 em Pênfigo Foliáceo. In: $53^{\circ}$. Congresso Brasileiro de Dermatologia, Blumenau, SC, 05 a 09 de setembro de 1998.

Roselino AM, Figueiredo JFC, Kounga K, Reddy VB, Lerner EA. Serum IgG from pemphigus foliaceus patients reacts against maxadilan. J Investig Dermatol. 2001;117:460.

Sakaguchi S, Sakaguchi N, Asano M, Itoh M, Toda M. Immunologic self-tolerance maintained by activated T cells expressing IL-2 receptor alpha-chains (CD25). Breakdown of a single mechanism of self-tolerance causes various autoimmune diseases. J Immunol. 1995;155:1151-1164.

Sami N, Bhol K C, Ahmed A R. Diagnostic features of pemphigus vulgaris in patients with pemphigus foliaceus: detection of both autoantibodies, long-term follow-up and treatment responses. Clin Exp Immunol. 2001 Sep;125(3):492-8. 
Sampaio SAP, Rivitti EA. Erupções vésico-bolhosas. In: Sampaio SAP, Rivitti EA. Dermatologia. 3 ed. São Paulo: Artes Médicas; 2007. P 301-330.

Sayama K, Yonehara S, Watanabe Y, Miki Y. Expression of Fas antigen on keratinocytes in vivo and induction of apoptosis in cultured keratinocytes. J Invest Dermatol. 1994;103(3):330-334.

Seishima M, Esaki C, Osada K, Mori S, Hashimoto T, Kitajima Y. Pemphigus IgG, but not bullous pemphigoid IgG, causes a transient increase in intracellular calcium and inositol 1,4,5-trisphosphate in DJM-1 cells, a squamous cell carcinoma line. J Invest Dermatol. 1995;104(1):33-37.

Seishima M, Iwasaki-Bessho Y, Itoh Y, Nozawa Y, Amagai M, Kitajima Y. Phosphatidylcholine-specific phospholipase $\mathrm{C}$, but not phospholipase $\mathrm{D}$, is involved in pemphigus IgG-induced signal transduction. Arch Dermatol Res. 1999;291(11):606-613.

Simpson CL, Patel DM, Green KJ. Deconstructing the skin: cytoarchitectural determinants of epidermal morphogenesis. Nat Rev Mol Cell Biol. 2011 Aug 23;12(9):565-80.

Sinha AA. The genetics of pemphigus. Dermatol Clin. 2011 Jul;29(3):381-91.

Soares KA, Ayala Urdapilleta AA, Dos Santos GM, Carneiro AL, Gomes CM, Roselino AM, Ribeiro Sampaio RN. Field validation of a Leishmania (Leishmania) mexicana exo-antigens ELISA for diagnosing tegumentary leishmaniasis in regions of Leishmania (Viannia) predominance. Braz J Infect Dis. 2015 May-Jun;19(3):302-7. doi: 10.1016/j.bjid.2015.03.010. Epub 2015 May 15.

Sousa Jx Jr, Diaz La, Eaton Dp, Hans-Filho G, Freitas El, Delgado L, Ichimura, Lm, Cristaldi F, Orlandi R, Kesper N Jr, Umezawa Es, Rivitti Ea, Aoki V; Cooperative Group On Fogo Selvagem Research. Profile of Trypanosoma cruzi reactivity in a population at high risk for endemic pemphigus foliaceus (Fogo selvagem). Am J Trop Med Hyg. 2012 Oct;87(4):675-80.

Stanley JR, Amagai M. Pemphigus, bullous impetigo, and the staphylococcal scalded-skin syndrome. N Engl J Med. 2006 Oct; 355(17):1800-10.

Stanley JR, Klaus-Kovtun V, Sampaio SAP. Antigenic specificity of fogo selvagem autoantibodies is similar to North American pemphigus foliaceus and distinct from pemphigus vulgaris antibodies. $\mathrm{J}$ Invest Dermatol. 1986;87:197-201;.

Stanley JR, Koulu L, Thivolet C. Distinction between epidermal antigens binding pemphigus vulgaris and pemphigus foliaceus autoantibodies. J Clin Invest. 1984;74:313-20.

Stanley JR. Pemphigus, in Fitzpatrick's Dermatology in General Medicine, 6a. ed, Ed. McGraw Hill, 2003, vol I, p 558-67.

Sugiyama $\mathrm{H}$ et al. CD4+CD25high regulatory $\mathrm{T}$ cells are markedly decreased in blood of patients with pemphigus vulgaris. Dermatology. 2007;214(3):210-20. 
Tron F, Gilbert D, Joly P, Mouquet H, Drouot L, Ayed MB, Sellami M, Masmoudi H, Makni S. Immunogeneticis of pemphigus: An update. Autoimmunity. 2006;39:531-40.

Tron F, Gilbert D, Mouquet H, et al. Genetic factors in pemphigus. J Autoimmunity. 2005;24:319-28.

Vargas JH, Dasher DA, Li N, et al. Prevalence of Anti- Desmoglein-3 Antibodies in Endemic Regions of Fogo Selvagem in Brazil. J Invest Dermatol. 2006;126:2044-8.

Vega Benedetti AF, Cimino RO, Cajal PS, Juarez Mdel V, Villalpando CA, Gil JF, Marcipar IS, Krolewiecki AJ, Nasser JR. Performance of different Trypanosoma cruzi antigens in the diagnosis of Chagas disease in patients with American cutaneous leishmaniasis from a co-endemic region in Argentina. Trop Med Int Health. 2013 Sep;18(9):1103-9. doi: 10.1111/tmi.12144. Epub 2013 Jul 10.

Venugopal SS, Murrell DF. Diagnosis and clinical features of pemphigus vulgaris. Dermatol Clin. 2011 Jul;29(3):373-80.

Vieira JP. Pênfigo foliáceo e síndrome de Senear-Uscher. São Paulo, Empresa Gráfica da Revista dos Tribunais, 1942.

Wang X, Brégégère F, Zlotkin MF, Feinmesser M, Michel B, Milner Y. Possible apoptotic mechanism in epidermal cell acantholysis induced by pemphigus vulgaris autoimmunoglobulins. Apoptosis. 2004;9(2):131-43.

Warren SJ, Lin MS, Giudice GJ, Hoffmann RG, Hans-Filho G, Aoki V, Rivitti EA, Santos V, Diaz LA. The prevalence of antibodies against desmoglein 1 in endemic pemphigus foliaceus in Brazil. Cooperative Group on Fogo Selvagem Research. N Engl J Med. 2000 Jul 6;343(1):23-30.

Waschke J. The desmosome and pemphigus. Histochem Cell Biol. 2008;130:21-54.

Weber R, Monteiro F, Preuhs-Filho G, Rodrigues H, Kalil J, Miziara ID. HLA-DRB1*04:02, DRB1*08:04 and $D R B 1^{*} 14$ alleles associated to pemphigus vulgaris in southeastern Brazilian population. Tissue Antigens. 2011 Aug;78(2):92-3. doi: 10.1111/j.1399-0039.2011.01705.x. Epub 2011 May 9.

Wolf R, Matz H, Ruocco E, Ruocco V. The putative role of apoptosis in the induction of pemphigus. Medical Hypotheses. 2005;64(1):44- 45.

Ye Qian, Stephen H. Clarke, Valeria Aoki, Gunter Hans-Filhio, Evandro A. Rivitti, Luis A. Diaz. Antigen selection of anti-Dsg1 autoantibodies during and prior to the onset of endemic pemphigus foliaceus. $\mathrm{J}$ Invest Dermatol. 2009 Dec;129(12):2823-34.

Zaraa I, Boussoffara T, Bem Ahmed M, Marzouki S, Bem Hassouna N, Kallel Sellami M, Makni S, Bem Osman A, Louzir H, Mokni M. Exposure to Phlebotomus papatasi and/or Leishmania major: Possible etiologic link to Tunisian pemphigus. J Invest Dermatol. 2012; advance online publication. 
Zeoti DM, Figueiredo JF, Chiossi MP, Roselino AM. Serum cytokines in patients with Brazilian pemphigus foliaceus (fogo selvagem). Braz J Med Biol Res. 2000 Sep;33(9):1065-8.

Zhu HQ1, Xu RC, Chen YY, Yuan HJ, Cao H, Zhao XQ, Zheng J, Wang Y, Pan M. Impaired function of CD19(+) CD24(hi) CD38(hi) regulatory B cells in patients with pemphigus. Br J Dermatol. 2015 Jan;172(1):101-10. doi: 10.1111/bjd.13192. Epub 2014 Nov 20.

Zuccolotto I, Roselino AM, Ramalho LN, Zucoloto S. Apoptosis and p63 expression in the pathogenesis of bullous lesions of endemic pemphigus foliaceus. Arch Dermatol Res. 2003 Dec;295(7):284-6 


\section{ANEXOS}

\section{Anexo 1:}

TERMO DE CONSENTIMENTO LIVRE E ESCLARECIDO AOS PACIENTES COM PÊNFIGO E/OU LEISHMANIOSE Referente ao projeto temático: RELAÇÃO DOS FATORES IMUNOGENÉTICOS E AMBIENTAIS NA ETIOPATOGÊNESE DOS PÊNFIGOS EM AMOSTRAGEM BRASILEIRA Subprojeto: RELAÇÃO IMUNOGENËTICA DOS PÊNFIGOS COM A LEISHMANIOSE TEGUMENTAR

Você está sendo convidado a participar de uma pesquisa realizada por uma equipe de Dermatologia do Hospital das Clinícas de Ribeirão Preto (HCFMRP), a qual tem como médica responsável a Dra. Priscilla Vargas Walsh e, como coordenadora, a Professora Dra. Ana Maria F. Roselino.

Esta pesquisa refere-se aos pênfigos, doenças com formação de bolhas na pele e mucosas, como boca, nariz e genitais, não transmissíveis entre pessoas, e cuja causa ainda não está totalmente esclarecida. O que se sabe é que fatores ambientais e genéticos têm participação no surgimento da doença. A equipe de Dermatologia do ambulatório de Dermatoses auto-imunes do HCFMRP acompanha diversos pacientes com diagnóstico de pênfigo. Desta forma, estamos trabalhando numa pesquisa sobre as causas ambientais, imunológicas (formação de anticorpos), e genéticas de ambos os pênfigos: vulgar e foliáceo; estudando, nesse subprojeto, principalmente a implicação da exposição à leishmaniose tegumentar, doença comum nessa região do país, no desencadeamento do pênfigo.

Para isso pedimos a colaboração dos pacientes com pênfigo que são acompanhados no HCFMRP, através da permissão para aplicação da Reação Intradérmica de Montenegro. Esse teste consiste na aplicação, com seringa de insulina, de 0,1 mL de uma substância chamada antígeno de Montenegro na pele da face anterior do antebraço. A leitura será feita após 48 a 72 horas (período no qual o sr/sra deverá voltar a este ambulatório) e o resultado será considerado negativo na ausência de qualquer sinal no ponto de inoculação ou de uma pápula com menos de $5 \mathrm{~mm}$ de diâmetro, e como reação positiva na presença de uma pápula ou nódulo, igual ou superior a $5 \mathrm{~mm}$ ou ulceração. Essas reações podem causar coceira, mas não costumam causar dor e têm resolução espontânea. Os resultados serão sigilosos e não terão influência sobre sua medicação ou modificação de seu tratamento.

Para participar desta pesquisa não será necessário pagar qualquer quantia. A qualquer momento você poderá desistir da participação na pesquisa sem ter nenhum prejuízo ao seu tratamento.

A sua participação será de grande valor e poderá ajudar na prevenção desta doença no futuro. Desde já agradecemos e nos colocamos à disposição para qualquer esclarecimento. Serão assinadas duas cópias, sendo que uma ficará com o (a) Sr. (a).

Afirmo que li o termo de consentimento e aceito participar da pesquisa.

Ass: Data:

Paciente: __ (NOME) ___ (Registro HC)

Responsáv

el legal: (NOME) $(\mathrm{RG})$

Ass: Data:

Médica responsável: Dra Priscilla Vargas Walsh

CRM: 146.181 CPF: 011.846.094-38

Tel: 16.3602 .2447

Ass:

Data:

Orientadora: Professora Dra Ana Maria Roselino

CRM:38.450 CPF: 052.189.868-44

Celular: 16.9793 .8116

Ribeirão Preto, de de 


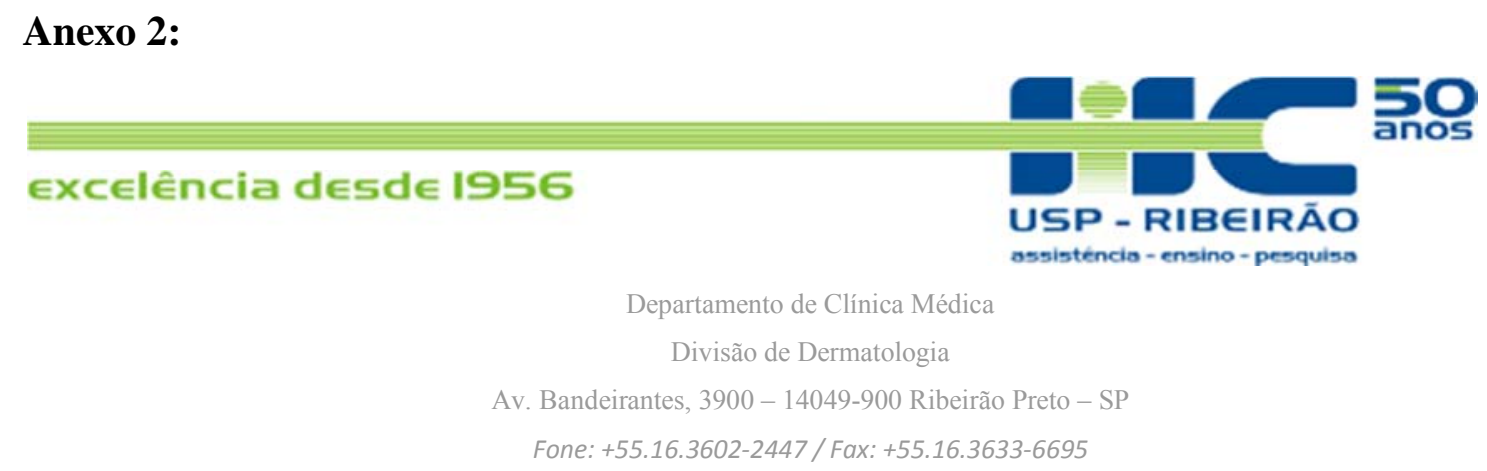

Termo de Consentimento de guarda de material biológico

O preenchimento e a assinatura deste termo de consentimento têm por objetivo a autorização para guardar a sobra da biópsia de pele ou de mucosa, utilizados para exame histopatológico, e $15 \mathrm{~mL}$ de sangue coletados do(a) $\operatorname{Sr}($ a) para exames considerados de rotina para auxílio do seu diagnóstico.

Este material será guardado em um freezer no Laboratório de Biologia Molecular do Hospital das Clínicas de Ribeirão Preto, identificado por um número, de forma a garantir o sigilo de sua identidade. Esta sobra de biópsia de pele ou de mucosa, e $15 \mathrm{~mL}$ de sangue guardados poderão ser utilizados para novos exames ou para pesquisas, e o (a) Sr (a) será informado (a) de possíveis resultados adquiridos a partir deste material, e poderá se beneficiar das descobertas que ocorrerem em estudos com o seu material.

Este banco de amostras chama-se Banco de Amostras Biológicas, alocado no Laboratório de Biologia Molecular, no Anexo B, da FMRP-USP, e seu responsável é a Profa. Dra. Ana Maria Ferreira Roselino (tel: 16.3602.2715).

Para a utilização do seu material guardado, será solicitada novamente a sua autorização. Todas as pesquisas serão autorizadas por um Comitê de Ética em Pesquisa e o(a) Sr(a) será comunicado(a) e poderá concordar ou não com o uso do material neste estudo.

Autorizo que as sobras de biópsia de pele ou de mucosa, e $15 \mathrm{~mL}$ de sangue utilizados nos exames de rotina sejam guardadas para uso futuro, com o meu consentimento.

Nome do paciente ou representante, se menor de idade:

Dados pessoais:

Registro do HC:

Endereço completo:

Telefone:

Assinatura do paciente ou do representante

Data

Eu conversei sobre a guarda de material em banco de amostra com o paciente utilizando uma linguagem adequada e apropriada. Acredito que o informei o suficiente para a tomada de decisão de maneira livre e esclarecida.

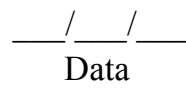

NOME, ENDEREÇO E TELEFONE DA RESPONSÁVEL PELO BANCO DE AMOSTRAS BIOLÓGICAS:

Profa. Dra. ANa Maria FerReIRA Roselino

LABORATÓRIO DE BIOLOGIA MOLECULAR - ANEXO B - FMRP- USP

AV. BANDEIRANTES 3900

14049-900 - RIBEIRÃo PRETO - SP 


\section{Anexo 3:}

TERMO DE CONSENTIMENTO LIVRE E ESCLARECIDO AOS FAMILIARES E DE PACIENTES COM PÊNFIGO E MORADORES DE ÁREAS ENDÊMICAS PARA PÊNFIGO

Referente ao projeto temático: RELAÇÃO DOS FATORES IMUNOGENÉTICOS E AMBIENTAIS NA ETIOPATOGÊNESE DOS PÊNFIGOS EM AMOSTRAGEM BRASILEIRA

Você está sendo convidado a participar de uma pesquisa realizada por uma equipe de Dermatologia do Hospital das Clinicas de Ribeirão Preto (HCFMRP), a qual tem como médica responsável a Dra Adriana S M Salathiel e, como coordenadora, a Professora Dra. Ana Maria F Roselino. Esta pesquisa refere-se ao pênfigo, doença com formação de bolhas na pele e mucosas como boca, nariz e genitais. Não é transmissível entre pessoas. Ainda não se sabe exatamente a causa desta doença. $\mathrm{O}$ que se sabe é que o organismo do doente forma anticorpos (que normalmente fazem a defesa do nosso organismo contra vírus e bactérias) que passam a atacar a pele e mucosas. Fatores ambientais e genéticos têm participação no surgimento da doença, no entanto, ainda há muito que se conhecer sobre os pênfigos. A equipe de Dermatologia do ambulatório de Dermatoses auto-imunes, HC-FMRPUSP, tem atendimento realizado às segundas-feiras, acompanha diversos pacientes com diagnóstico de pênfigo. Desta forma, estamos iniciando uma pesquisa sobre as causas ambientais, imunológicas (formação de anticorpos), e genéticas de ambos os pênfigos: vulgar e foliáceo. Estamos estudando principalmente a implicação de mosquitos, de agrotóxicos e de acometimento familiar no desencadeamento do pênfigo. Para isso pedimos a colaboração dos familiares dos pacientes com pênfigo acompanhados no HCFMRP, e de moradores de áreas com grande número de casos da doença, através da permissão da coleta de aproximadamente $45 \mathrm{~mL}$ de sangue, um frasco de urina e uma mecha de cabelo, além do preenchimento de questionário.

Para participar desta pesquisa não será necessário pagar qualquer quantia. Se você for convocado a participar da pesquisa fora do horário do seu atendimento ou internação no HCFMRP, você receberá ressarcimento dos seus gastos com transporte de ônibus e alimentação. Basta apresentar o comprovante da passagem. Quanto à alimentação, será pago o valor de $\mathrm{R} \$ 12,00$. A qualquer momento você poderá desistir da participação na pesquisa sem ter nenhum prejuízo. Os resultados serão confidenciais. Desde já agradecemos e nos colocamos á disposição para qualquer esclarecimento. Serão assinadas duas cópias, sendo que uma ficará com o (a) Sr. (a).

Eu, RG li o termo de consentimento e aceito participar da pesquisa.

Nome

Orientadora: Professora Dra Ana Maria Roselino

CRM: 38.450 CPF: 052.189.868-44

Celular: 16.9793 .8116

Ribeirão Preto, de de 


\section{Anexo 4: Aprovação do trabalho pelo Comitê de Ética em Pesquisa HC FMRP}

HOSPITAL DAS CLÍNICAS DA FACULDADE DE MEDICINA DE RIBEIRÃO PRETO DA UNIVERSIDADE DE SÃO PAULO

Ribeirão Preto, 04 de dezembro de 2013

Oficio $\mathrm{n}^{\circ} 4417 / 2013$

$\mathrm{CEP} / \mathrm{MGV}$

Prezadas Senhoras,

O trabalho intitulado "RELAÇÃo IMUNOGENÉTICA DOS PÊNFIGOS COM A LEISHMANIOSE TEGUMENTAR" - versão 2, de 25/11/2013, foi analisado "AD REFERENDUM" pelo Comitê de Ética em Pesquisa, e enquadrado na categoria: APROVADO, bem como o Termo de Consentimento Livre e Esclarecido - versão 2, de 22/11/2013, de acordo com o Processo HCRP n ${ }^{\circ} 8716 / 2013$.

De acordo com Carta Circular $n^{\circ}$ 003/2011/CONEP/CNS, datada de 21/03/2011, o sujeito de pesquisa ou seu representante, quando for o caso, deverá rubricar todas as folhas do Termo de Consentimento Livre $e$ Esclarecido - TCLE - apondo sua assinatura na última do referido Termo; o pesquisador responsável deverá da mesma forma, rubricar todas as folhas do Termo de Consentimento Livre e Esclarecido - TCLE - apondo sua assinatura na última página do referido Termo.

Este Comitê segue integralmente a Conferência Internacional de Harmonização de Boas Práticas Clínicas (IGH-GCP), bem como a Resolução $n^{o}$ 196/96 CNS/MS.

Lembramos que devem ser apresentados a este CEP, o Relatório Parcial e o Relatório Final da pesquisa.

Atenciosamente.

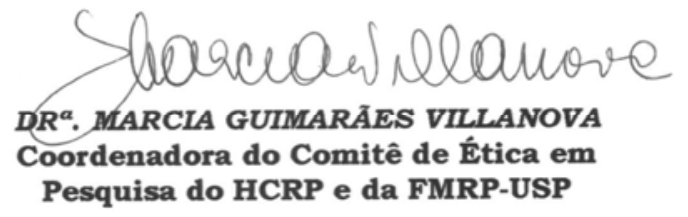

Ilustríssimas Senhoras

PRISCILLA VARGAS WALSH GONCCALVES DOS SANTOS

PROF $^{\mathrm{a}}$. DR $^{\mathrm{a}}$. ANA MARIA FERREIRA ROSELINO(Orientadora)

Depto. de Clinica Médica - Divisão de Dermatologia 
Anexo 5: Aprovação do Banco de Amostras de Pele e Sangue pelo Comitê de Ética em

\section{Pesquisa HC FMRP}

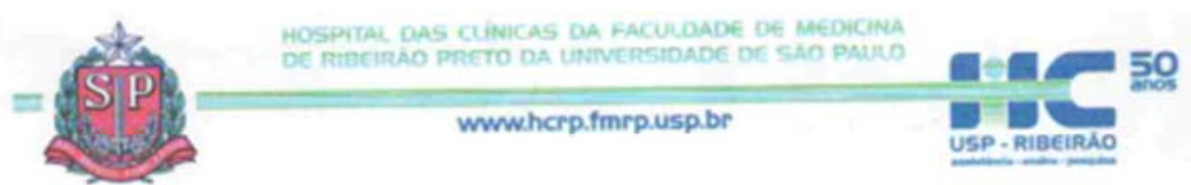

Ribeirão Preto, 28 de fevereiro de 2007

Oficio $n^{\circ} 572 / 2007$

$\mathrm{CEP} / \mathrm{MGV}$

Prezada Professora,

O Comitê de Ética em Pesquisa recebeu carta, onde Vossa Senhoria encaminha a proposta de criação de um banco de amostras de biópsias de pele e de sangue de pacientes com os diagnósticos de leishmaniose tegumentar americana, hanseniase c outras doenças granulomatosas.

Sobre o assunto, o Comitê de Êtica em Pesquisa em sua $241^{*}$ Reunião Ordinária realizada em 26.02.2007, analisou a proposta de criaçấo e a enquadrou na categoria: APROVADO, de acordo com o Processo HCRP n 3605/2006.

Atenciosamente.

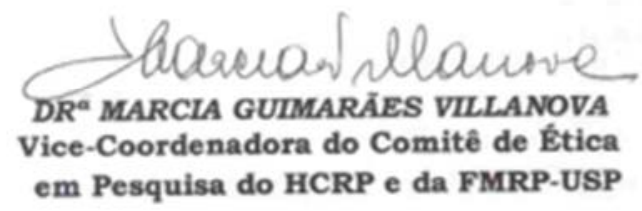

Ilustríssima Senhora

PROF ${ }^{\star}$ DR $^{a}$ ANA MARIA FERREIRA ROSELINO

Laboratório de Biologia Molecular - Anexo B - FMRP-USP

Comite de Ética em Pesquisa HC e FMRP. USP - Campus Universitario

Fone (16) 3602-2228 - E-mail : cepiathcrp finrpuspibr

Monte Alegre 14048-900 Ribeiraso Preto SP 


\section{Anexo 6: Aprovação do Projeto Temático pelo Comitê de Ética em Pesquisa HC FMRP}

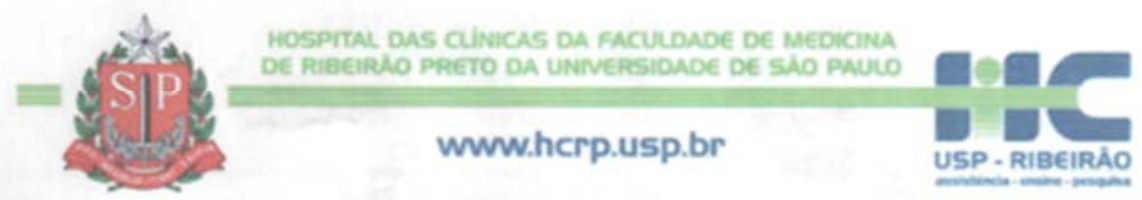

Ribeiråo Preto, 09 de fevereiro de 2011

Oficio $n^{\circ} 423 / 2011$

CEP/MGV

Prezada Professora,

O trabalho intitulado "RELAÇÃo DOS FATORES IMUNOGENÉTICOS E AMBIENTAIS NA ETIPATOGÊNESE DOS PÊNFIGOS EM AMOSTRAGEM BRASILEIRA" foi analisado pelo Comitê de Ética em Pesquisa, em sua $317^{*}$ Reuniâo Ordinária realizada em 07/02/2011 e enquadrado na categoria: APROVADO, bem como o Termo de Consentimento Livre e Esclarecido, de acordo com o Processo HCRP $\mathrm{n}^{\circ} 12248 / 2010$.

Este Comite segue integralmente a Conferência Internacional de Harmonizaçao de Boas Práticas Clinicas (IGH-GCP), bem como a Resoluçao n 196/96 CNS/MS,

Lembramos que devem ser apresentados a este CEP. o Relatório Parcial e o Relatório Final da pesquisa.

Atenciosamente.

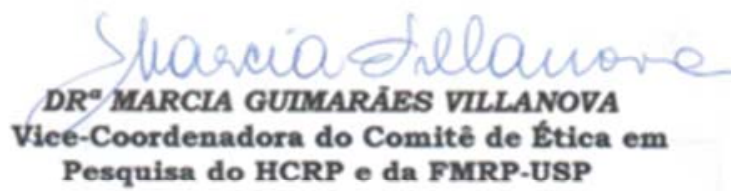

Ilustrissima Senhora

PROF* DR* ANA MARIA FERREIRA ROSELINO

Depto. de Clínica Médica - Divisâo de Dermatologia 